\title{
AGC-2 Graphite Preirradiation Data Package
}

David Swank Joseph Lord David Rohrbaugh William Windes

The INL is a

U.S. Department of Energy National Laboratory operated by

Battelle Energy Alliance

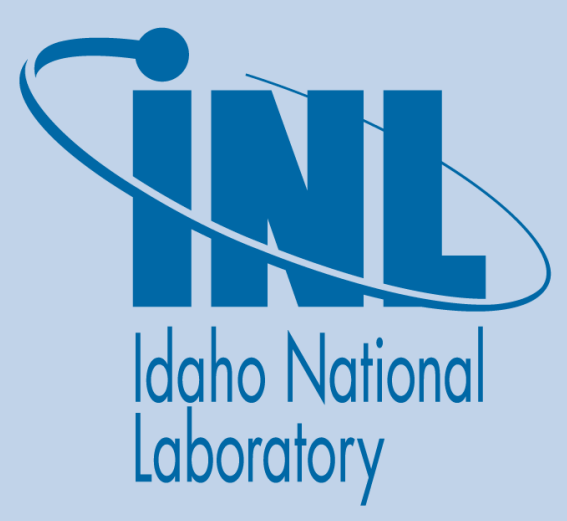

August 2010

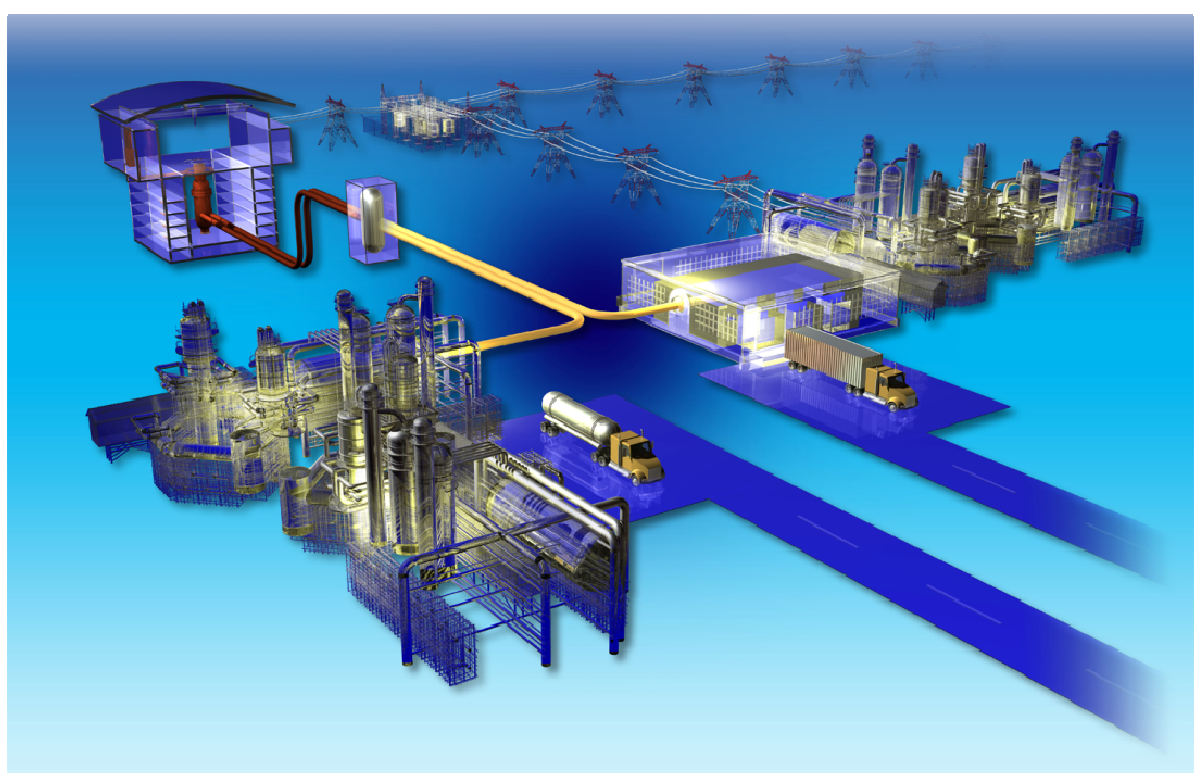




\section{DISCLAIMER}

This information was prepared as an account of work sponsored by an agency of the U.S. Government. Neither the U.S. Government nor any agency thereof, nor any of their employees, makes any warranty, expressed or implied, or assumes any legal liability or responsibility for the accuracy, completeness, or usefulness, of any information, apparatus, product, or process disclosed, or represents that its use would not infringe privately owned rights. References herein to any specific commercial product, process, or service by trade name, trade mark, manufacturer, or otherwise, does not necessarily constitute or imply its endorsement, recommendation, or favoring by the U.S. Government or any agency thereof. The views and opinions of authors expressed herein do not necessarily state or reflect those of the U.S. Government or any agency thereof. 
INL/EXT-10-19588

\title{
AGC-2 Graphite Preirradiation Data Package
}

\author{
David Swank, Joseph Lord, David Rohrbaugh, William Windes
}

August 2010

\begin{abstract}
Idaho National Laboratory
Next Generation Nuclear Plant Project

Idaho Falls, Idaho 83415
\end{abstract}

http://www.inl.gov

Prepared for the

U.S. Department of Energy

Office of Nuclear Energy

Under DOE Idaho Operations Office

Contract DE-AC07-05ID14517 
This page is intentionally left blank 


\section{Next Generation Nuclear Plant Project}

\section{AGC-2 Graphite Preirradiation Data Package}

INL/EXT-10-19588

August 2010

Approved by:

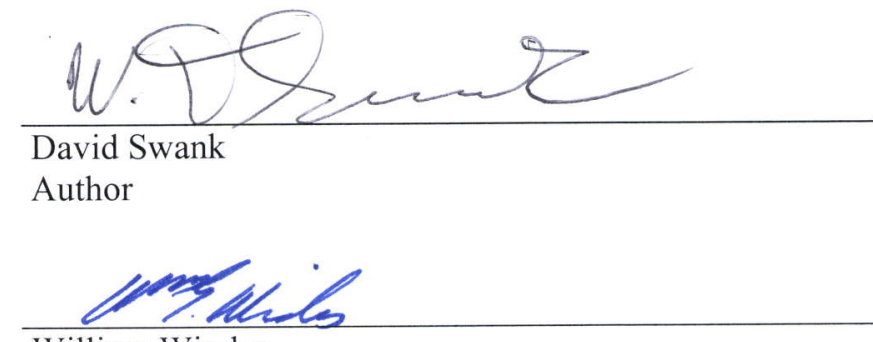

William Windes

VHTR TDO Graphite R\&D Lead

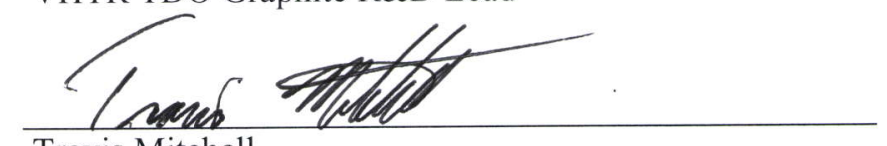

Travis Mitchell

VHTR TDO Project Manager
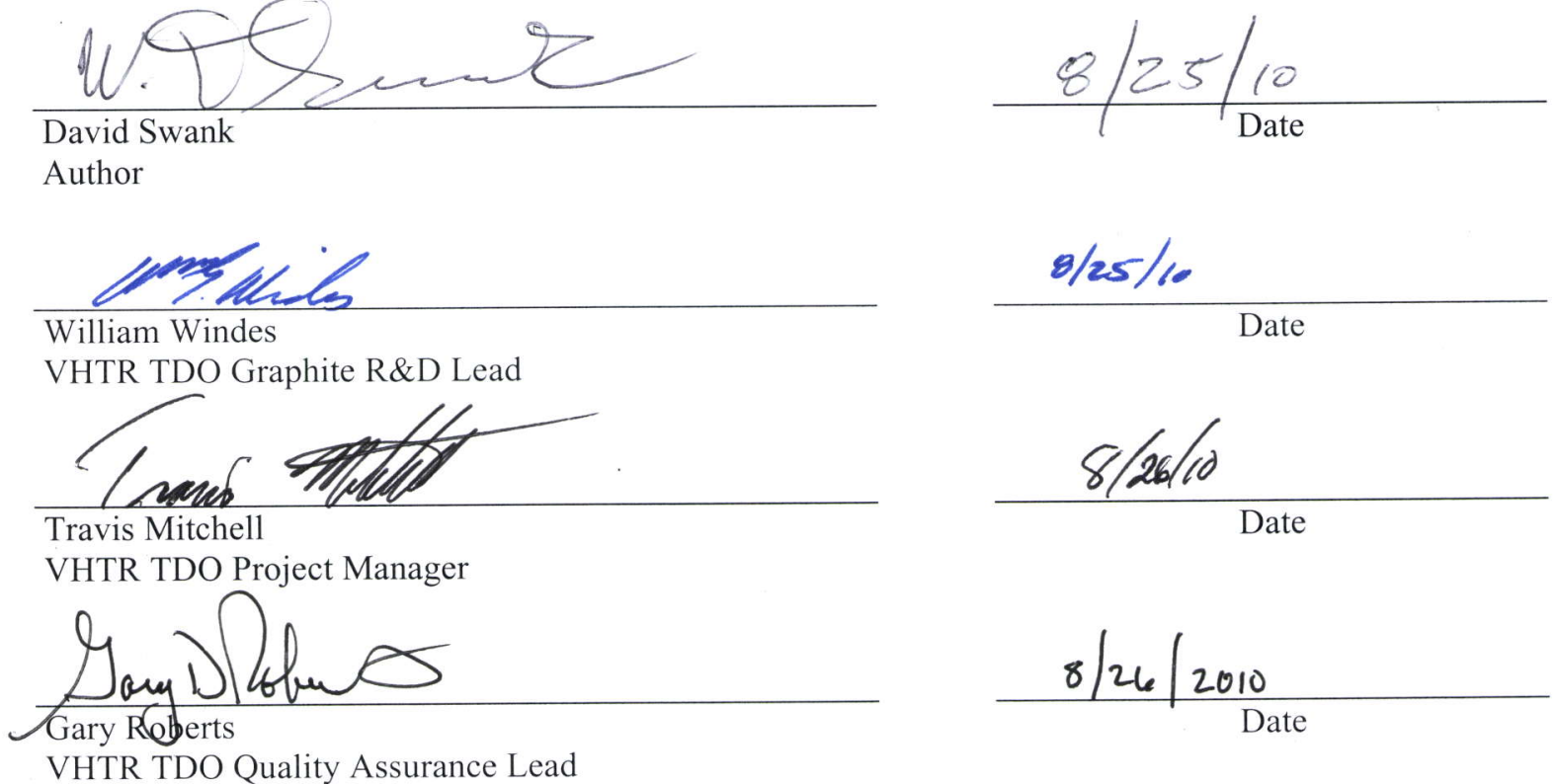
This page is intentionally left blank 


\section{SUMMARY}

The Next Generation Nuclear Plant Project Graphite Research and Development program is currently establishing the safe operating envelope of graphite core components for a very high temperature reactor design. The program is generating quantitative data necessary for predicting the behavior and operating performance of the new nuclear graphite grades. To determine the inservice behavior of the graphite for pebble bed and prismatic designs, the Advanced Graphite Creep (AGC) experiment is underway. This experiment is examining the properties and behavior of nuclear grade graphite over a large spectrum of temperatures, neutron fluencies, and compressive loads. Each experiment consists of over 400 graphite specimens that are characterized prior to irradiation and following irradiation. Six experiments are planned with the first, AGC-1, currently being irradiated in the Advanced Test Reactor and preirradiation characterization of the second, AGC-2, completed. This data package establishes the readiness of 512 specimens for assembly into the AGC-2 capsule. 
This page is intentionally left blank 


\section{CONTENTS}

SUMMARY

vi

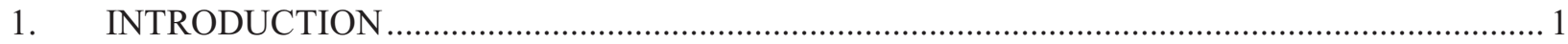

2. PREIRRADIATION PROPERTY CHARACTERIZATION .................................................... 1

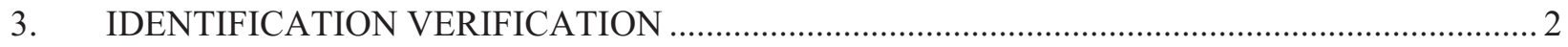

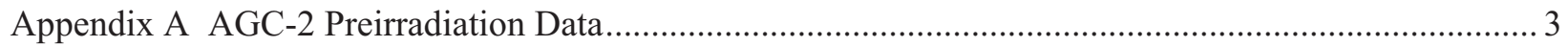

Appendix B Source/Receiving Inspection Instruction for AGC-2 Specimens ...................................... 39 
This page is intentionally left blank 


\section{AGC-2 Graphite Preirradiation Data Package}

\section{INTRODUCTION}

The Next Generation Nuclear Plant (NGNP) will be a high temperature gas-cooled reactor (HTGR) with a large graphite core. Graphite has been effectively used as both structural and moderator material in research reactors as well as commercial HTGRs. While the general characteristics necessary for producing nuclear grade graphite are understood, historical nuclear grades no longer exist. New grades must therefore be produced, characterized, and irradiated in order to demonstrate that current grades of graphite exhibit acceptable irradiated and nonirradiated properties, upon which the thermomechanical design of the structural graphite in the NGNP is based.

The nuclear graphite type H-451, used previously in the United States for HTGR graphite components, is no longer available. New graphite types have been developed and are considered suitable candidates for the new NGNP reactor design. To support the design and licensing of NGNP core components within a commercial reactor, a complete properties database must be developed for these current grades of graphite. Quantitative data are required for the physical, mechanical (including radiation-induced creep), and oxidation properties of each graphite type.

To determine the in-service behavior of the graphite for both pebble bed and prismatic reactor designs, the Advanced Graphite Creep (AGC) experiment is underway. This experiment is examining the properties and behavior of nuclear grade graphite over a large spectrum of temperatures, irradiation fluencies, and compressive loads. Each experiment consists of over 500 graphite specimens that are characterized before and after irradiation. Six experiments are planned with the first, AGC-1, currently being irradiated in the Advanced Test Reactor (ATR) and preirradiation characterization of the second, AGC-2, completed. This data package establishes the readiness of 512 specimens for assembly into the AGC-2 capsule buy documenting the completion of the preirradiation characterization and establishing that the laser engraved identity of each specimen is legible and the specimen is contained in a correctly labeled container.

\section{PREIRRADIATION PROPERTY CHARACTERIZATION}

The objective of the AGC-2 experiment is to determine the material property changes induced in nuclear grade graphite during exposure to a high temperature neutron environment. The approach is to perform extensive preirradiation characterization testing on each sample before exposing the graphite samples to various neutron doses. After irradiation, the same characterization tests will be performed on each irradiated sample to ascertain the quantitative changes to the material properties of the graphite.

The AGC-2 specimens have been characterized per PLN-3267 "AGC-2 Characterization Plan." This plan describes the thermal, physical, and mechanical measurement techniques and methods that were used to characterize the different graphite types being tested in the AGC-2 experiment and is intended to meet the requirements of Management Control Procedure (MCP) MCP-1380, "Research and Development Test Control," and NQA-1 Test Control. Described within the plan are the instruments, fixtures, and methods used for preirradiation material property measurements of bulk density, thermal diffusivity, coefficient of thermal expansion, elastic modulus, and electrical resistivity.

Major grades of the nuclear-grade graphite types to be tested in AGC-2 are NBG-17, NBG-18, PCEA, IG-430, H-451, 2114, and IG-110. Minor grades of graphite include NBG-25, PCIB, PPEA, NBG-10, BAN, HLM, PGX, S2020, HOPG, and A3 matrix. All major grades have been characterized fully per PLN-3267 and the minor grades have only had dimensional, density and thermal diffusivity measurements performed on them. The two primary specimen types in the AGC experiments are creep samples and piggyback samples. "Creep" specimens from major grade graphite types are shown in INL Drawing 600786-21, Rev. 1, and will be subjected to a mechanical load during irradiation to induce irradiation creep within the specimens. "Piggyback" specimens from both major and minor grade graphite 
types are shown in INL Drawing 600786-1, Rev. 1. They are not subjected to a mechanical load and are subjected only to neutron irradiation at high operating temperatures to assess the effects of a reactor environment on the specific graphite grade.

All specimens are $12.7 \mathrm{~mm}$ in diameter, with the creep specimens being $25.4 \mathrm{~mm}$ long and the piggyback specimens being $6 \mathrm{~mm}$ long. Details of how specimens were cut from the graphite blocks are contained in INL Drawing 600787, Rev. 2, "ATR Advanced Graphite Capsule (AGC-2) Experiment Graphite Specimen Cut-Out Diagrams.”

The data resulting from the preirradiation characterization are plotted in Figures A-1 through A-66 in Appendix A. Interpretation and detailed analysis of the data will follow in an AGC-2 data analysis report. Statistical evaluation will be performed using an inner quartile range analysis to identify levels of uncertainty and outliers in the data. The measured properties and characteristics of different graphite types will be compared along with the effect of grain orientation. As part of the publication of this report, the data and report will be independently reviewed by Oak Ridge National Lab.

\section{IDENTIFICATION VERIFICATION}

To establish the condition and identification of the AGC-2 specimens a "Source/Receiving Inspection Instruction" was completed by an INL certified inspector after all characterization measurements were complete. Each specimen was photographed four times around the circumference to record its physical condition. Each specimen's laser engraved identification was verified to match the bar-coded label on the specimen container. The complete "Source/Receiving Inspection Instruction" is contained in Appendix B. 
Appendix A

AGC-2 Preirradiation Data 


\section{Appendix A-AGC-2 Preirradiation Data}

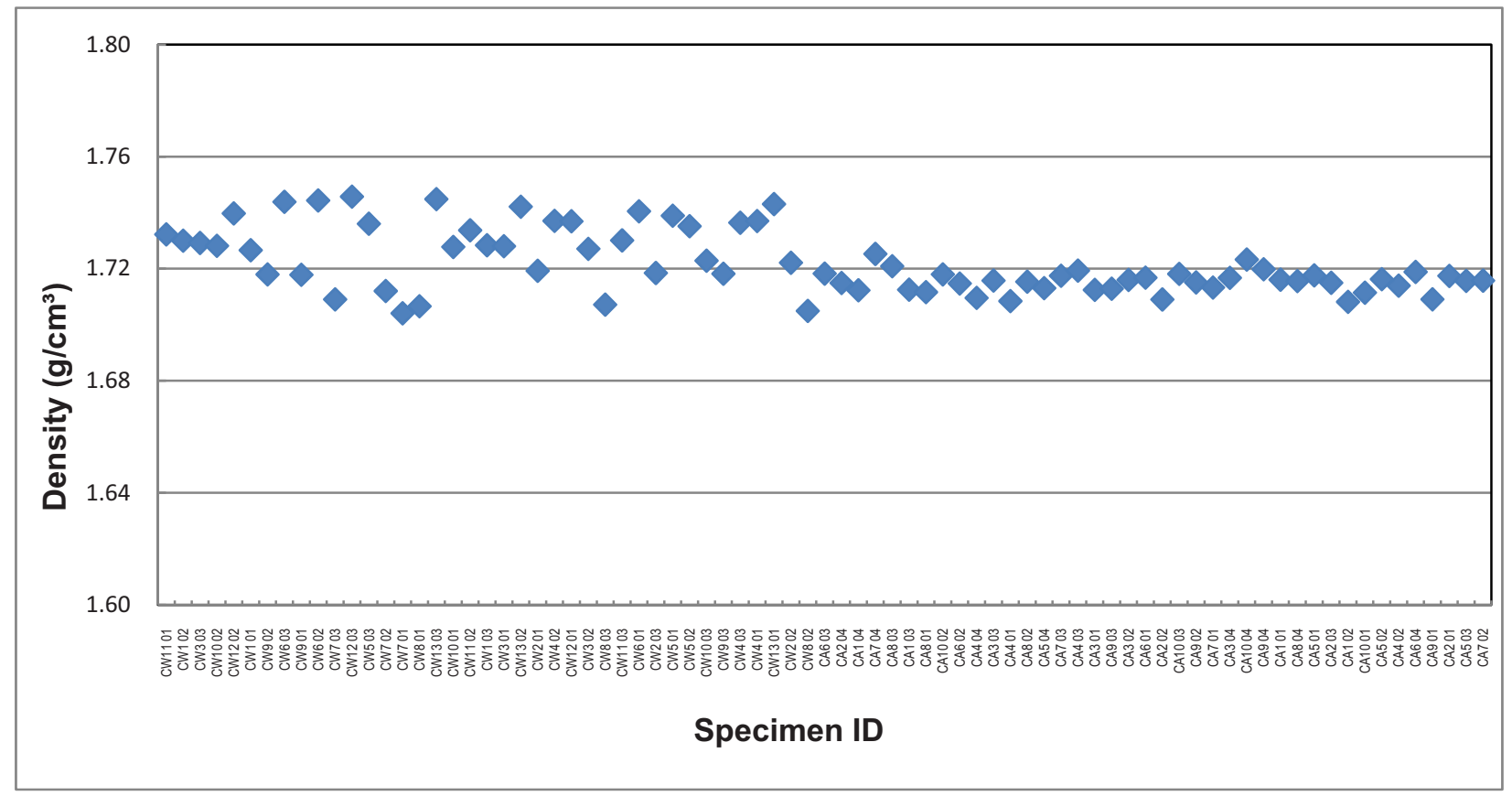

Figure A-1. Density for H-451.

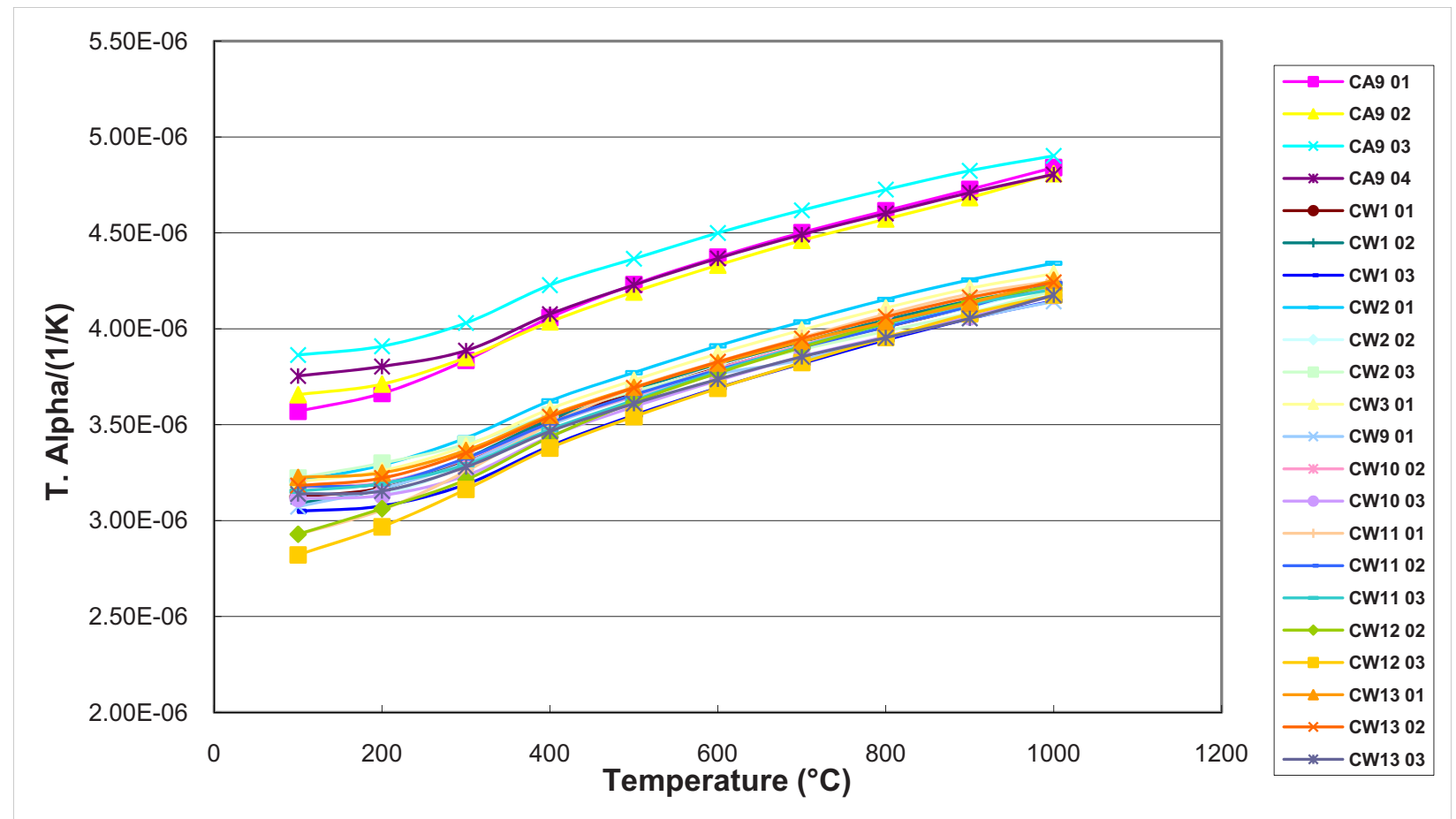

Figure A-2. Coefficient of thermal expansion for H-451. 


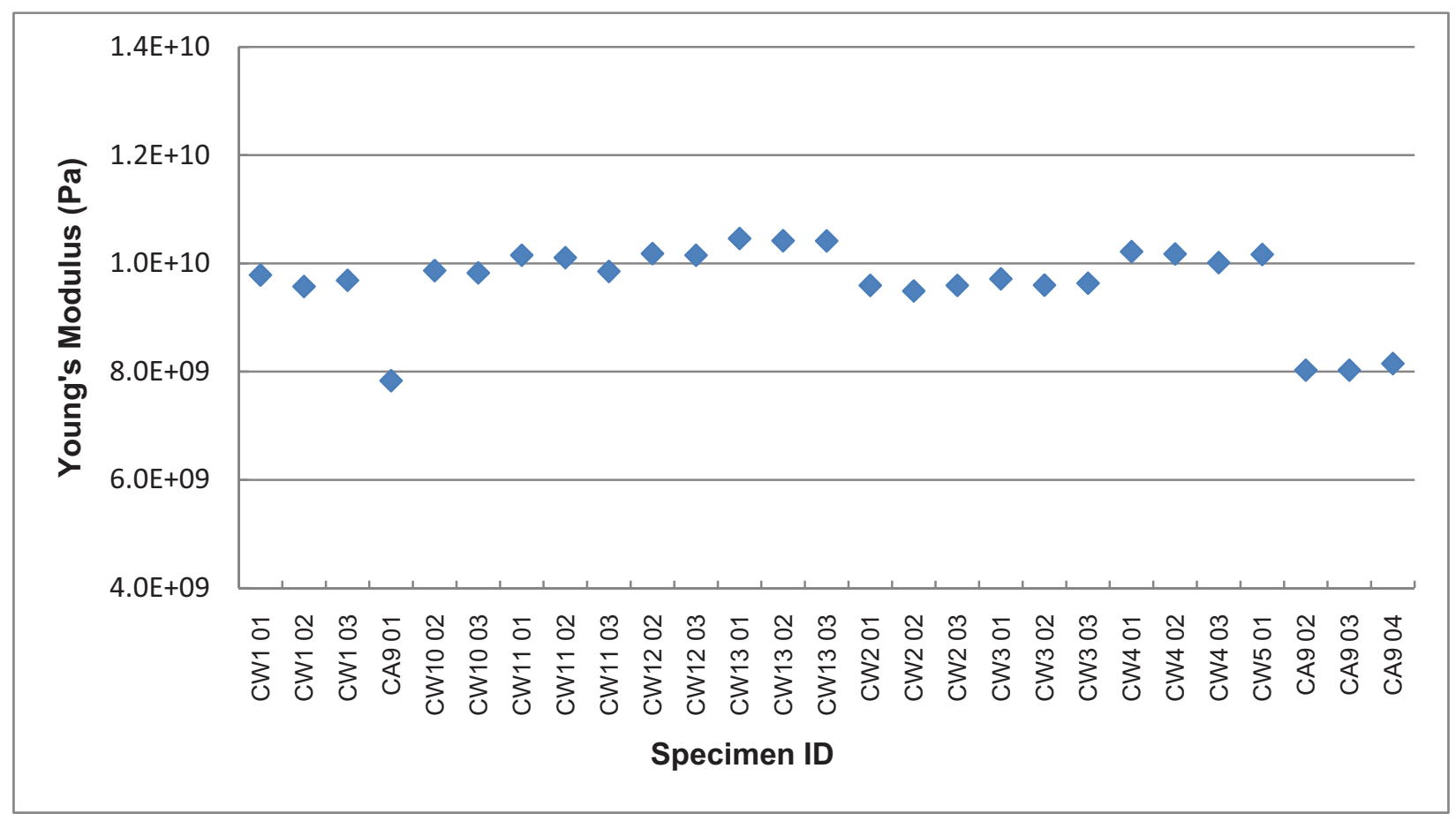

Figure A-3. Young's Modulus by sonic resonance for H-451.

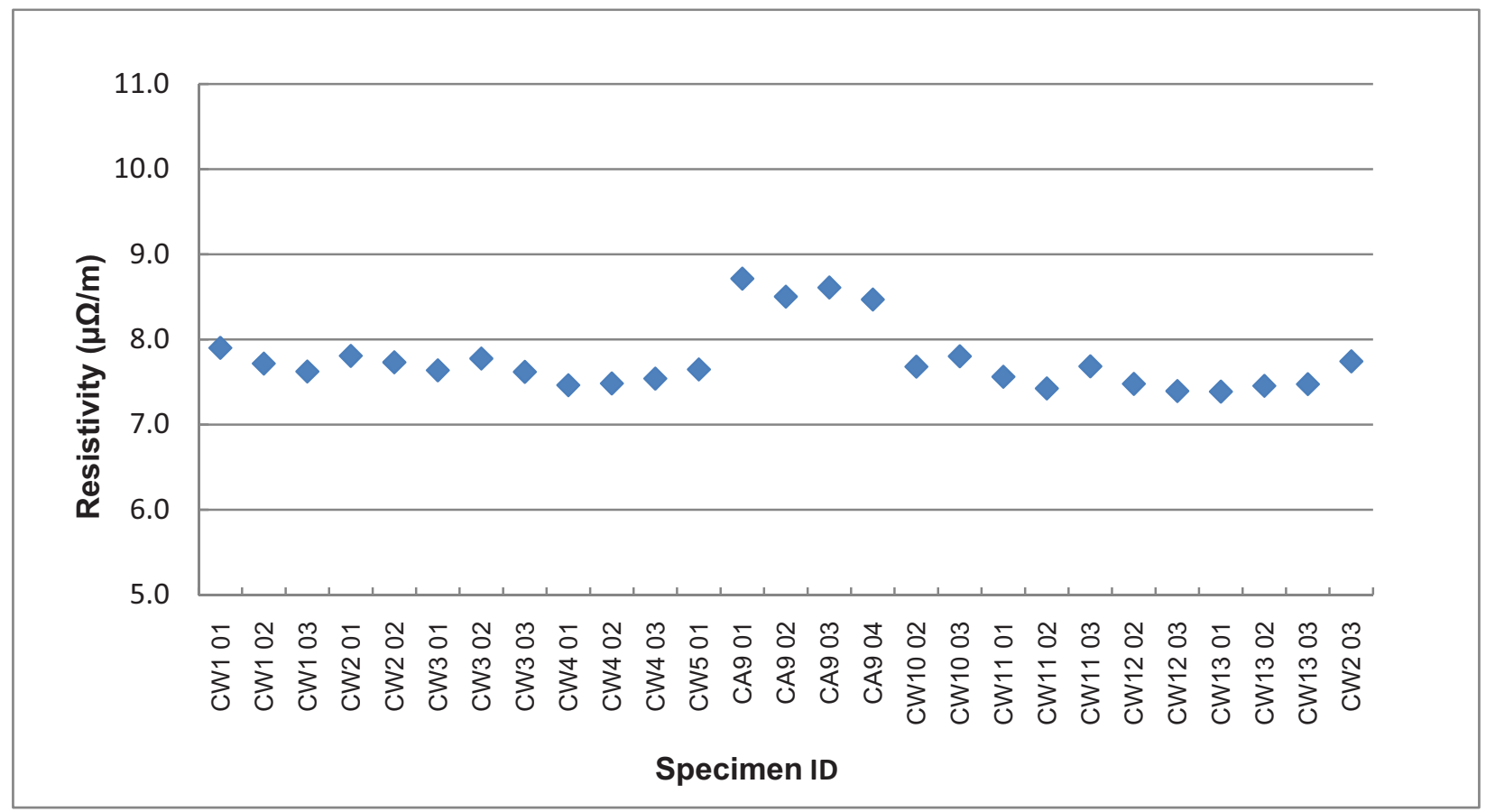

Figure A-4. Resistivity for H-451. 


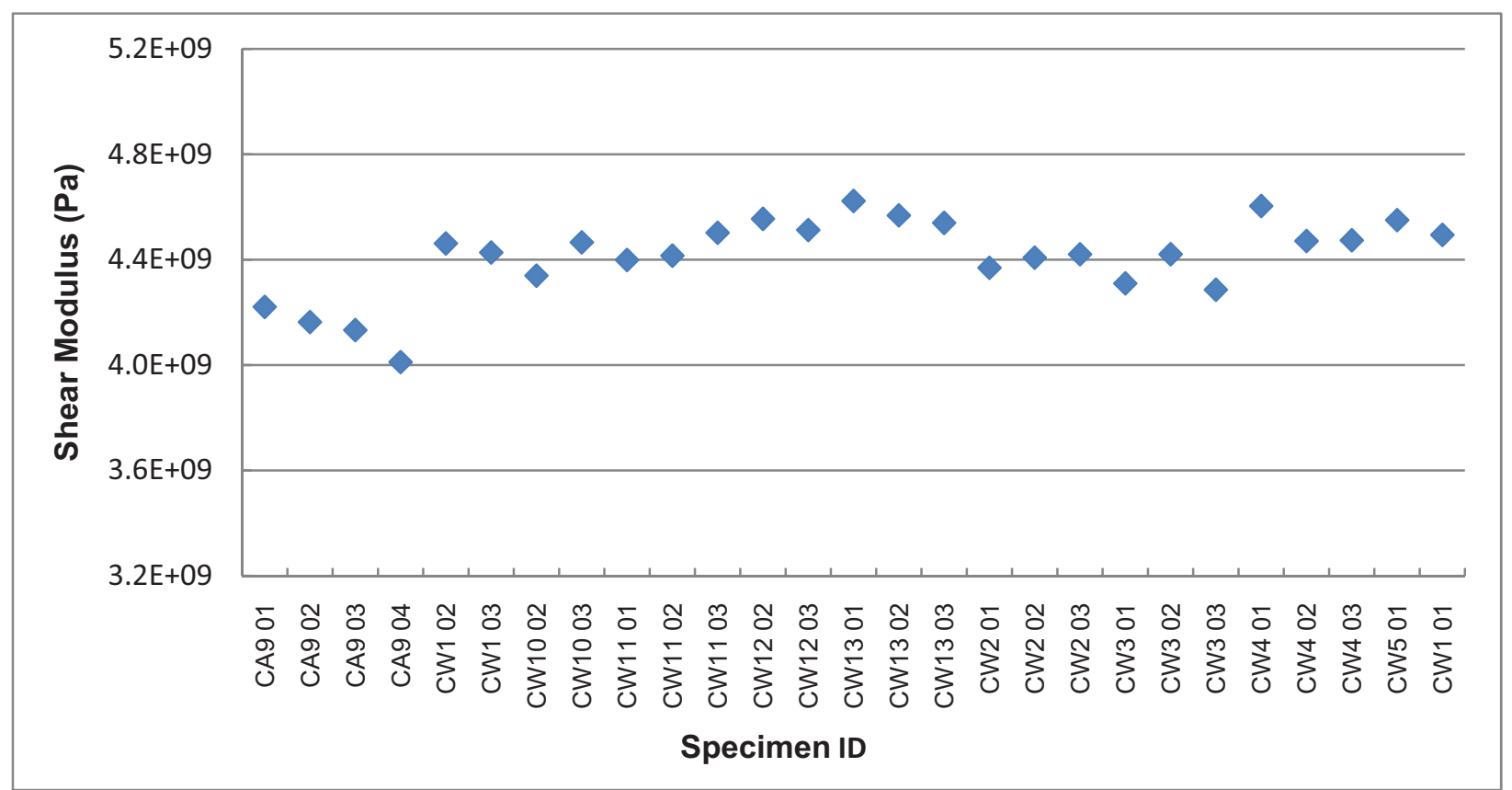

Figure A-5. Shear Modulus by sonic velocity for H-451.

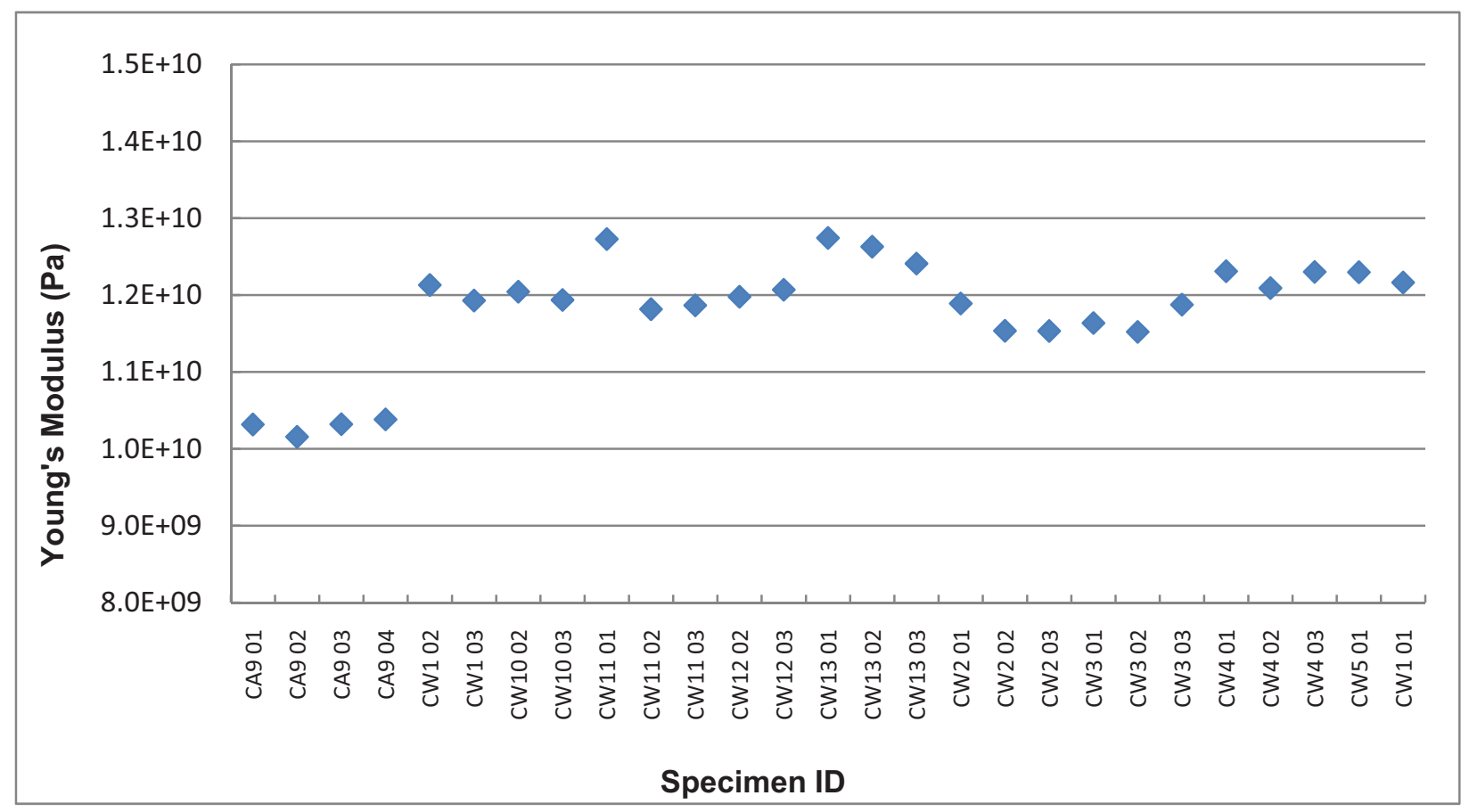

Figure A-6. Young's Modulus by sonic velocity for H-451. 


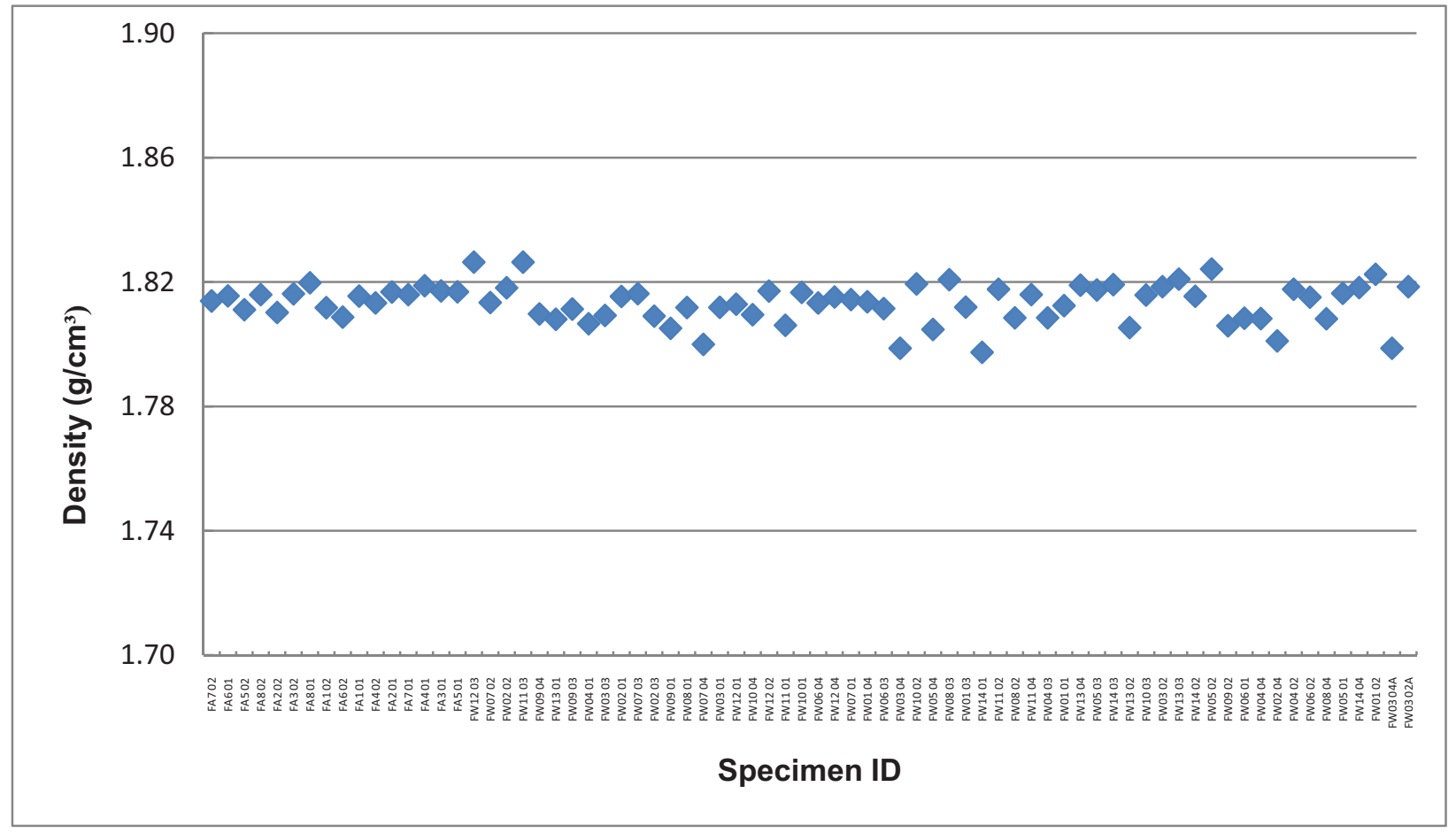

Figure A-7. Density for IG-430.

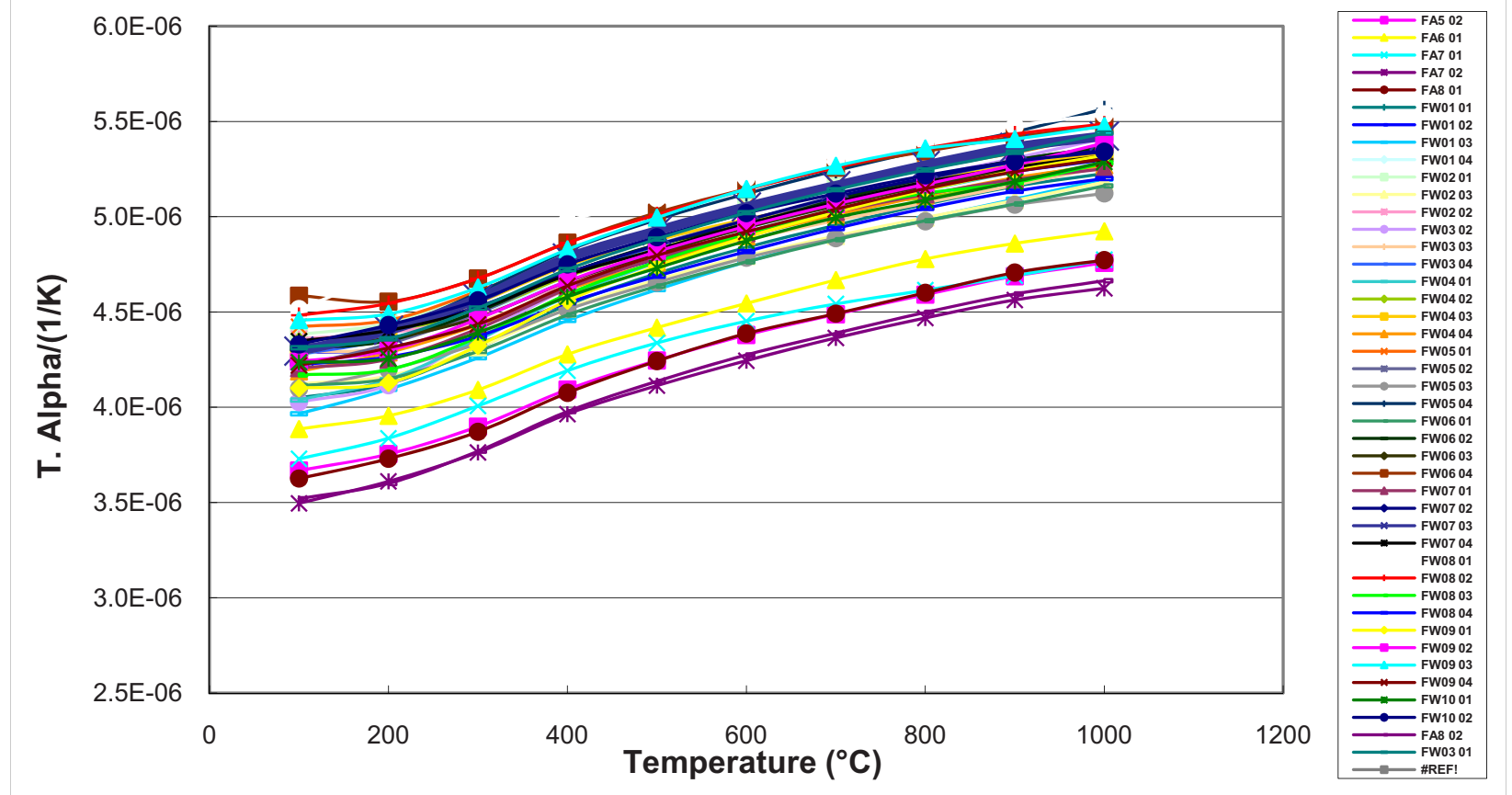

Figure A-8. Coefficient of thermal expansion for IG-430. 


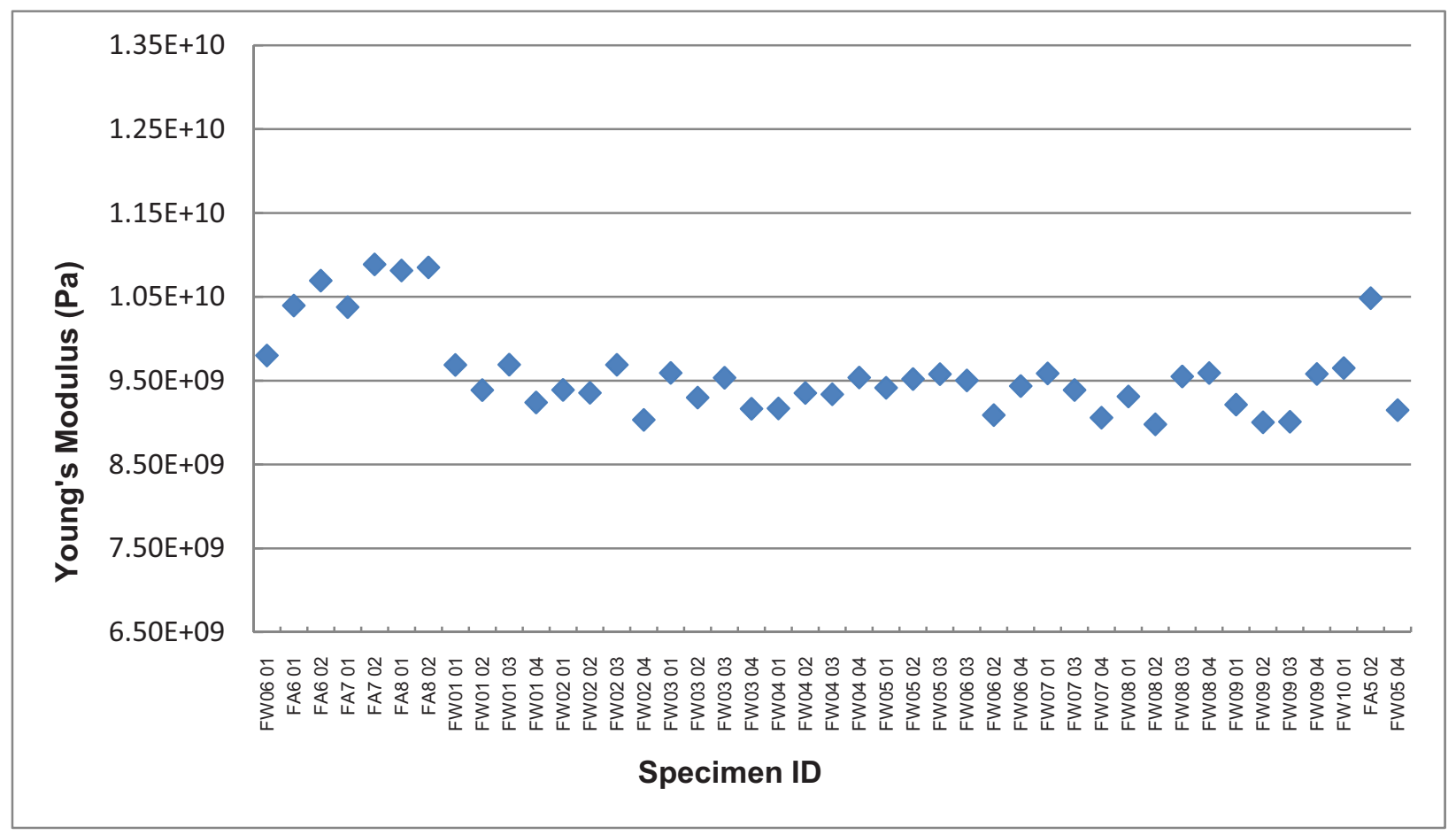

Figure A-9. Young's Modulus by sonic resonance for IG-430.

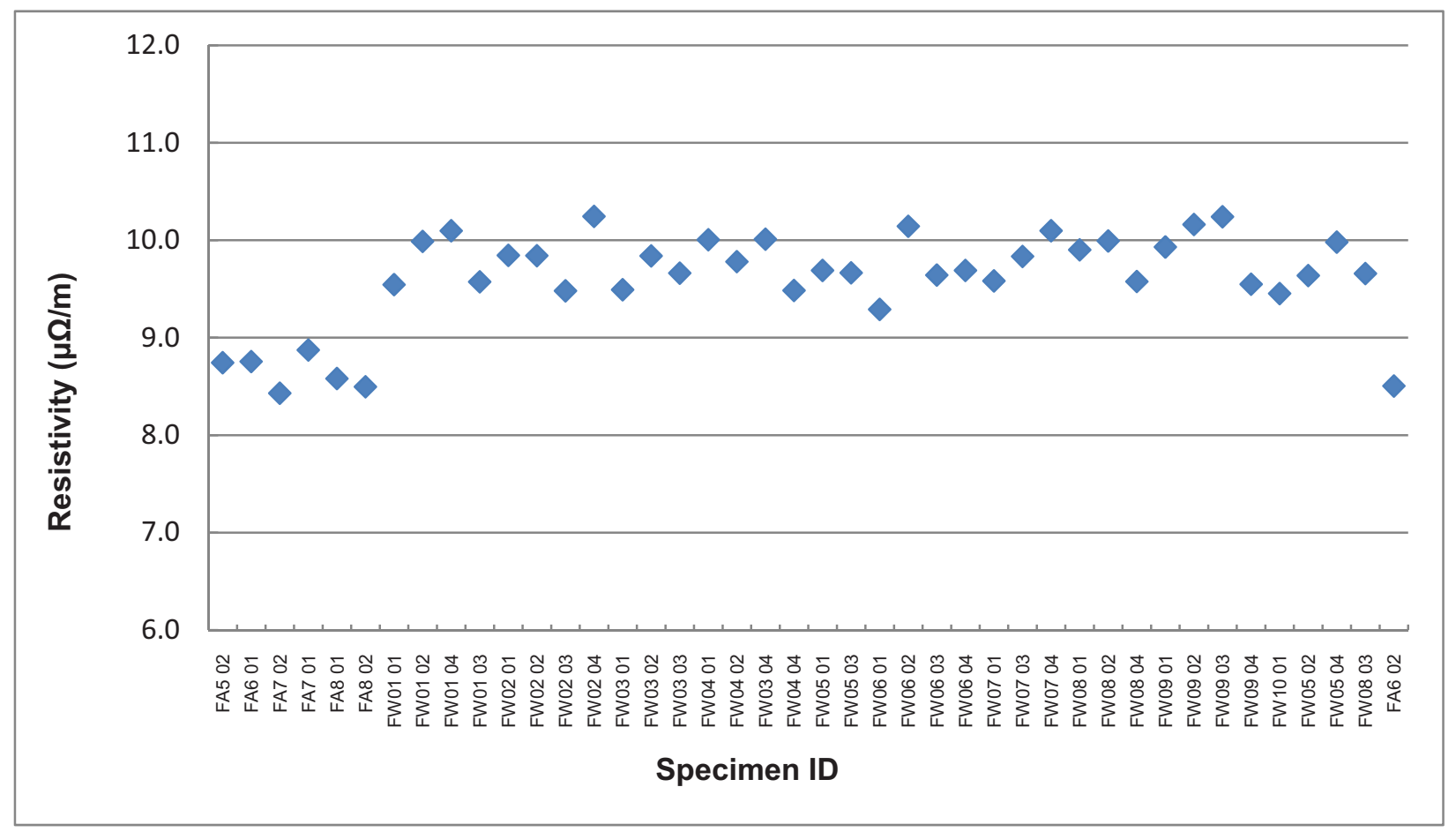

Figure A-10. Resistivity for IG-430. 


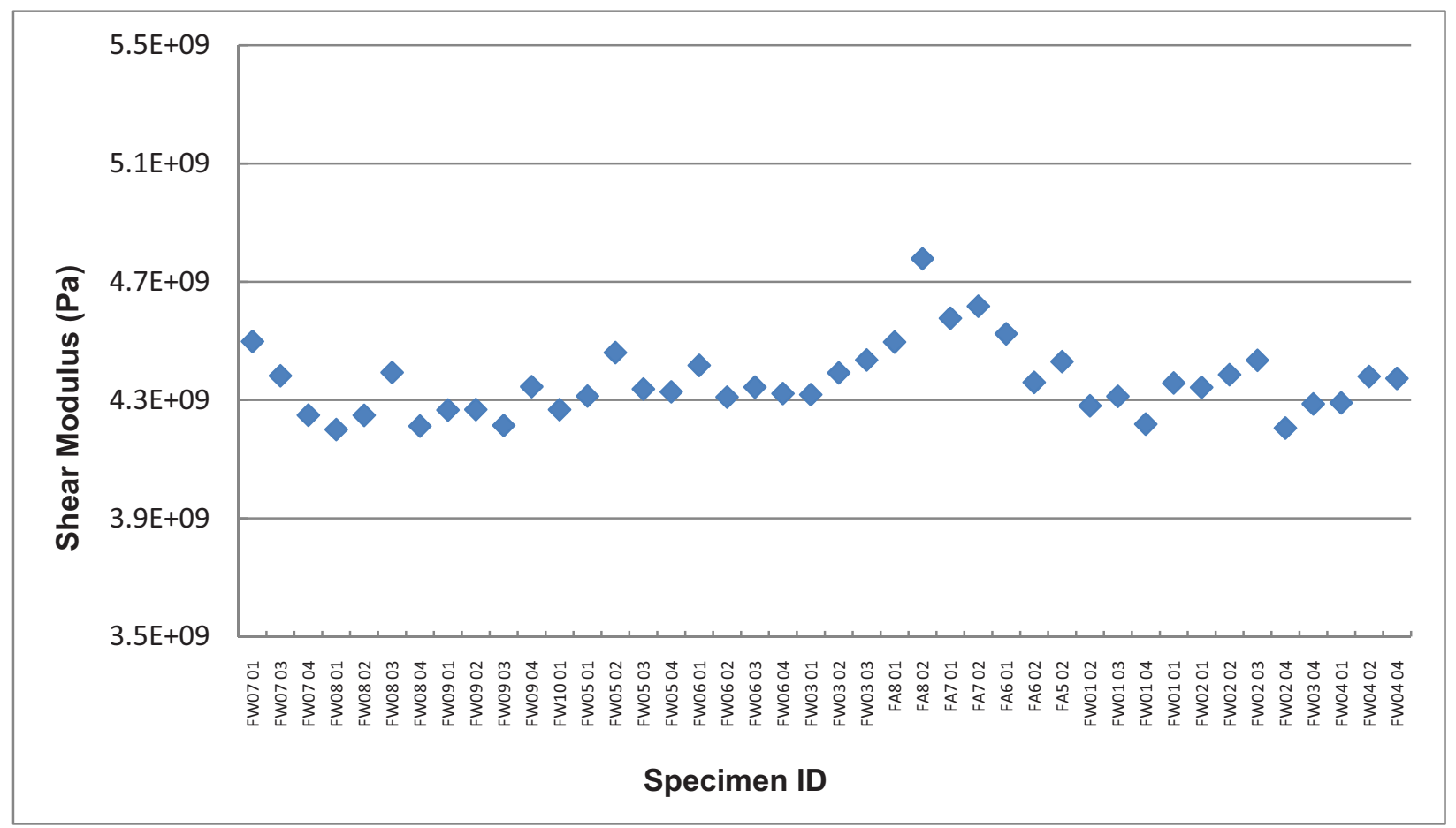

Figure A-11. Shear Modulus by sonic velocity for IG-430.

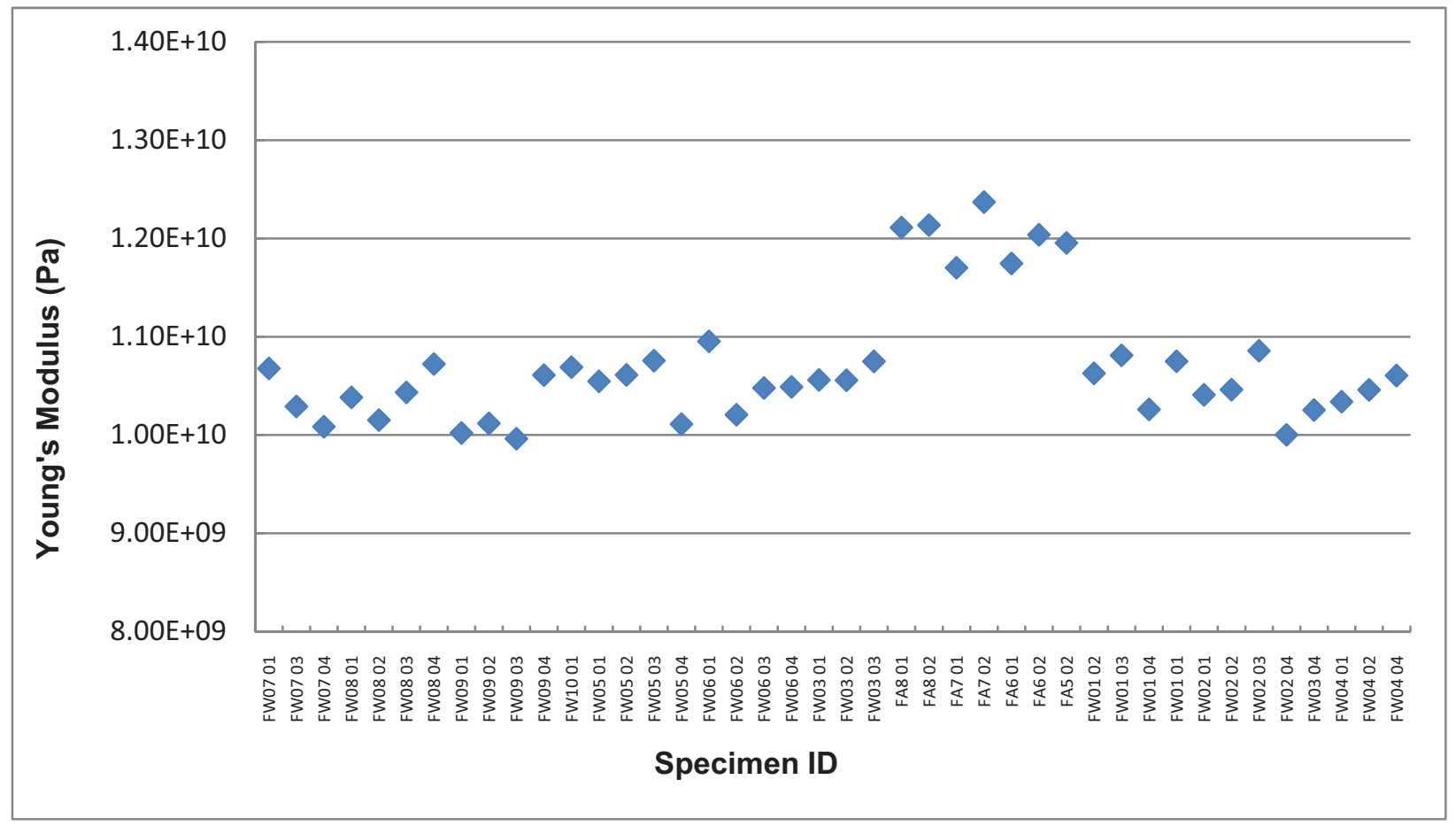

Figure A-12. Young's Modulus by sonic velocity for IG-430. 


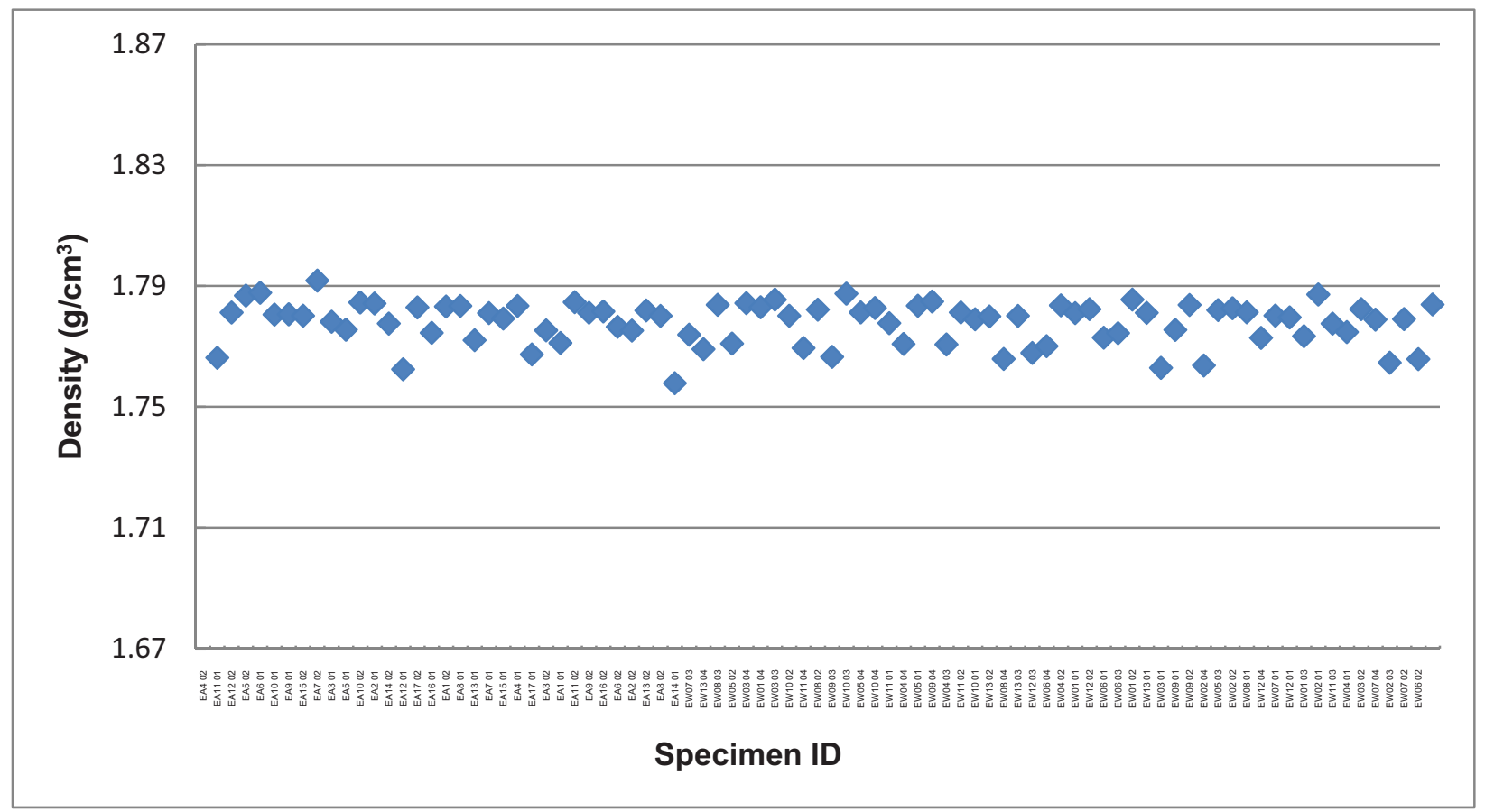

Figure A-13. Density for IG-110.

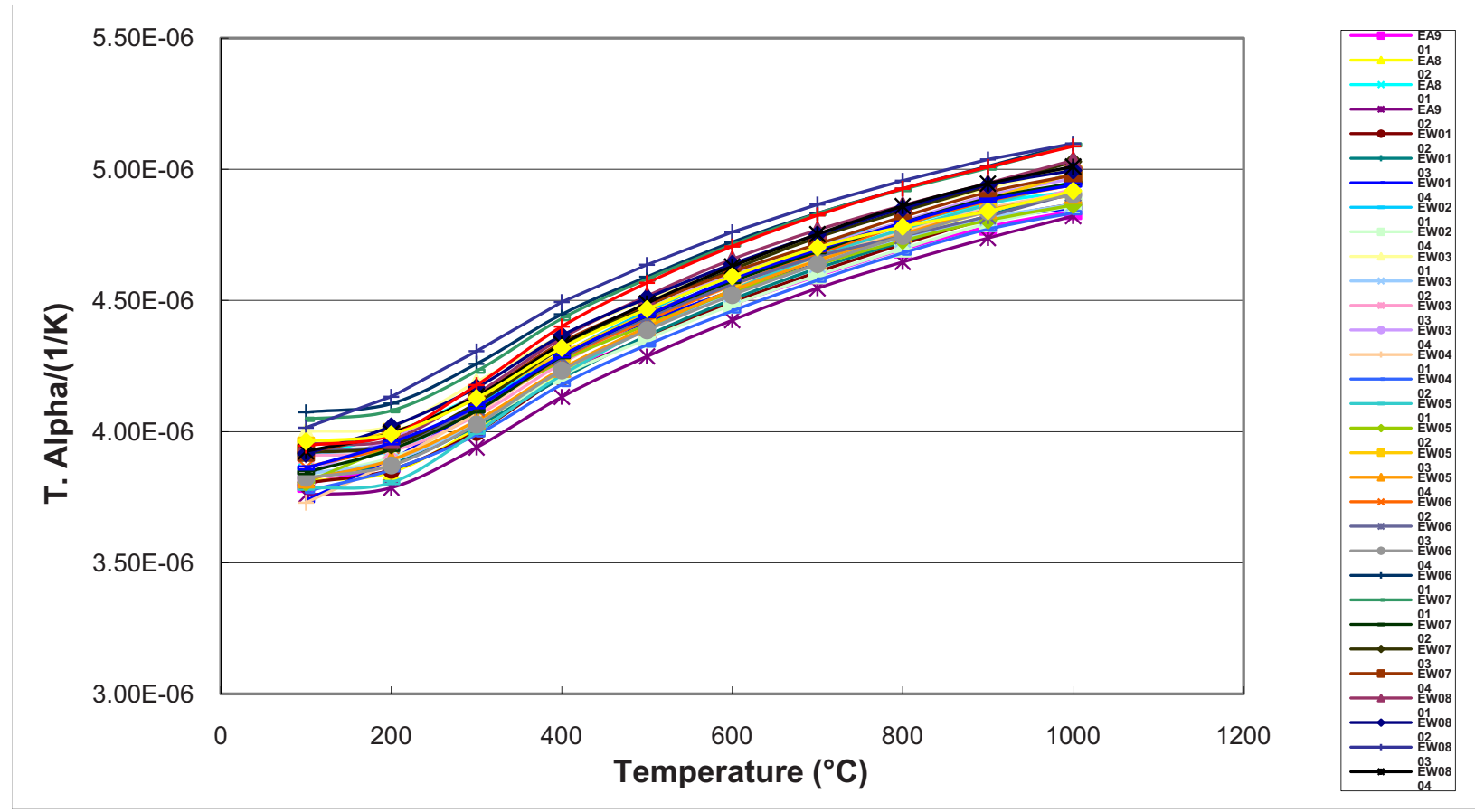

Figure A-14. Coefficient of thermal expansion for IG-110. 


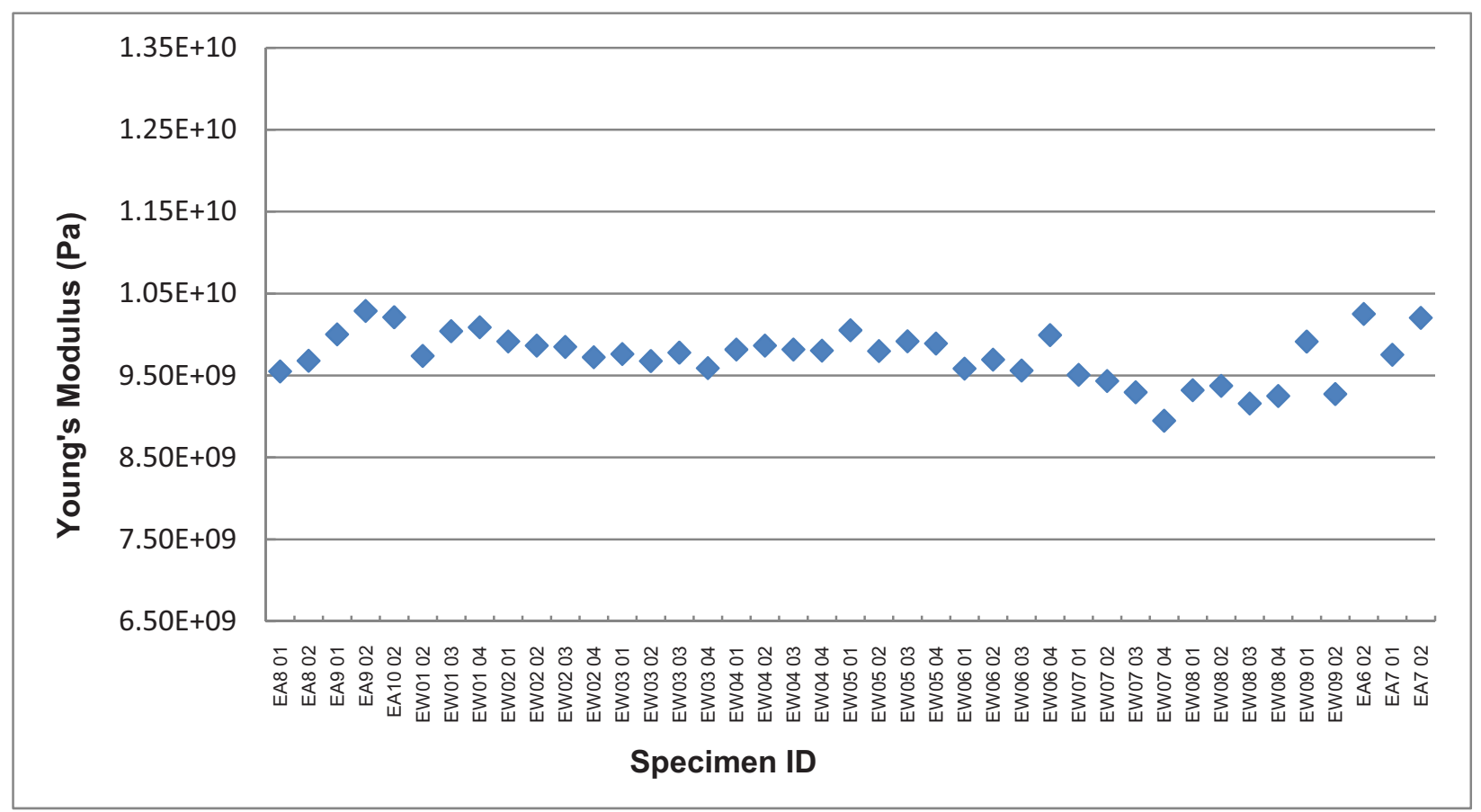

Figure A-15. Young's Modulus by sonic resonance for IG-110.

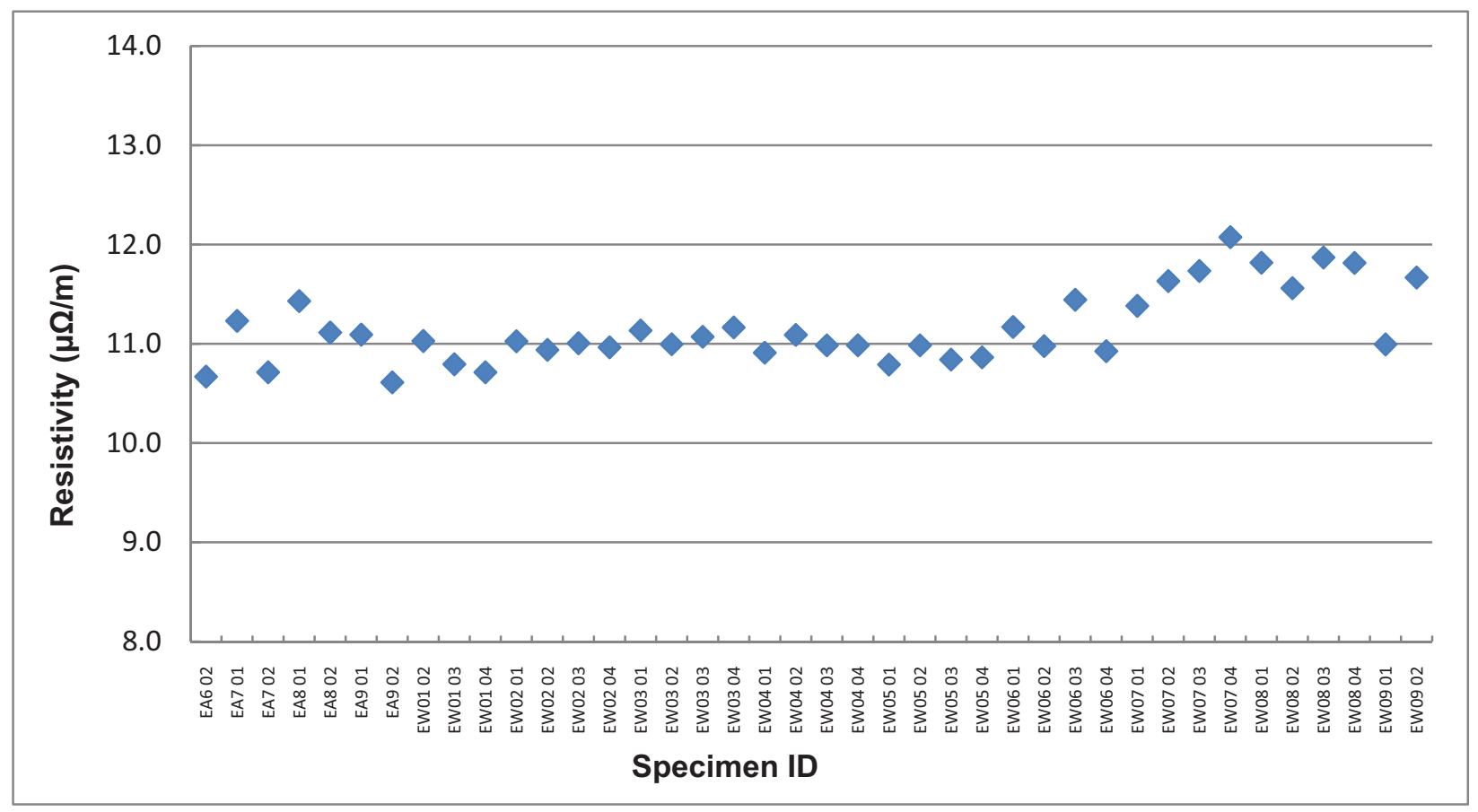

Figure A-16. Resistivity for IG-110. 


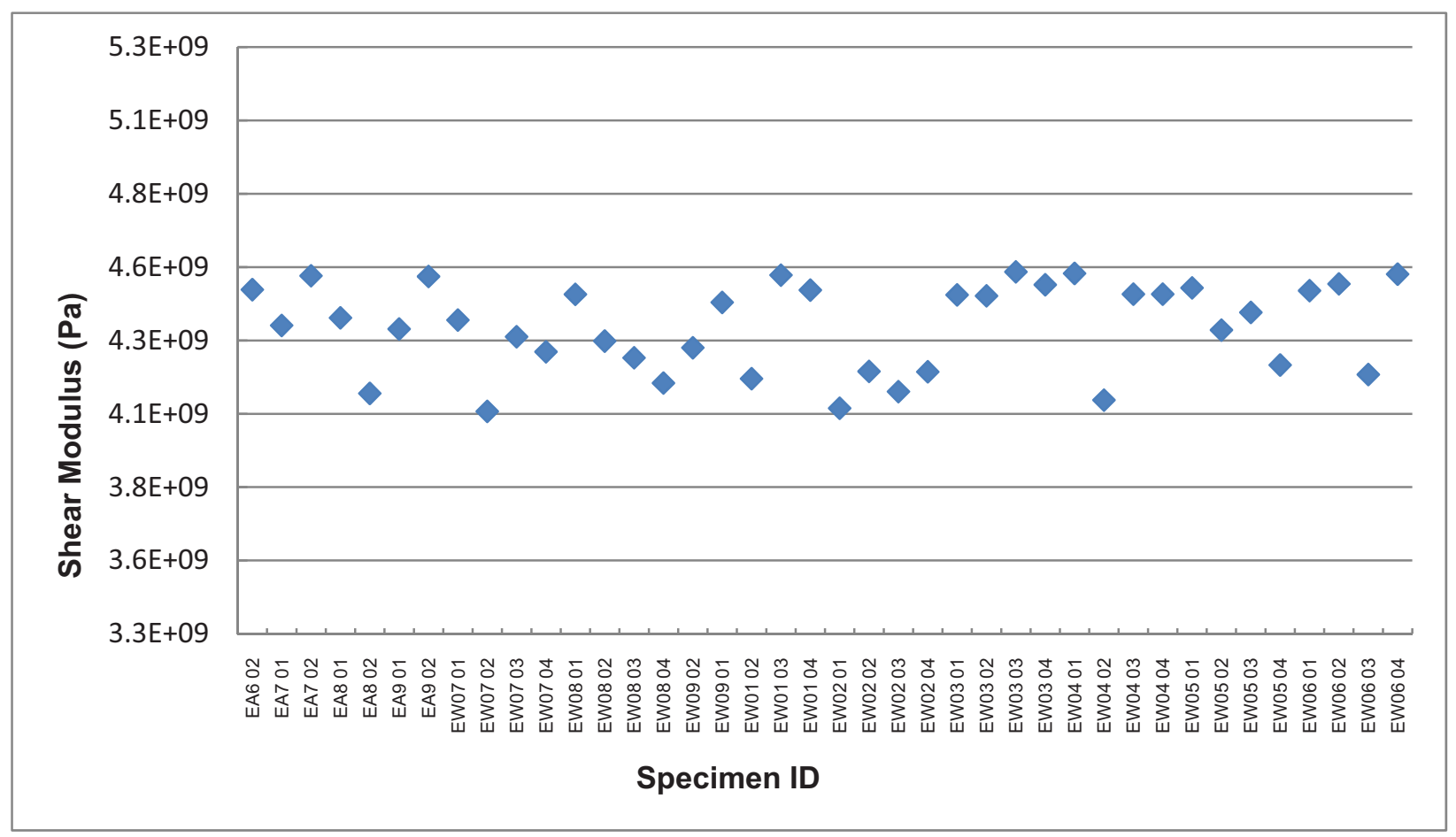

Figure A-17. Shear Modulus by sonic velocity for IG-110.

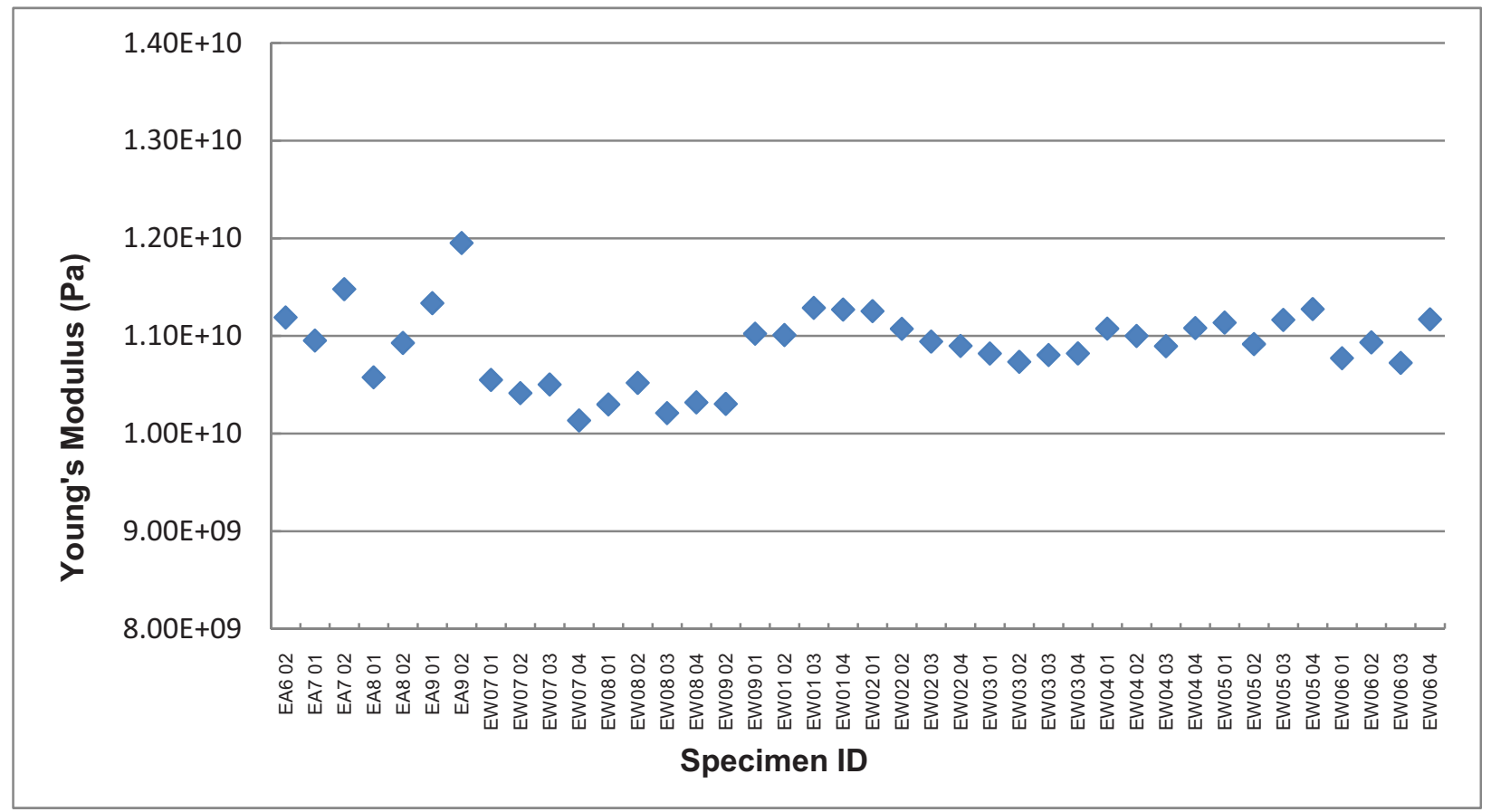

Figure A-18. Young's Modulus by sonic velocity for IG-110. 


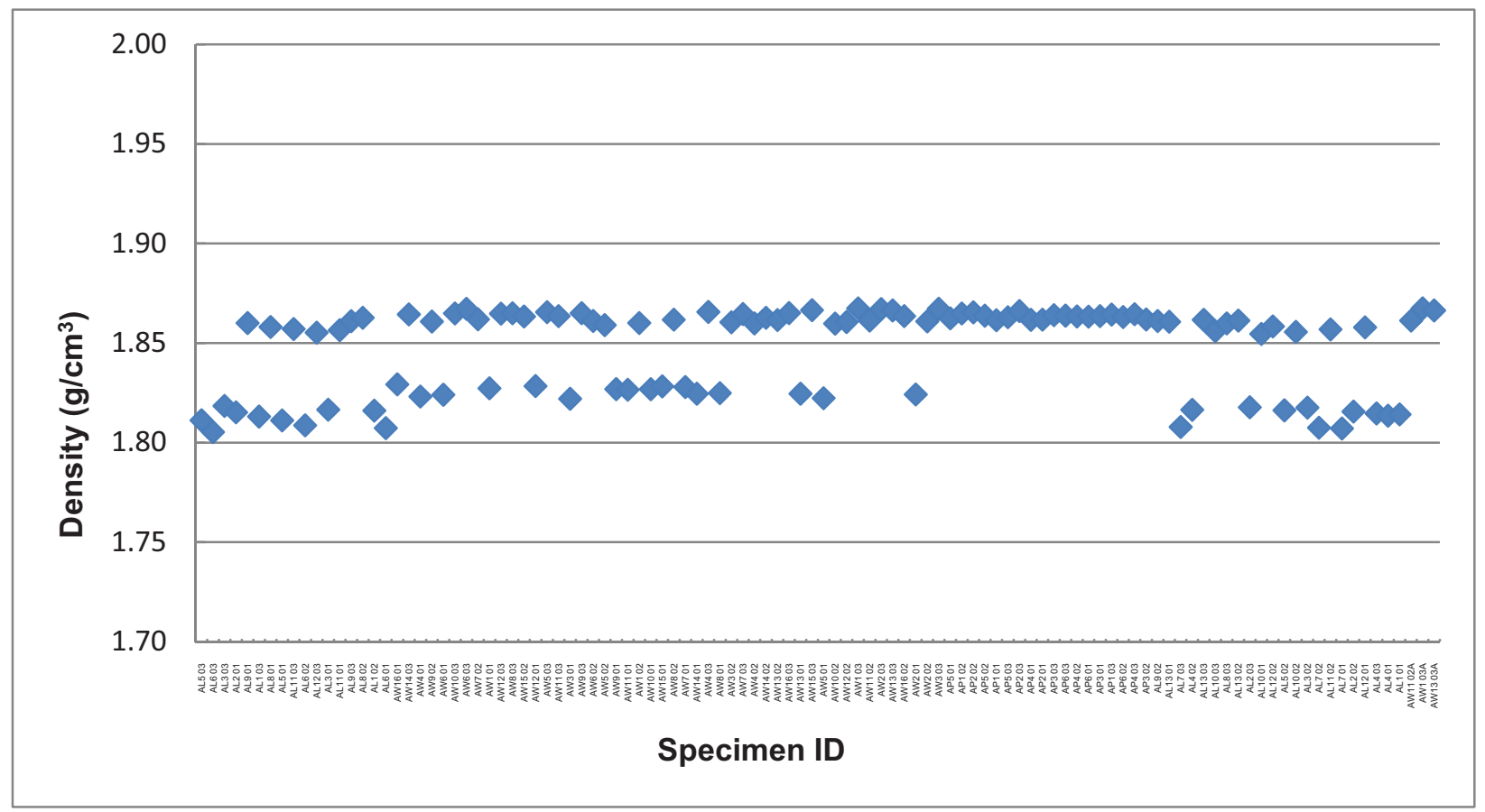

Figure A-19. Density for NBG-17.

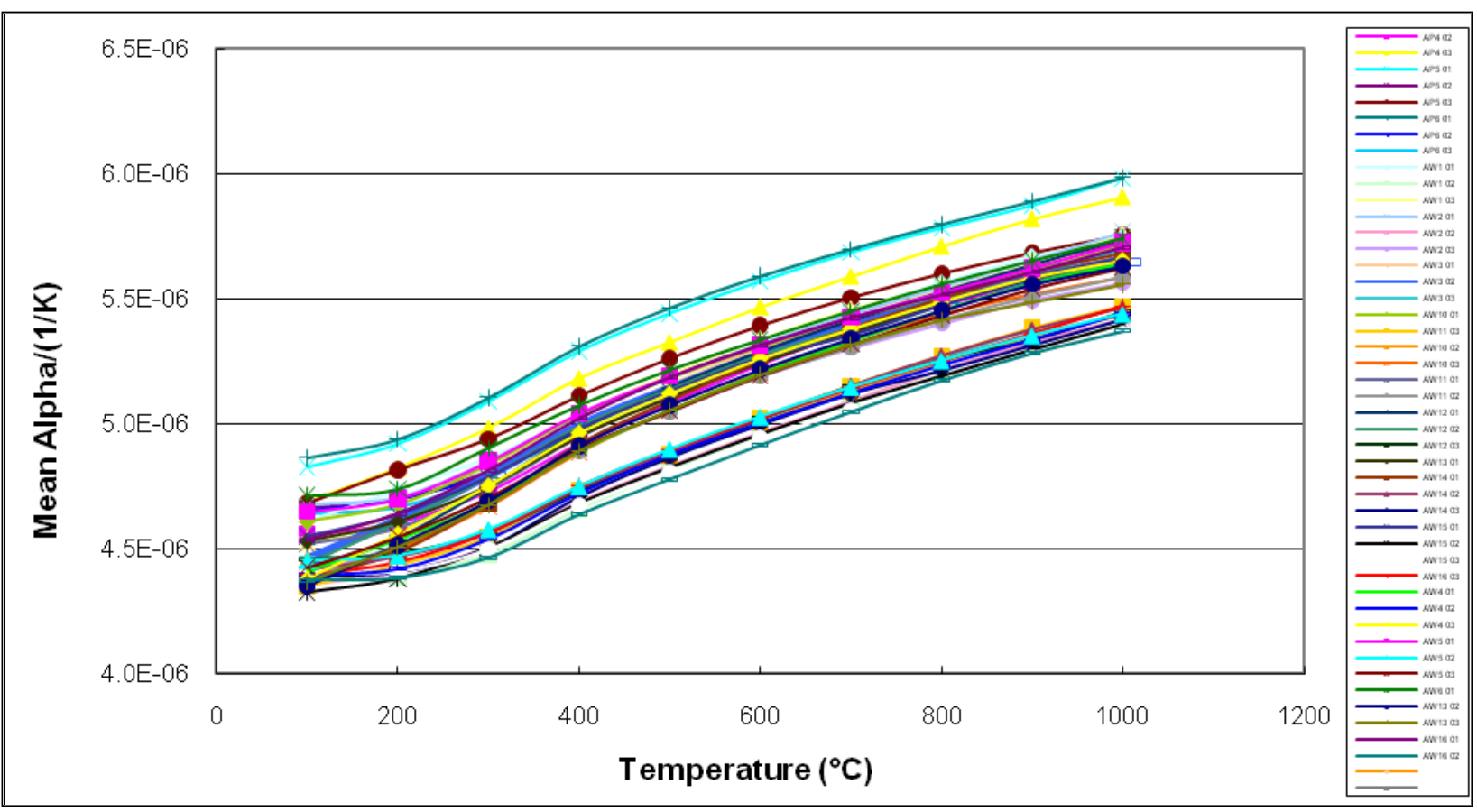

Figure A-20. Coefficient of thermal expansion for NBG-17. 


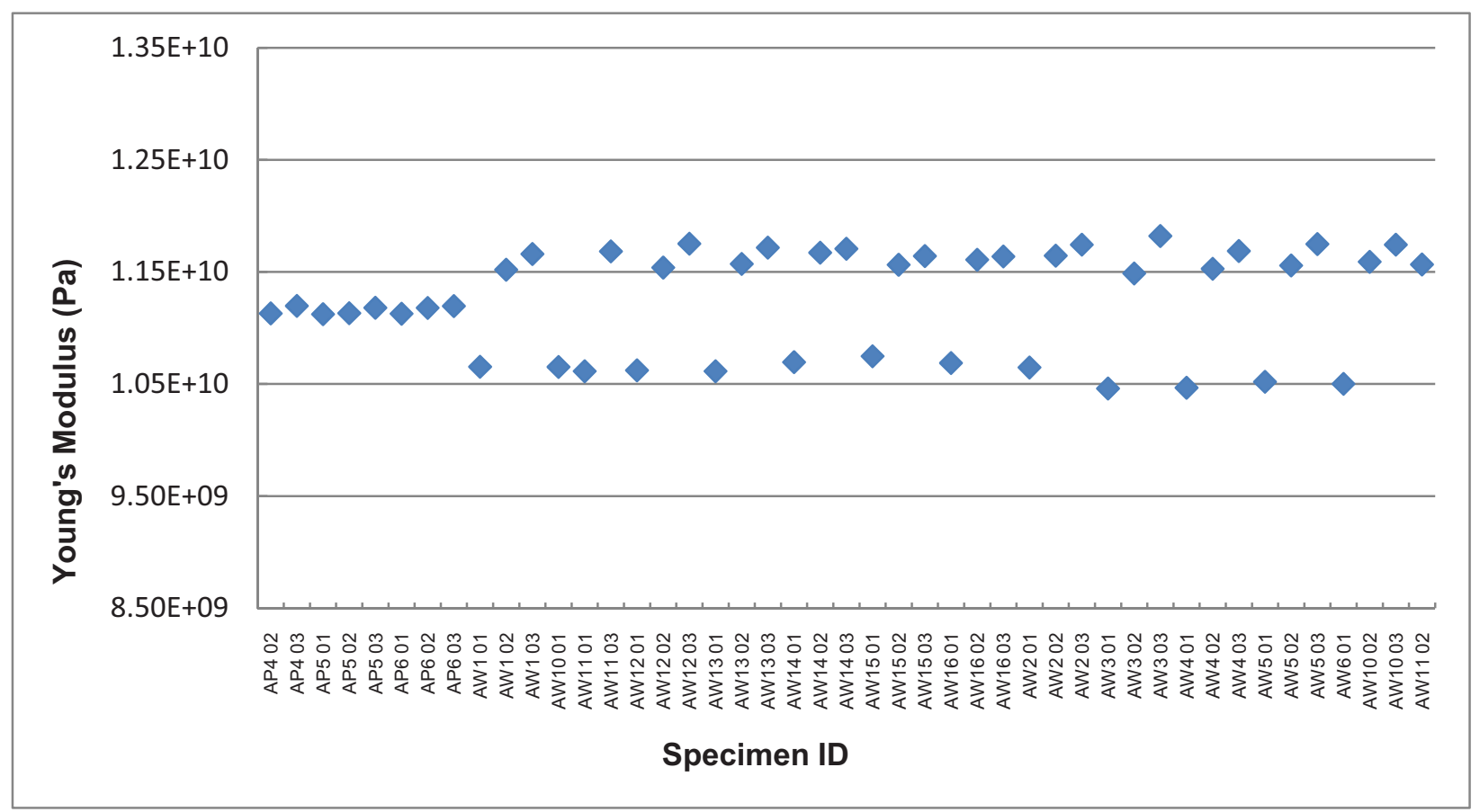

Figure A-21. Young's Modulus by sonic resonance for NBG-17.

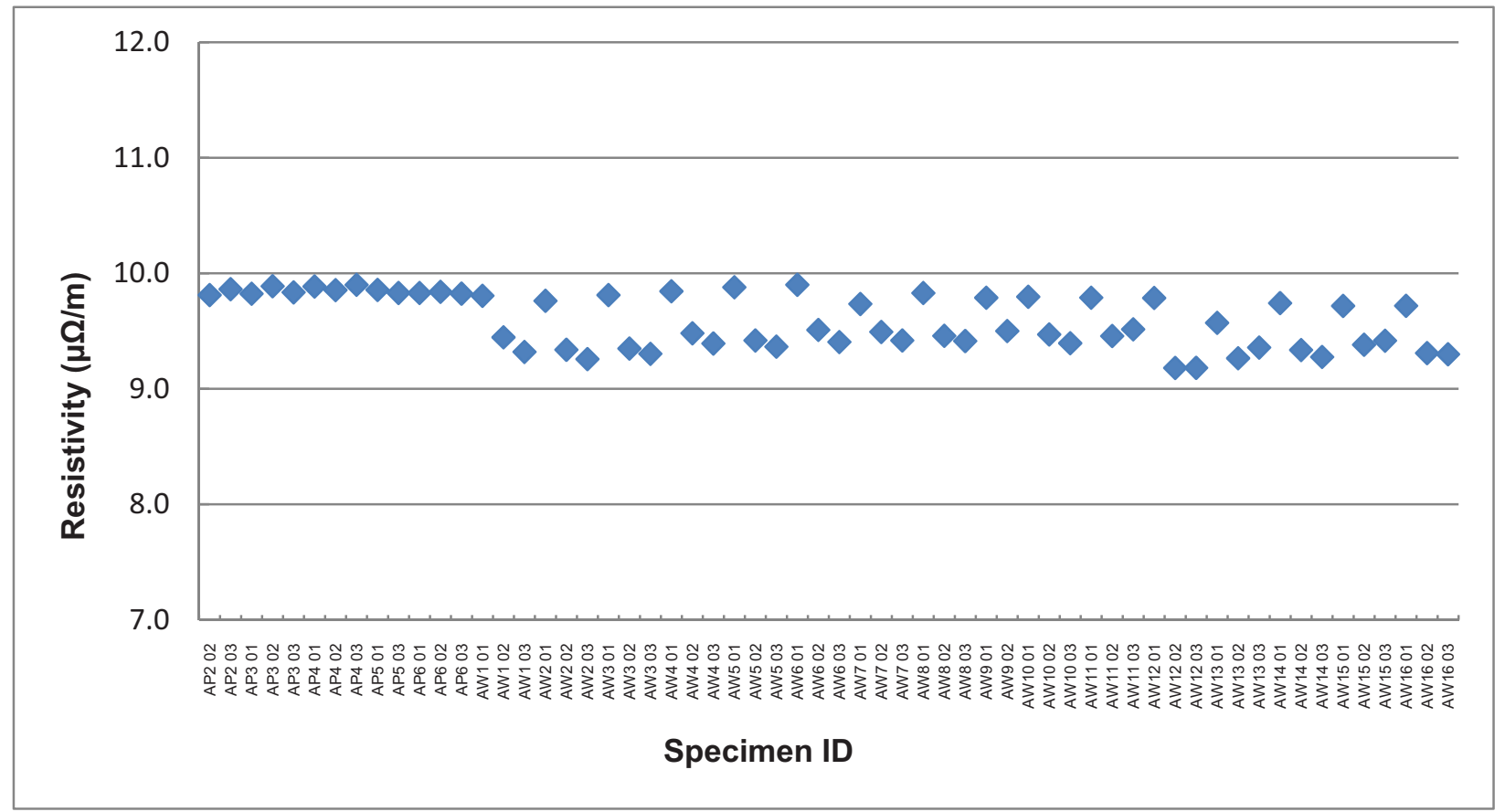

Figure A-22. Resistivity for NBG-17. 


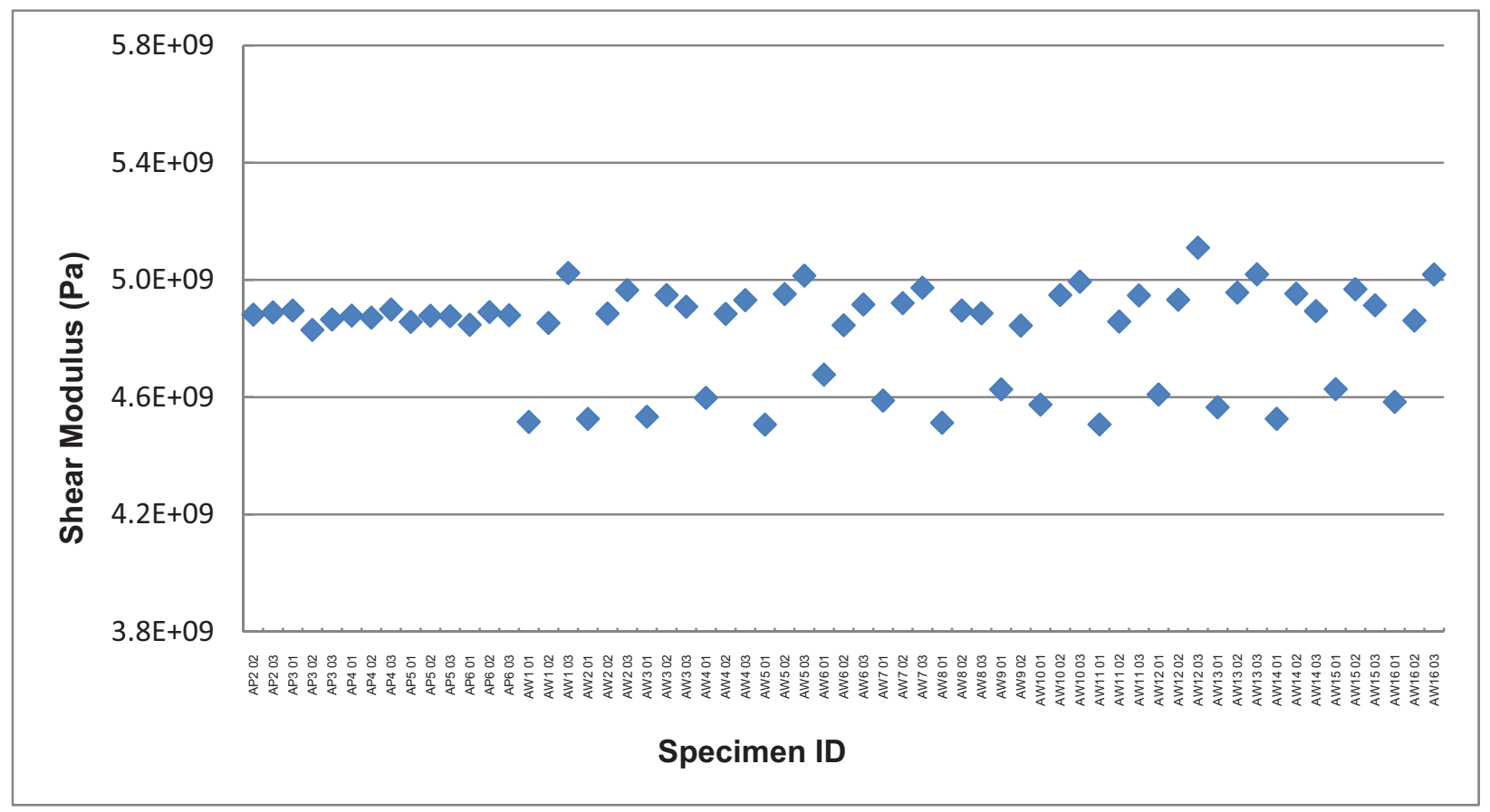

Figure A-23. Shear Modulus by sonic velocity for NBG-17.

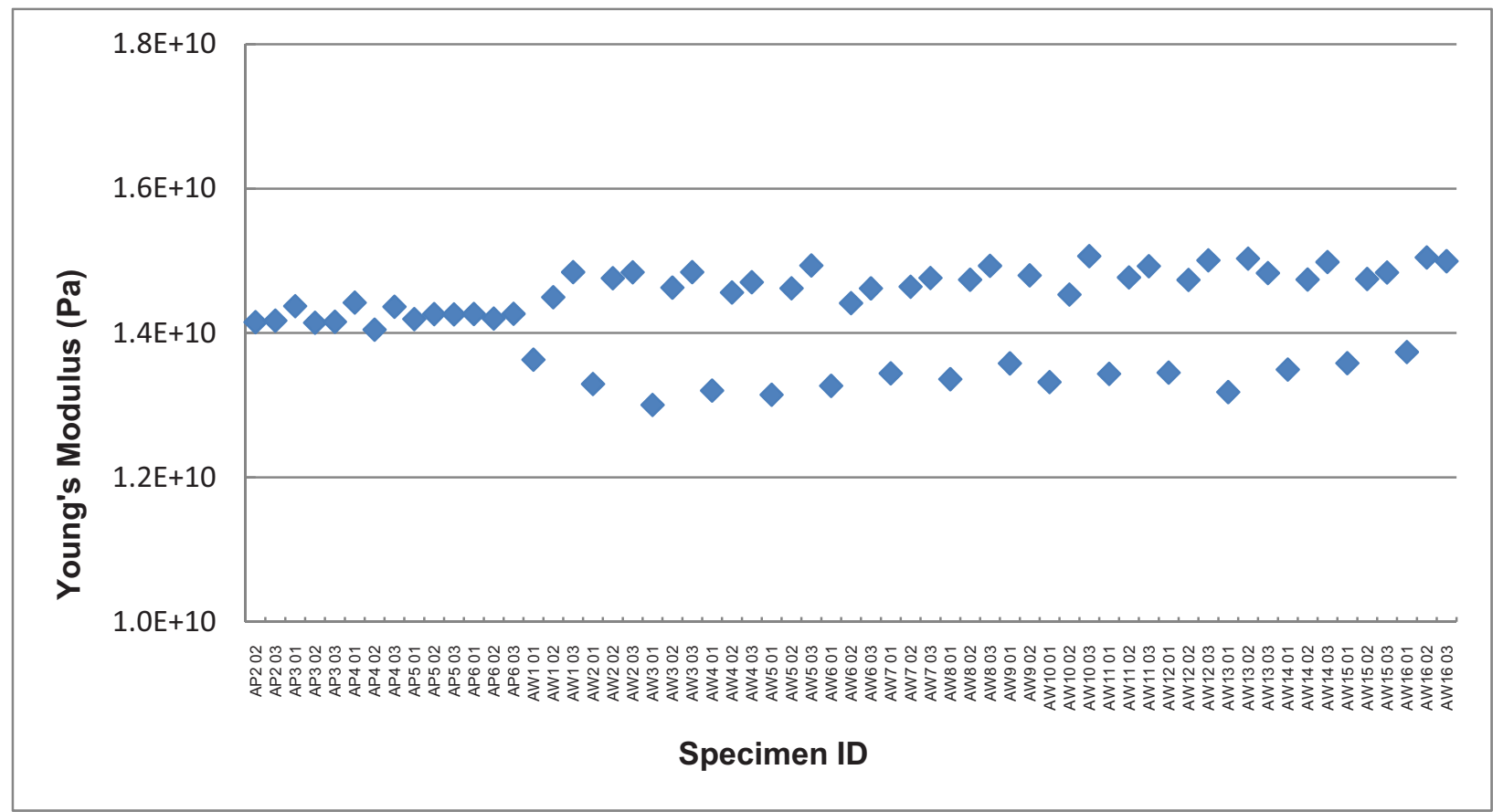

Figure A-24. Young's Modulus by sonic velocity for NBG-17. 


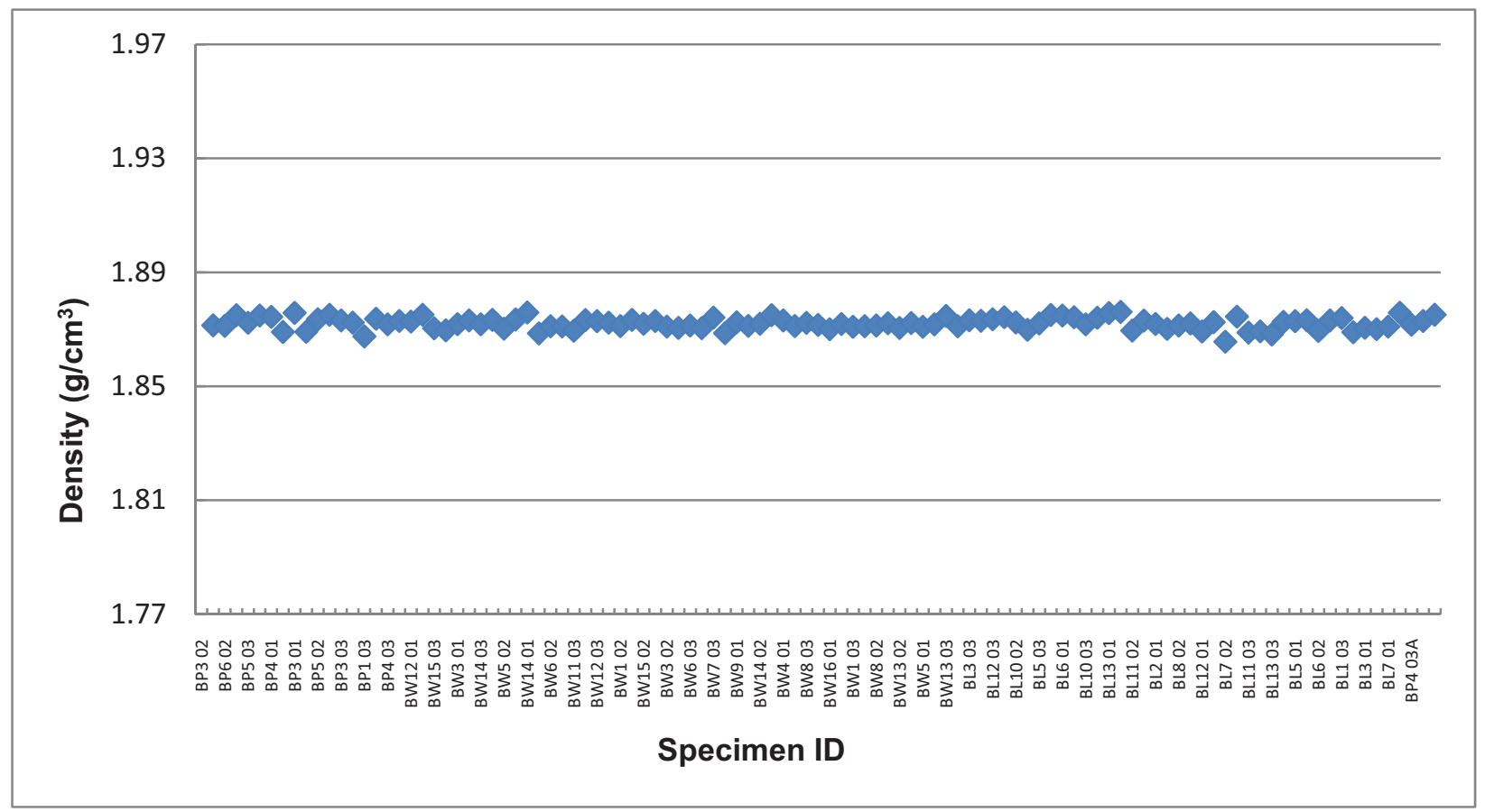

Figure A-25. Density for NBG 18.

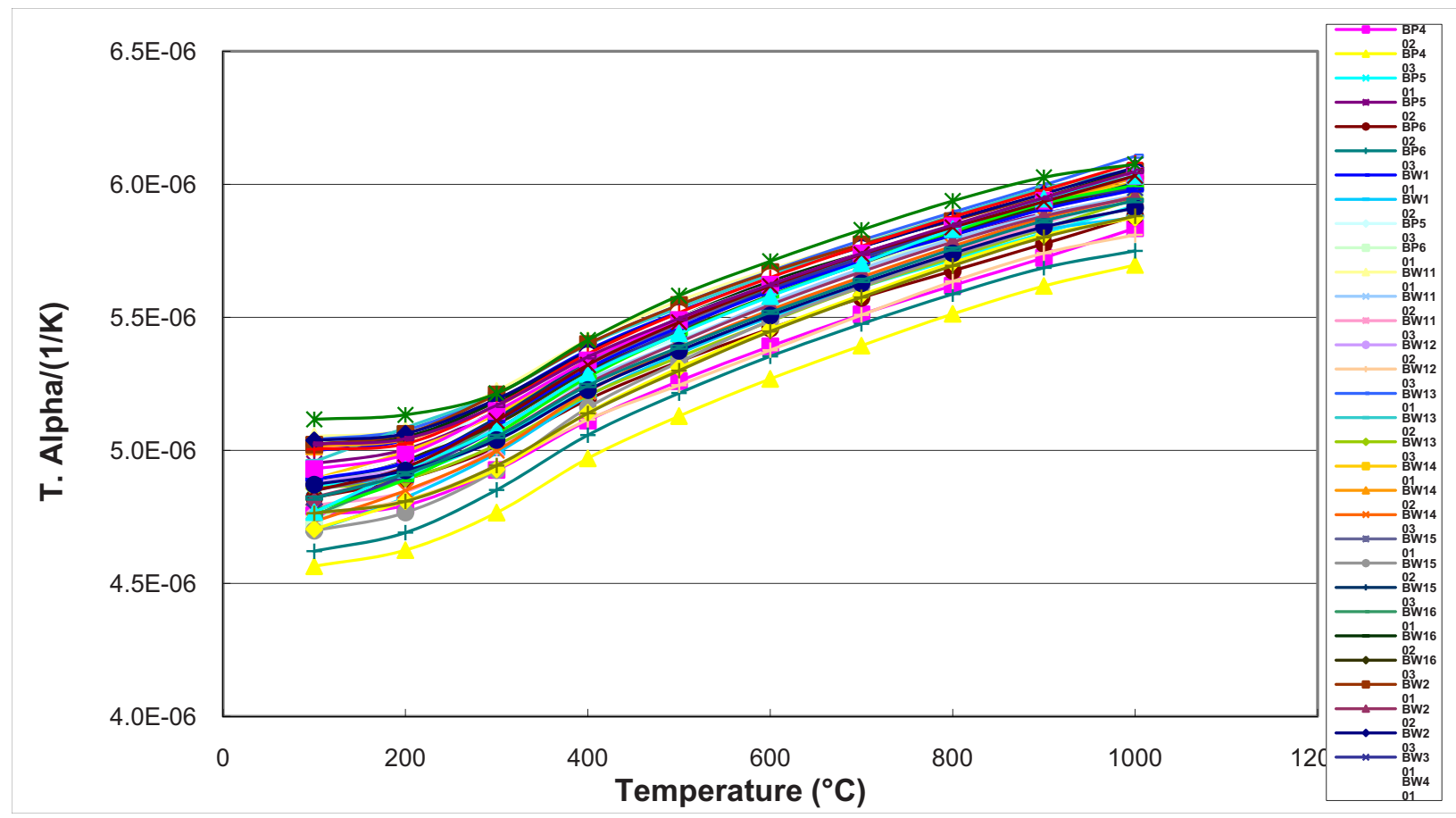

Figure A-26. Coefficient of thermal expansion for NBG-18. 


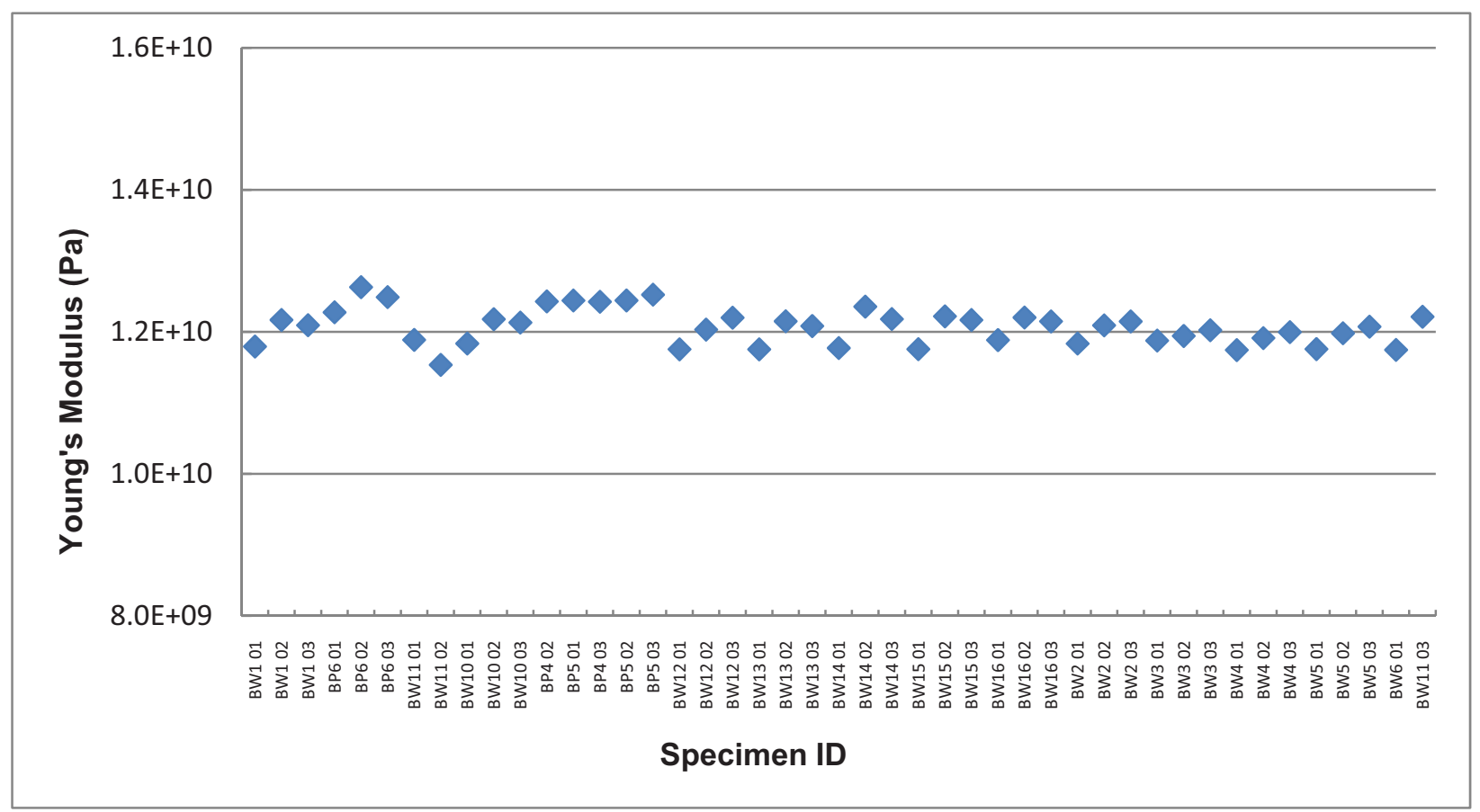

Figure A-27. Young's Modulus by sonic resonance for NBG-18.

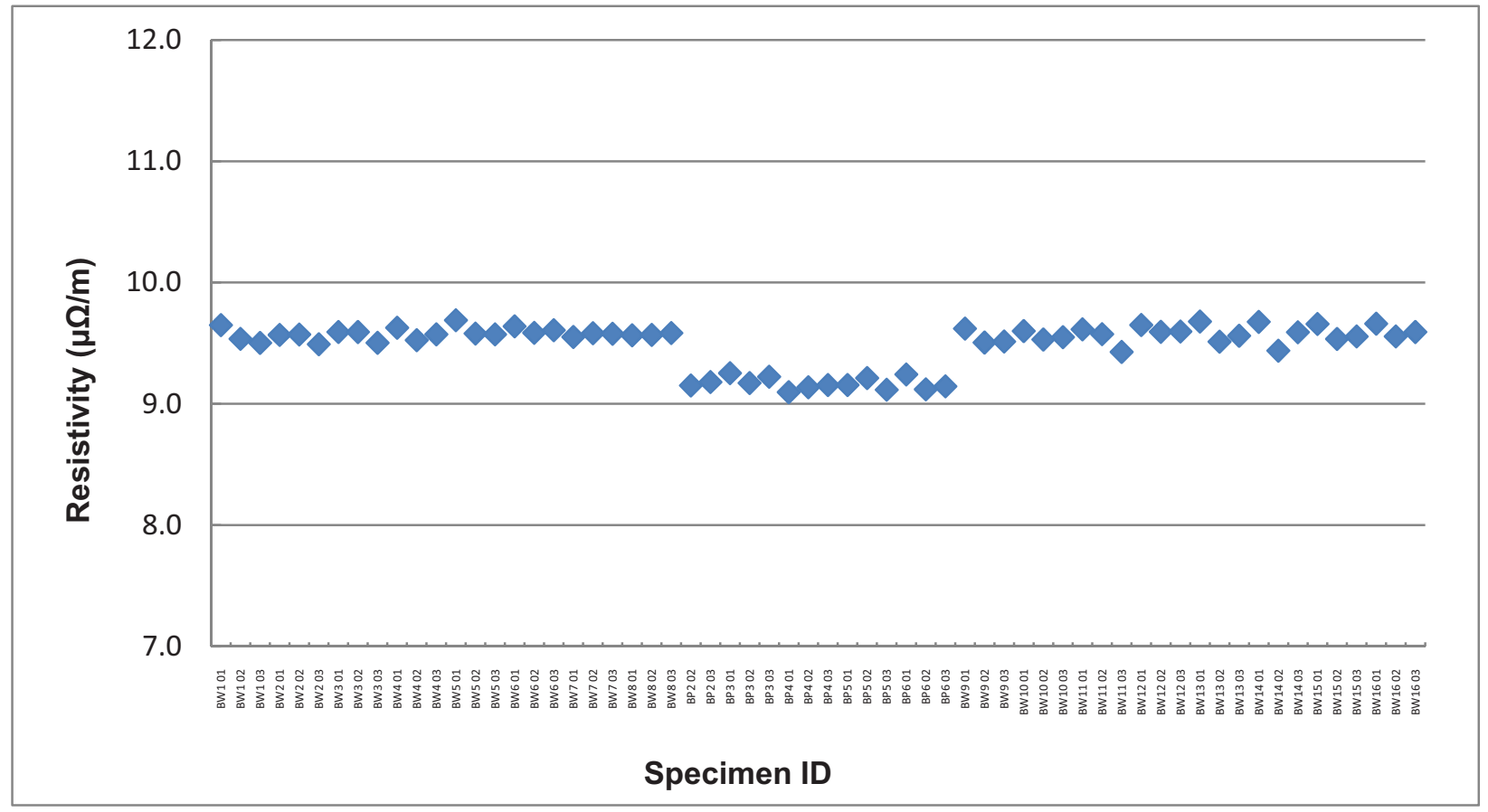

Figure A-28. Resistivity for NBG-18. 


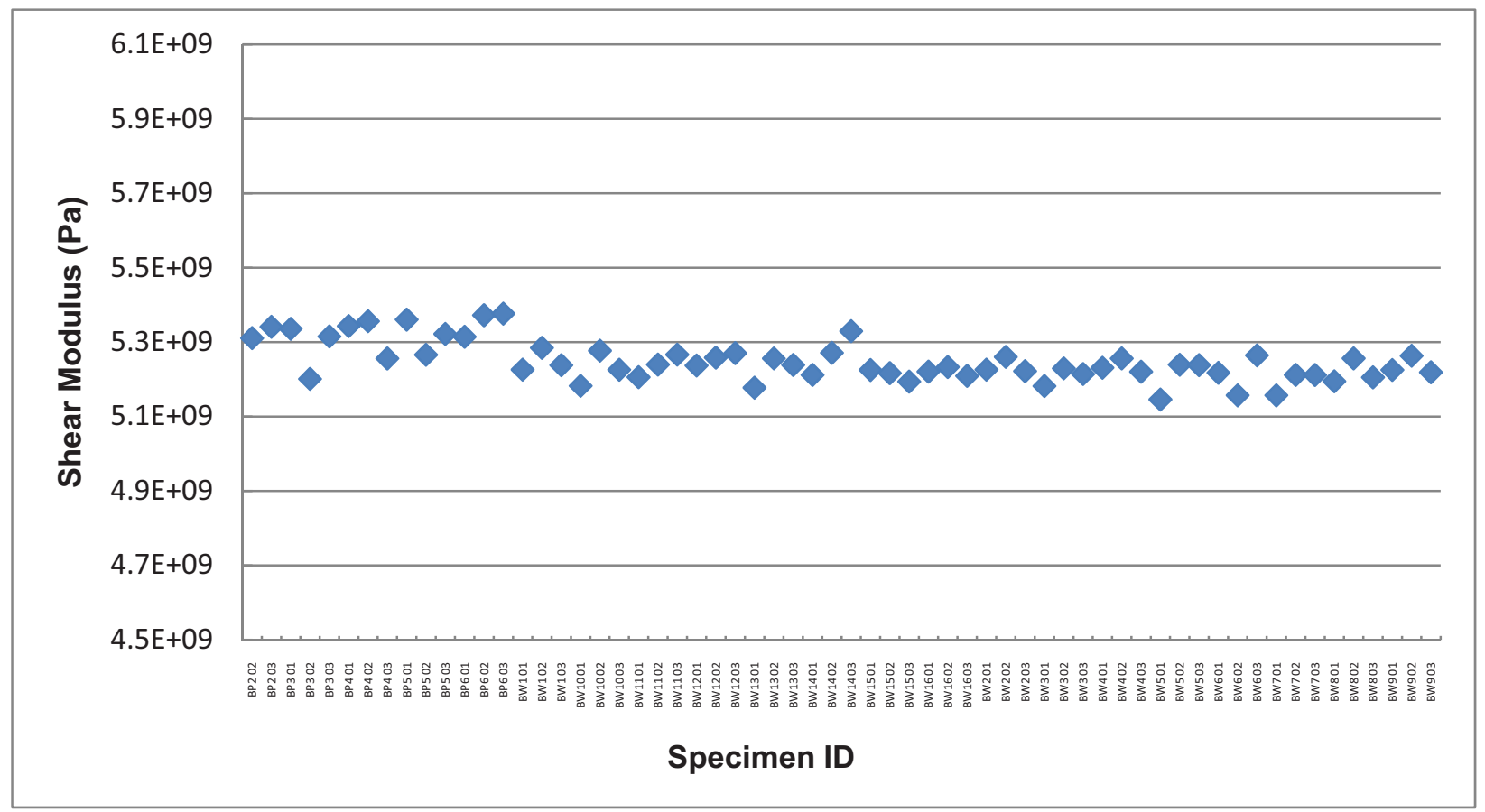

Figure A-29. Shear Modulus by sonic velocity for NBG-18.

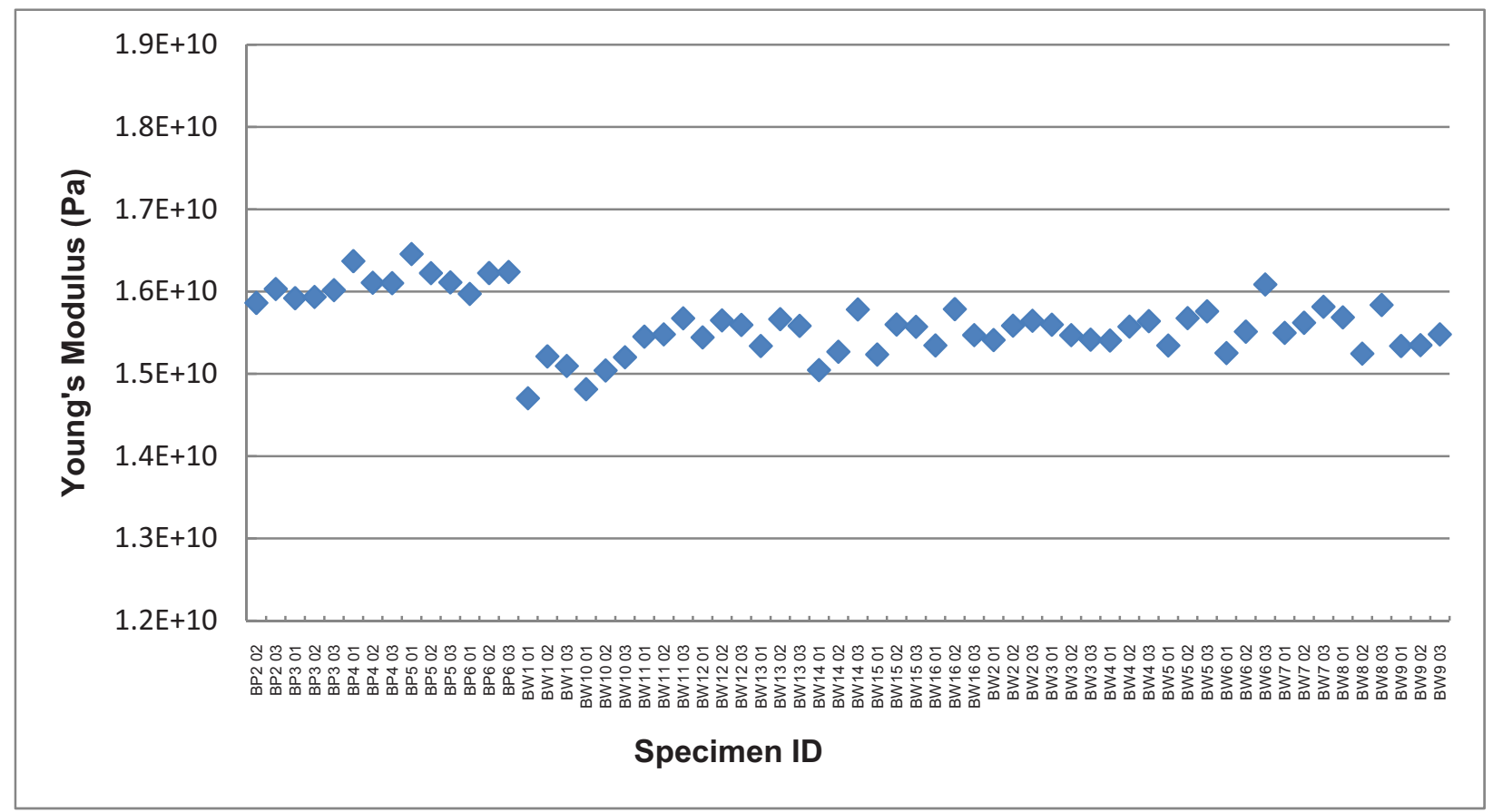

Figure A-30. Young's Modulus by sonic velocity for NBG-18. 


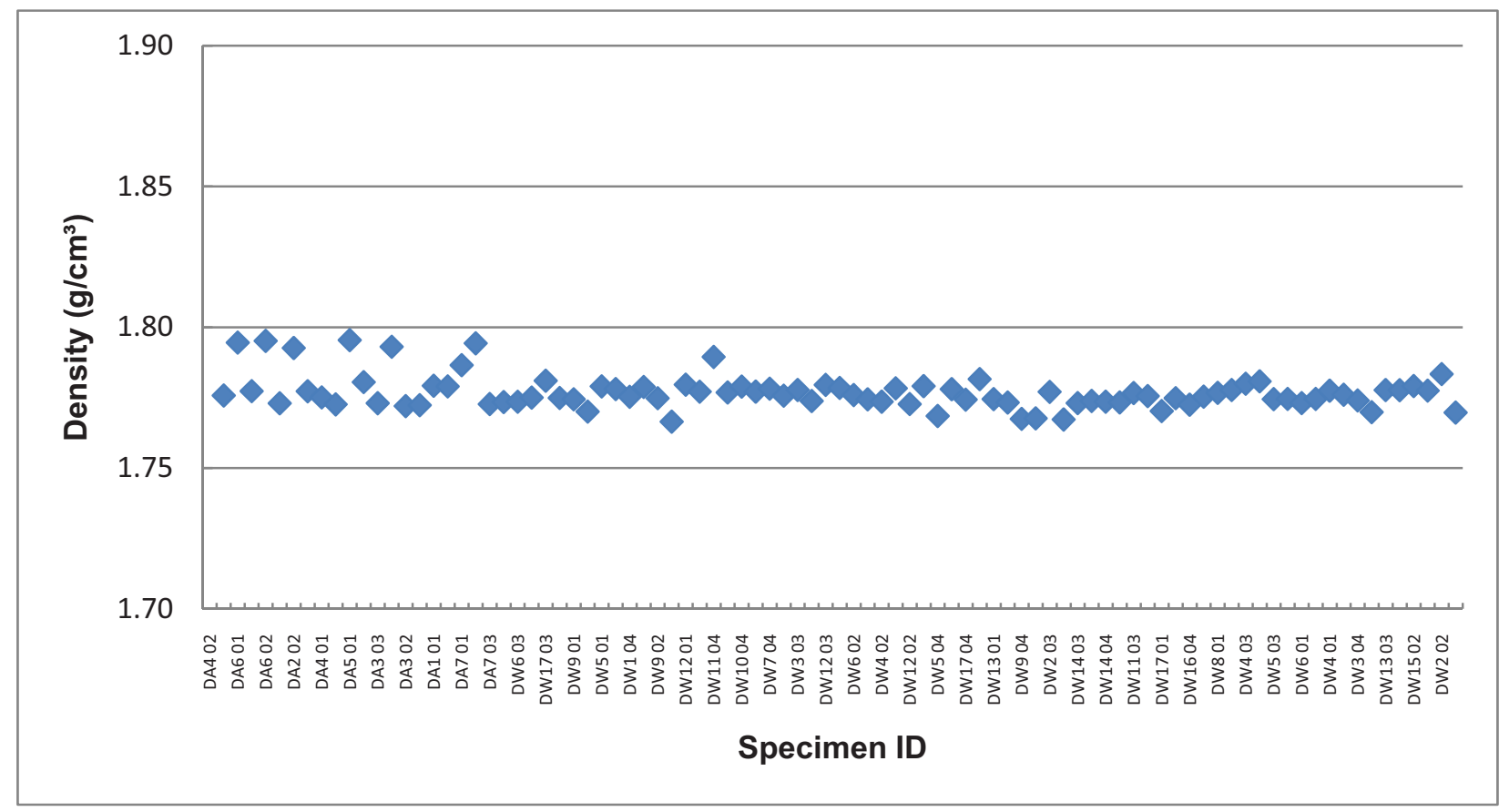

Figure A-31. Density for PCEA.

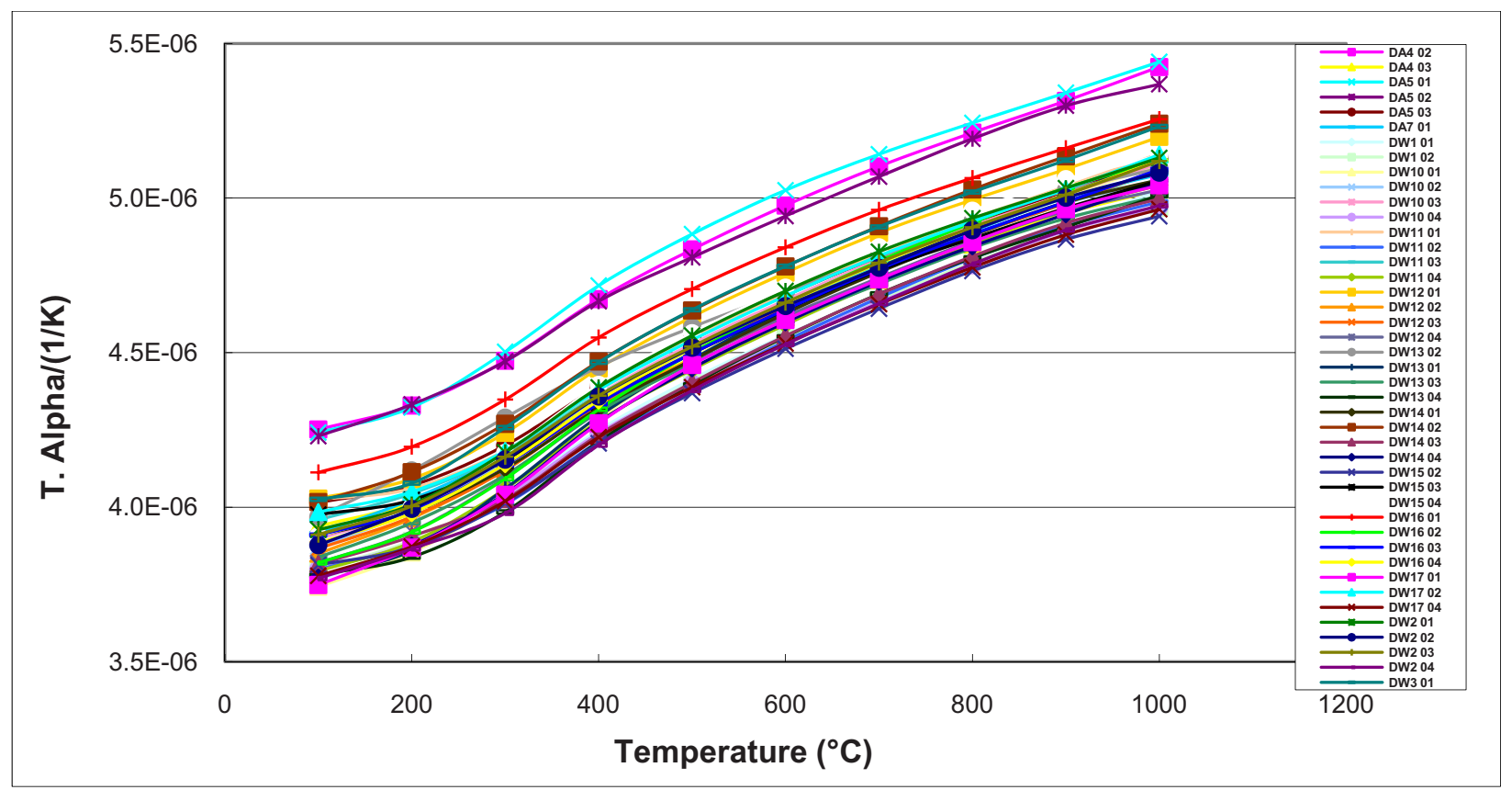

Figure A-32. Coefficient of thermal expansion for PCEA. 


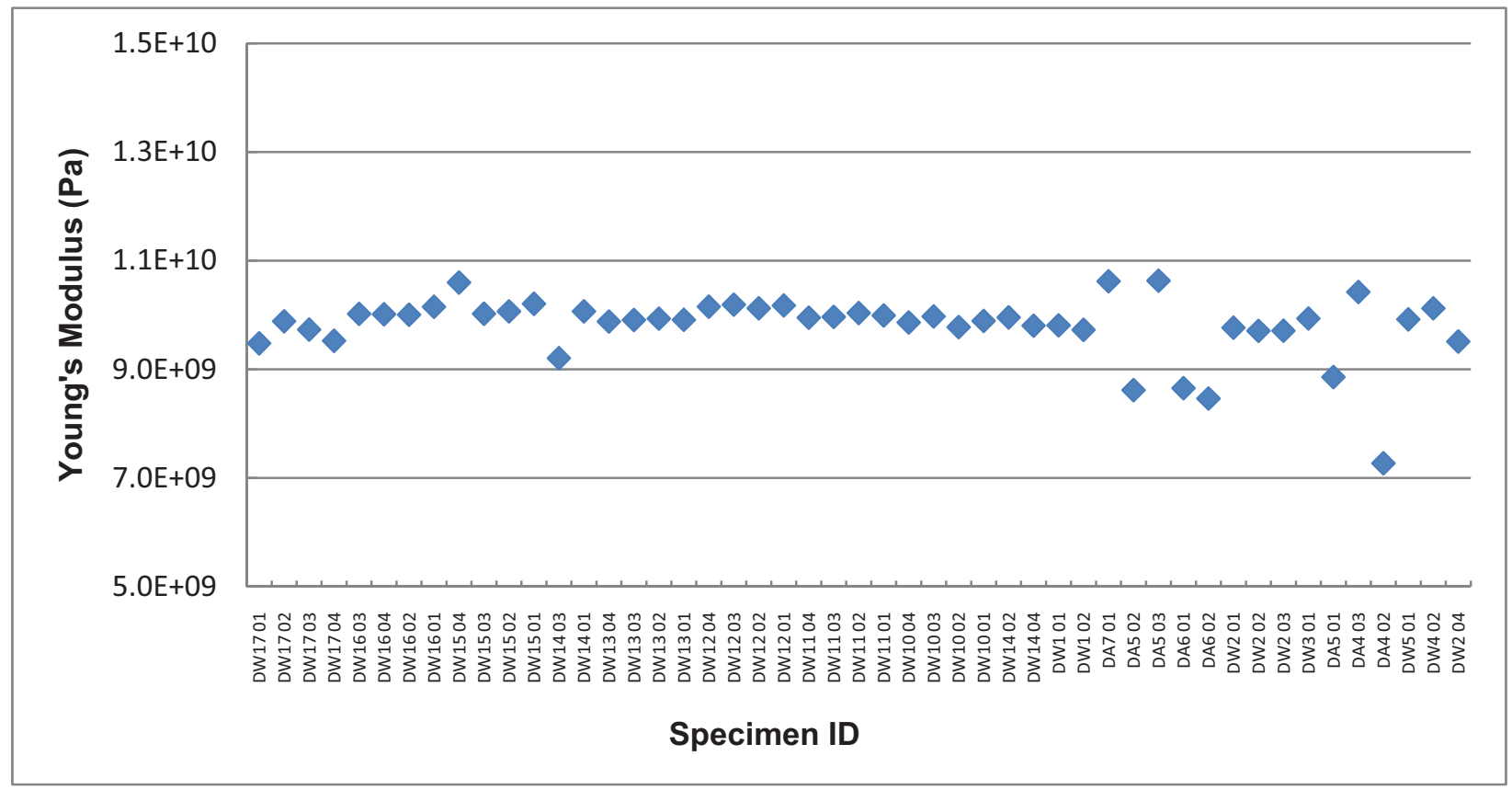

Figure A-33. Young's Modulus by sonic resonance for PCEA.

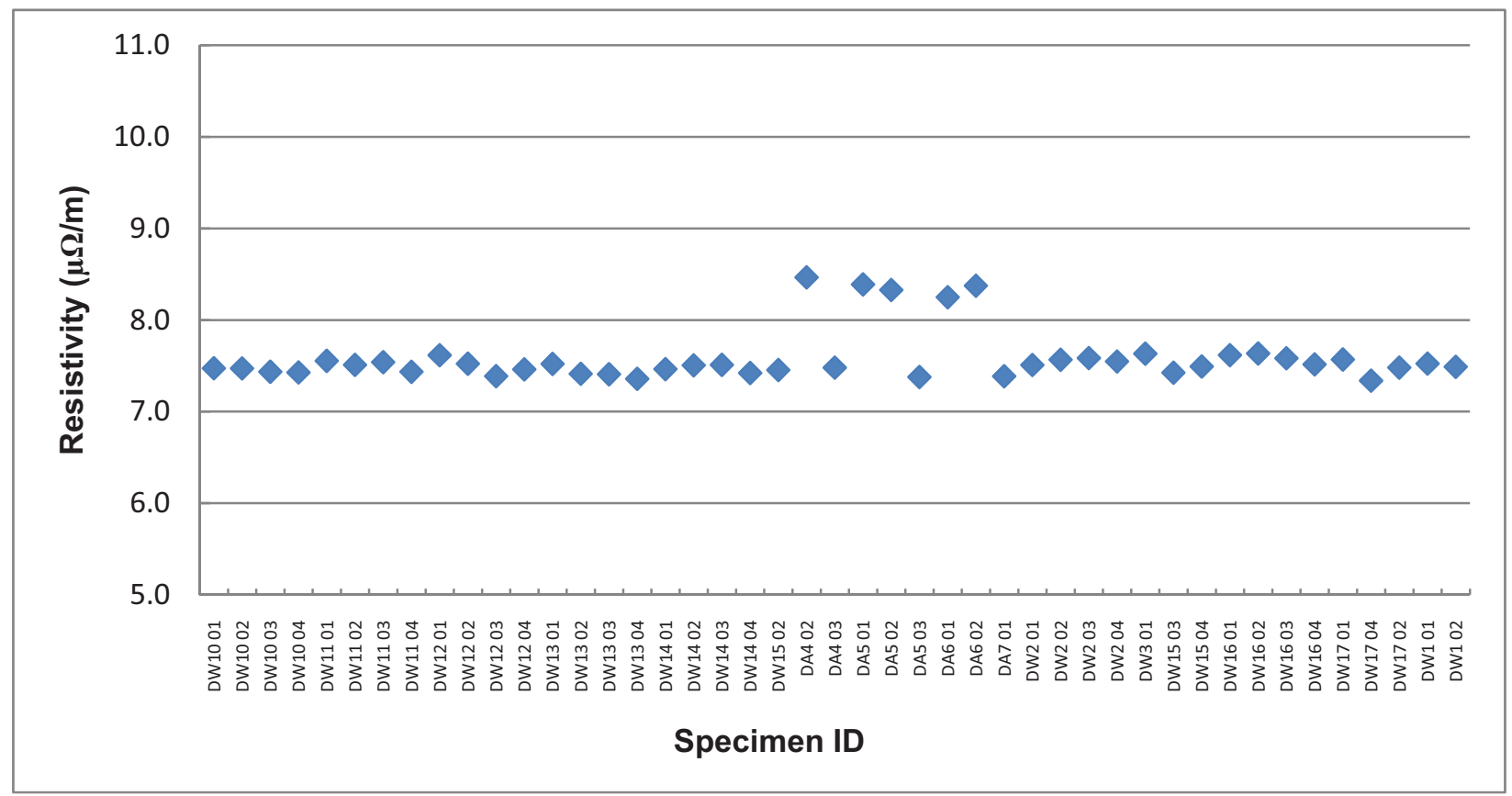

Figure A-34. Resistivity for PCEA. 


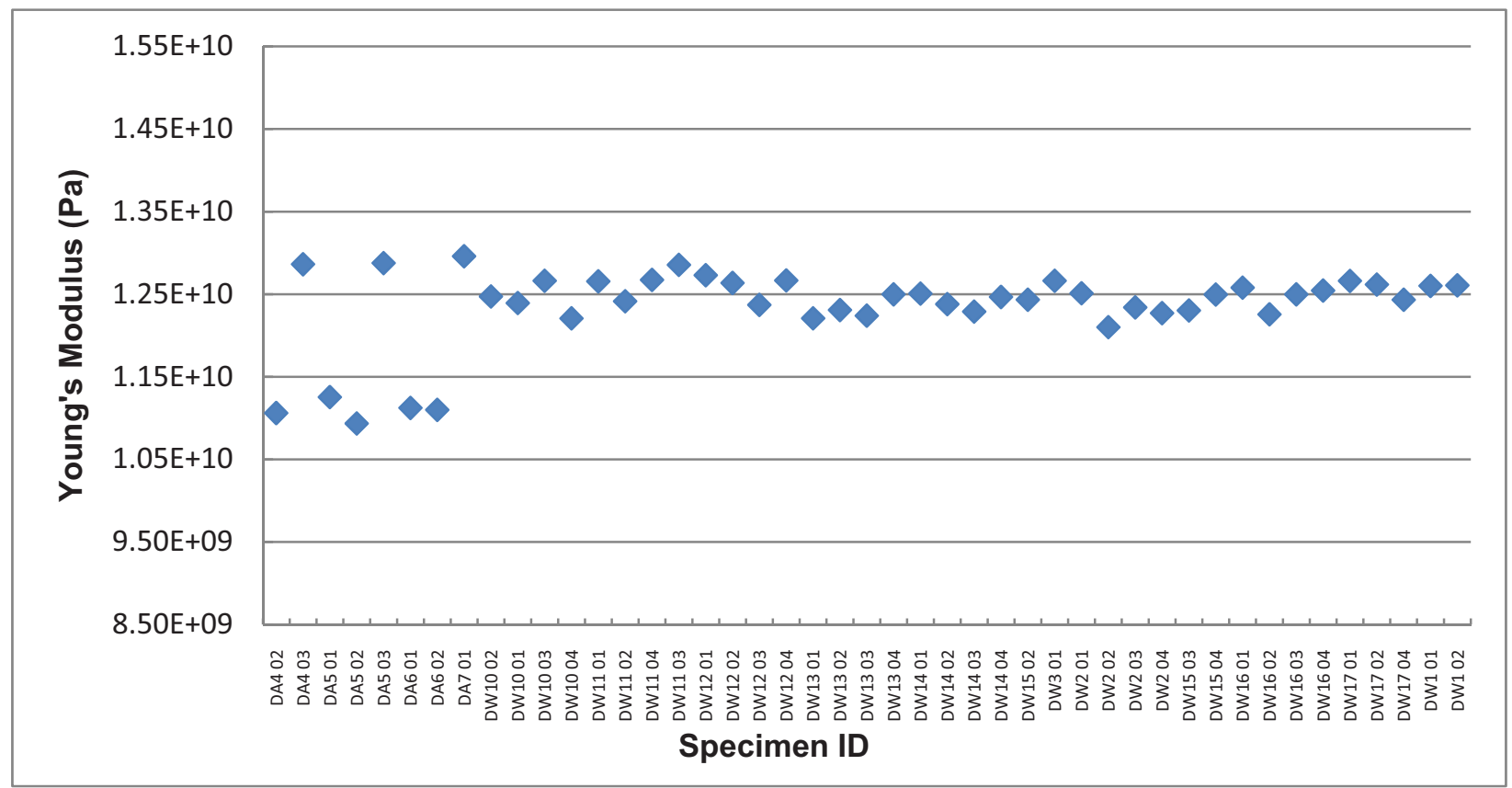

Figure A-35. Young's Modulus by sonic velocity for PCEA.

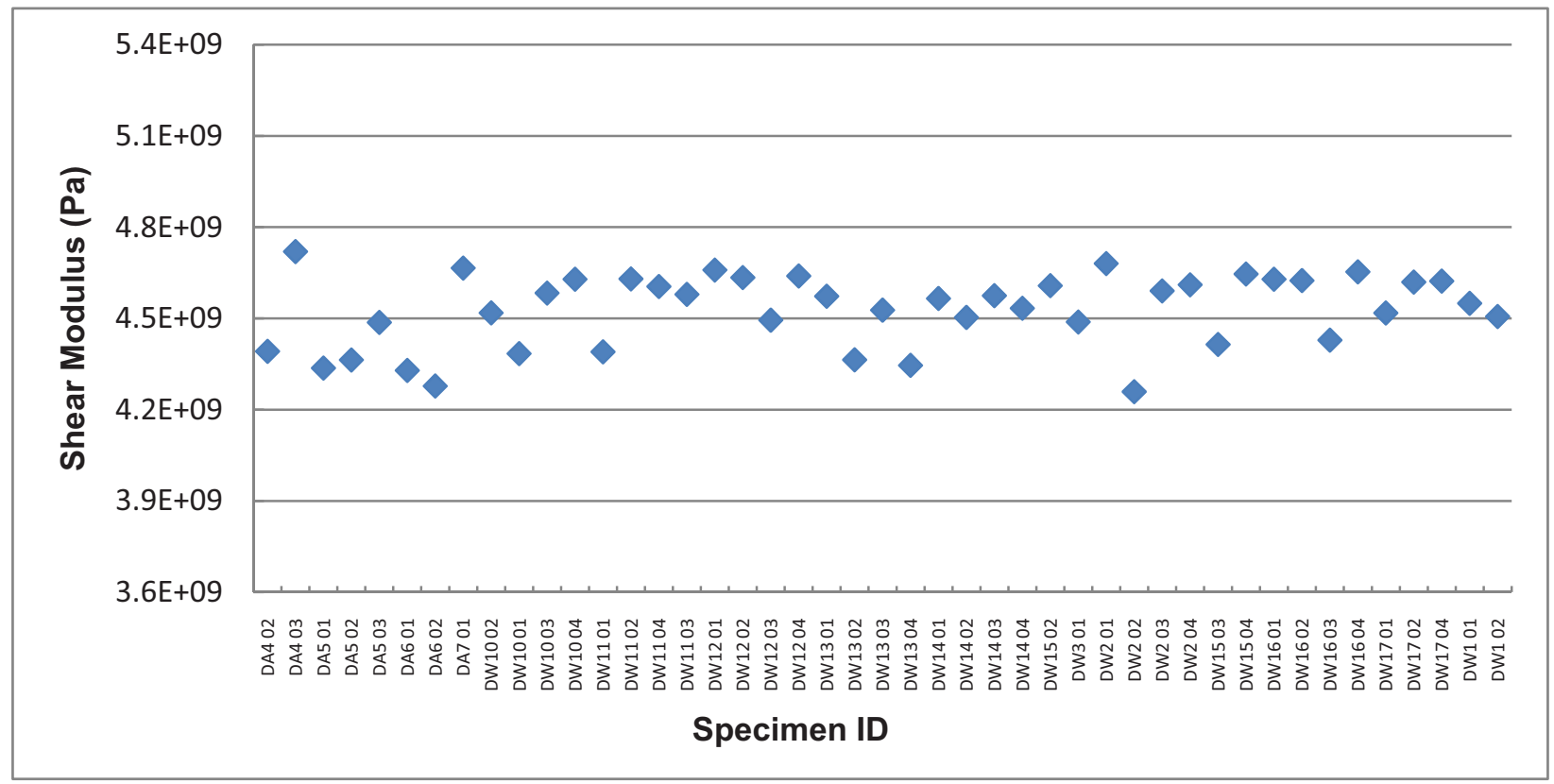

Figure A-36. Shear Modulus by sonic velocity for PCEA. 


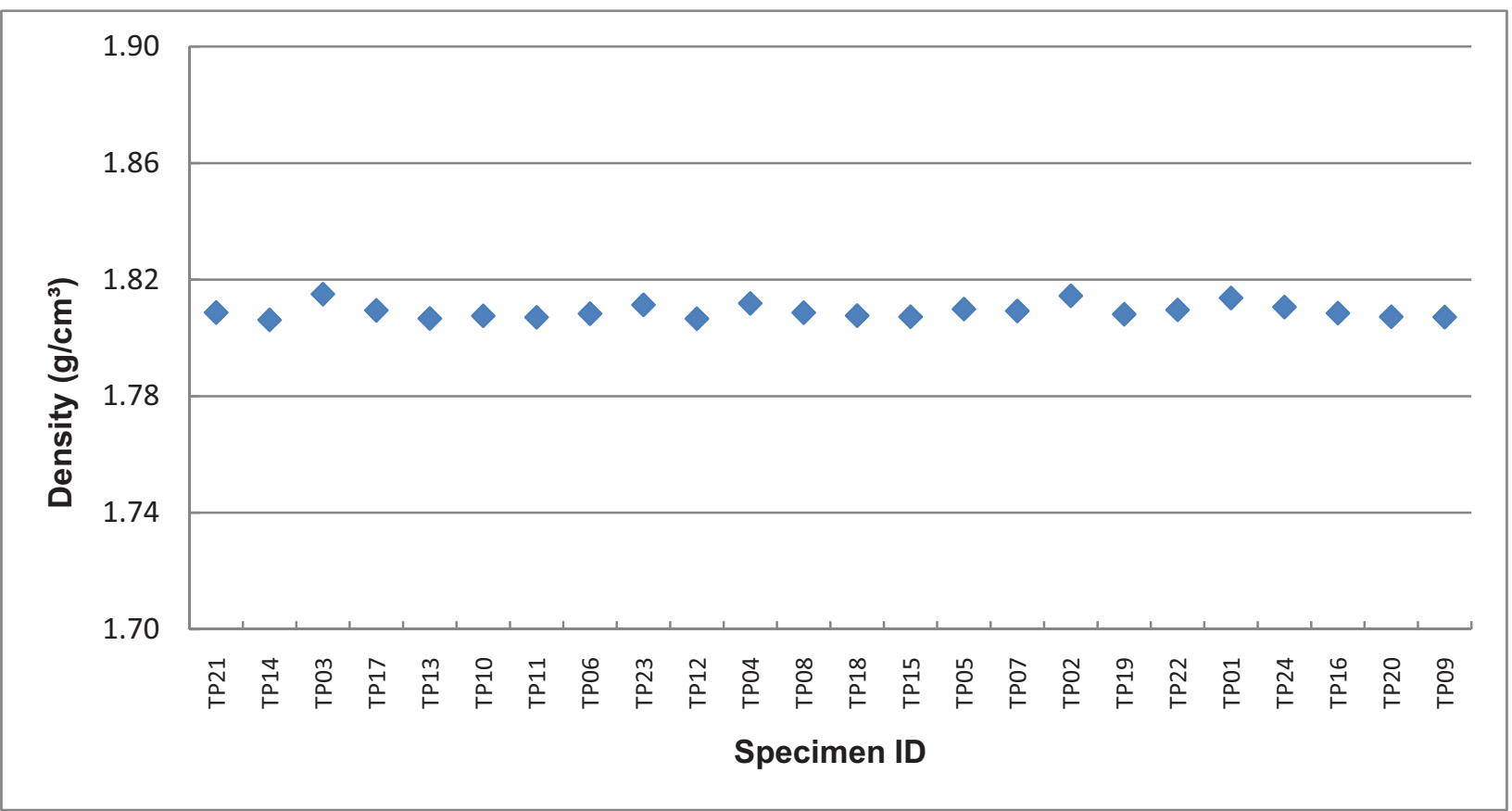

Figure A-37. Density for 2114.

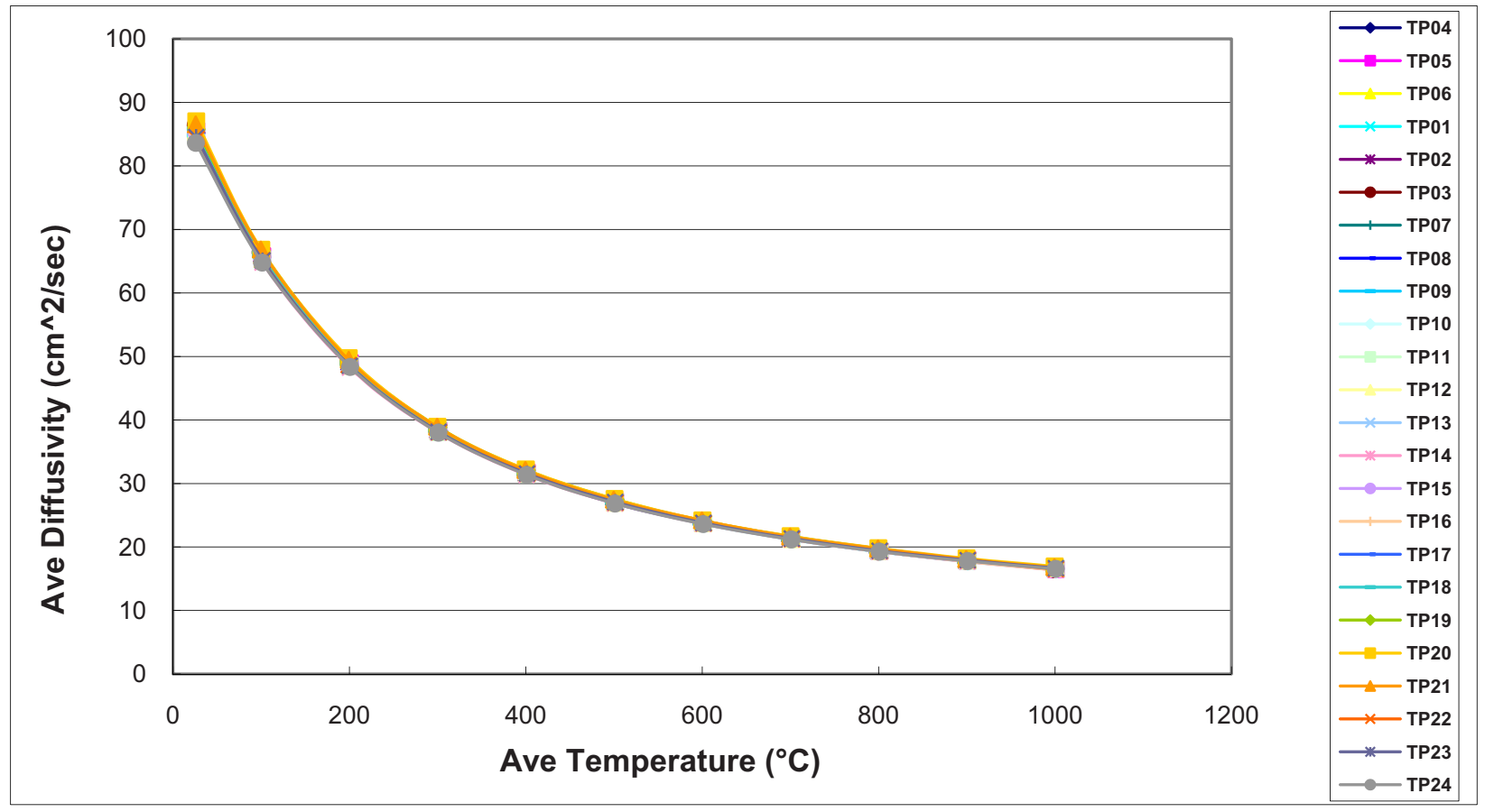

Figure A-38. Thermal diffusivity for 2114. 


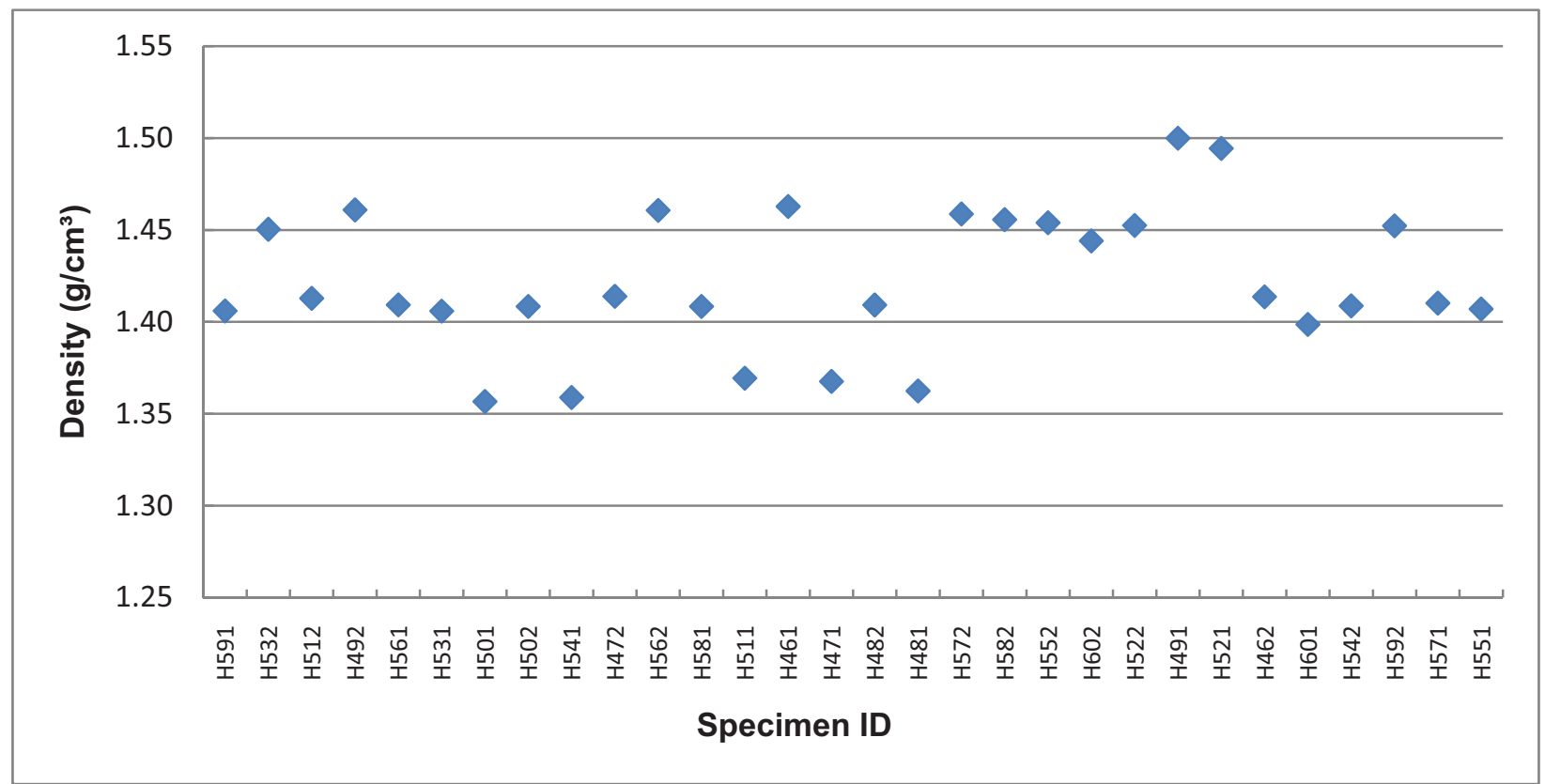

Figure A-39. Density for A3 Matrix.

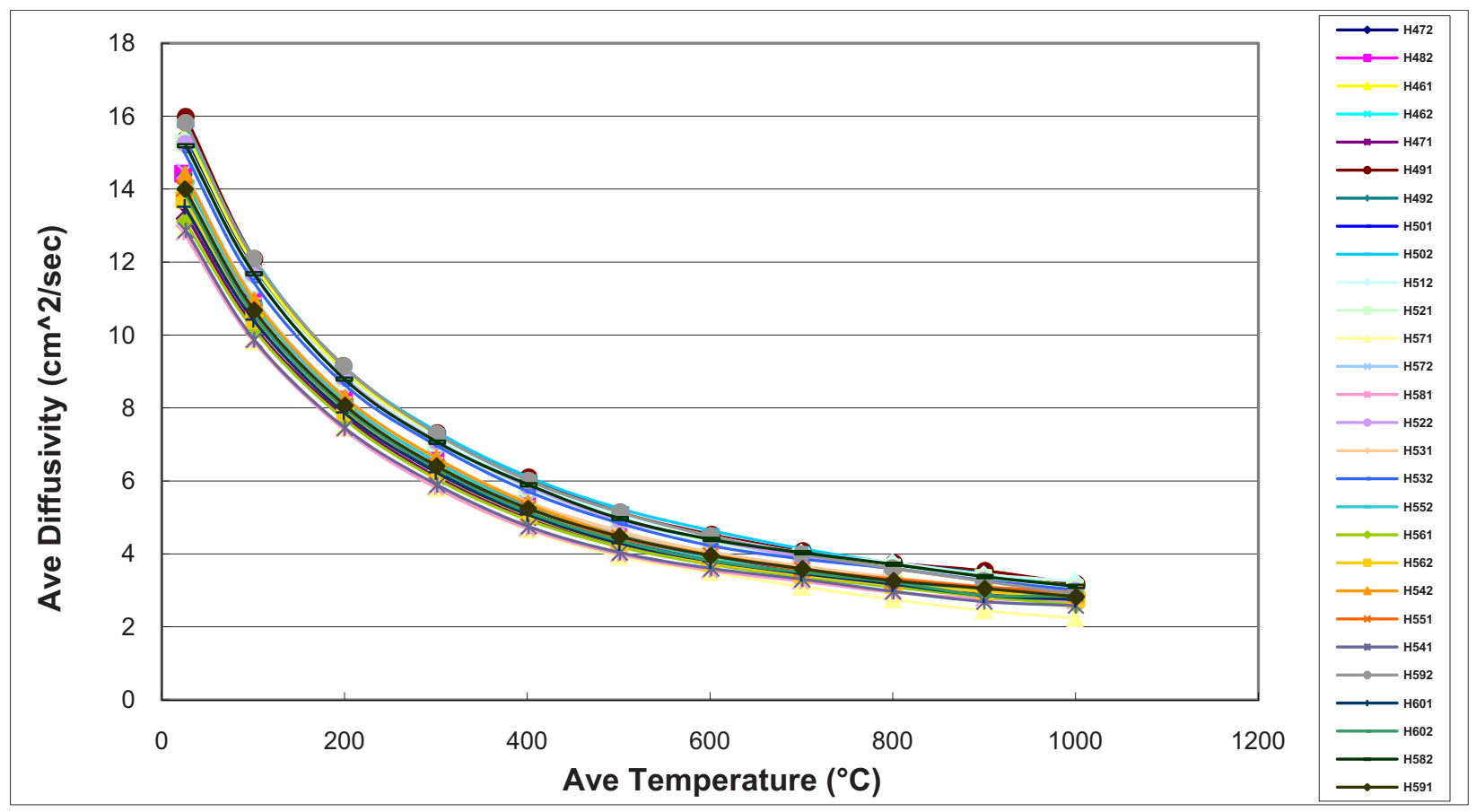

Figure A-40. Thermal diffusivity for A3 Matrix. 


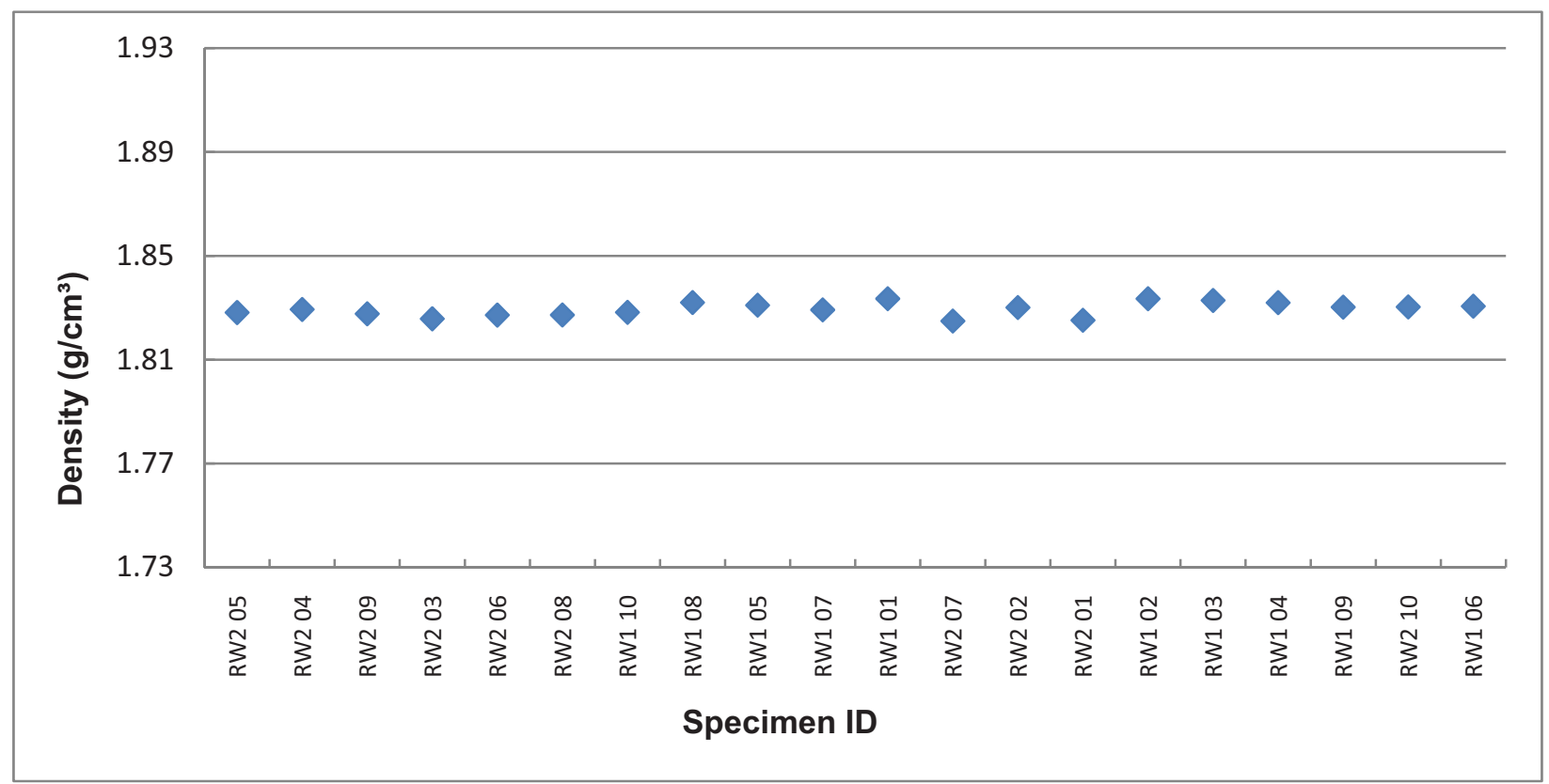

Figure A-41. Density for BAN.

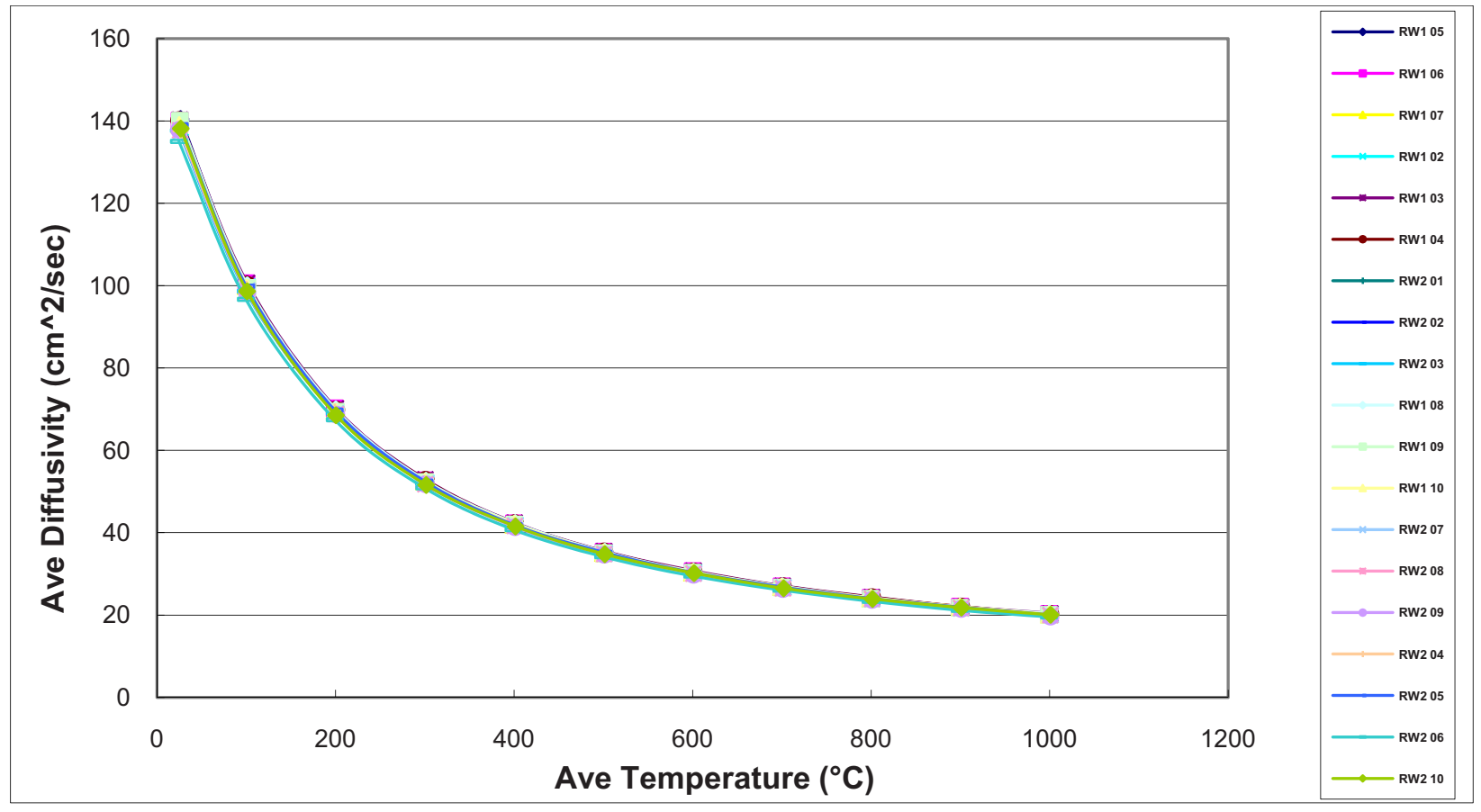

Figure A-42. Thermal diffusivity for BAN. 


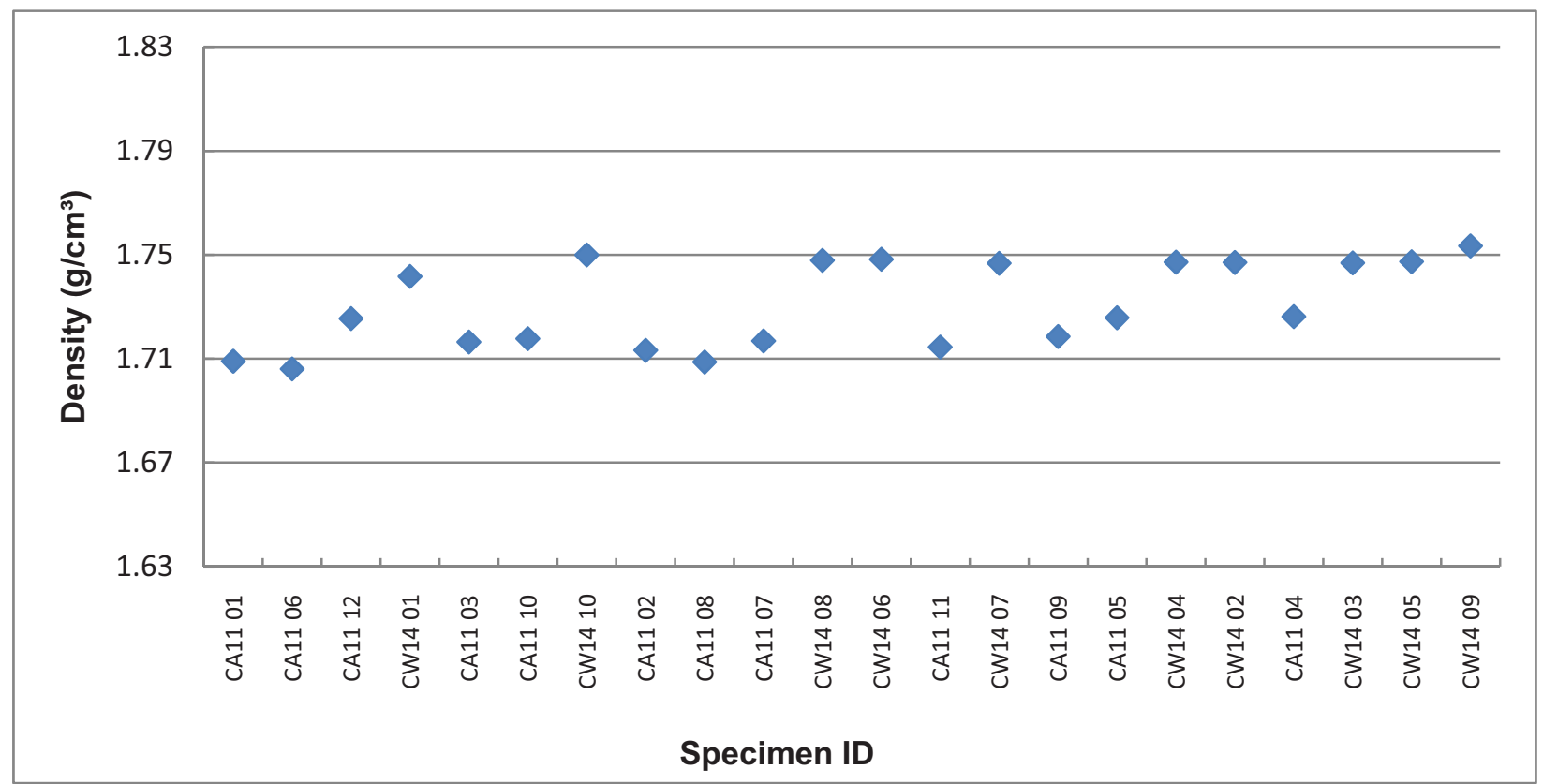

Figure A-43. Density for H-451.

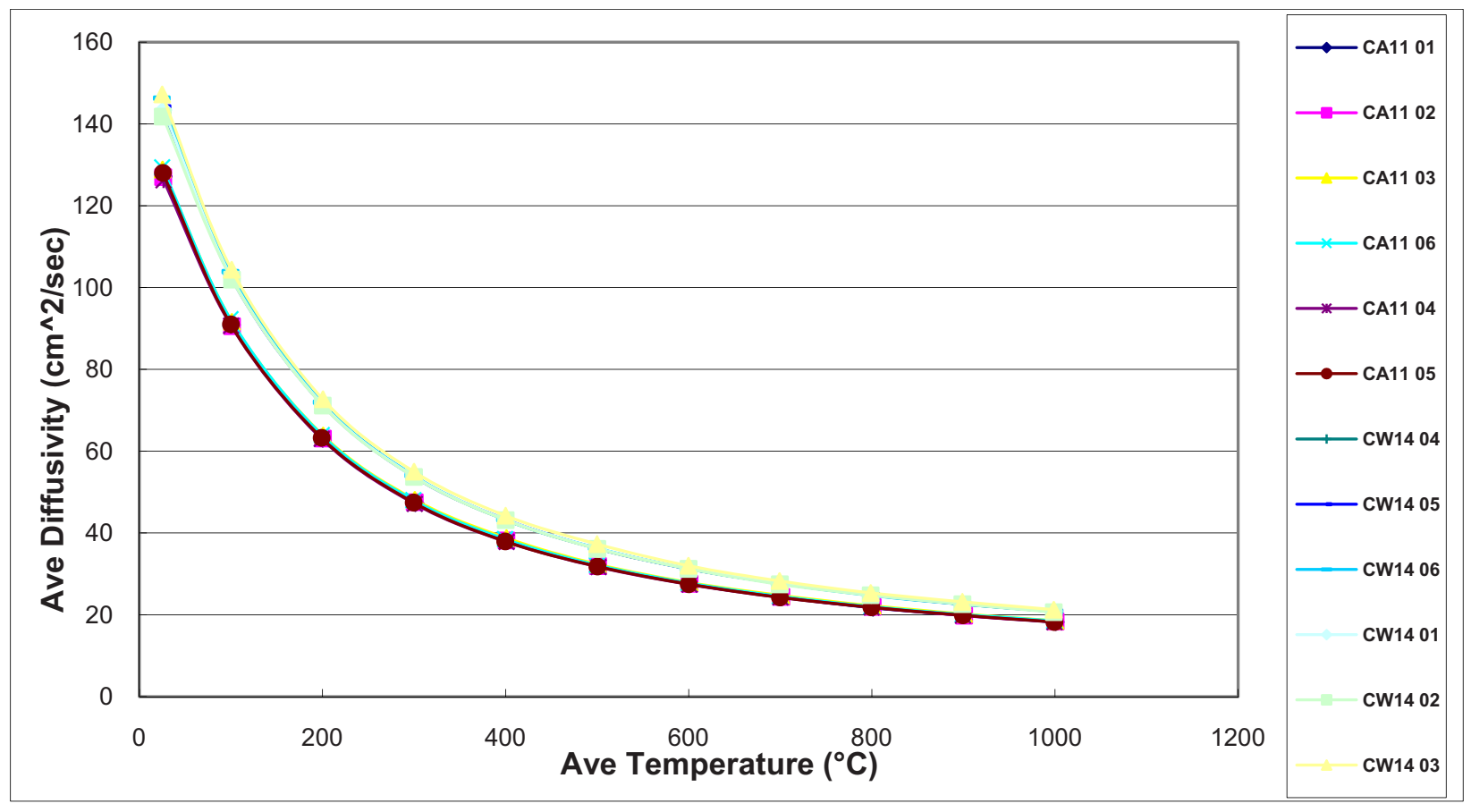

Figure A-44. Thermal diffusivity for H-451. 


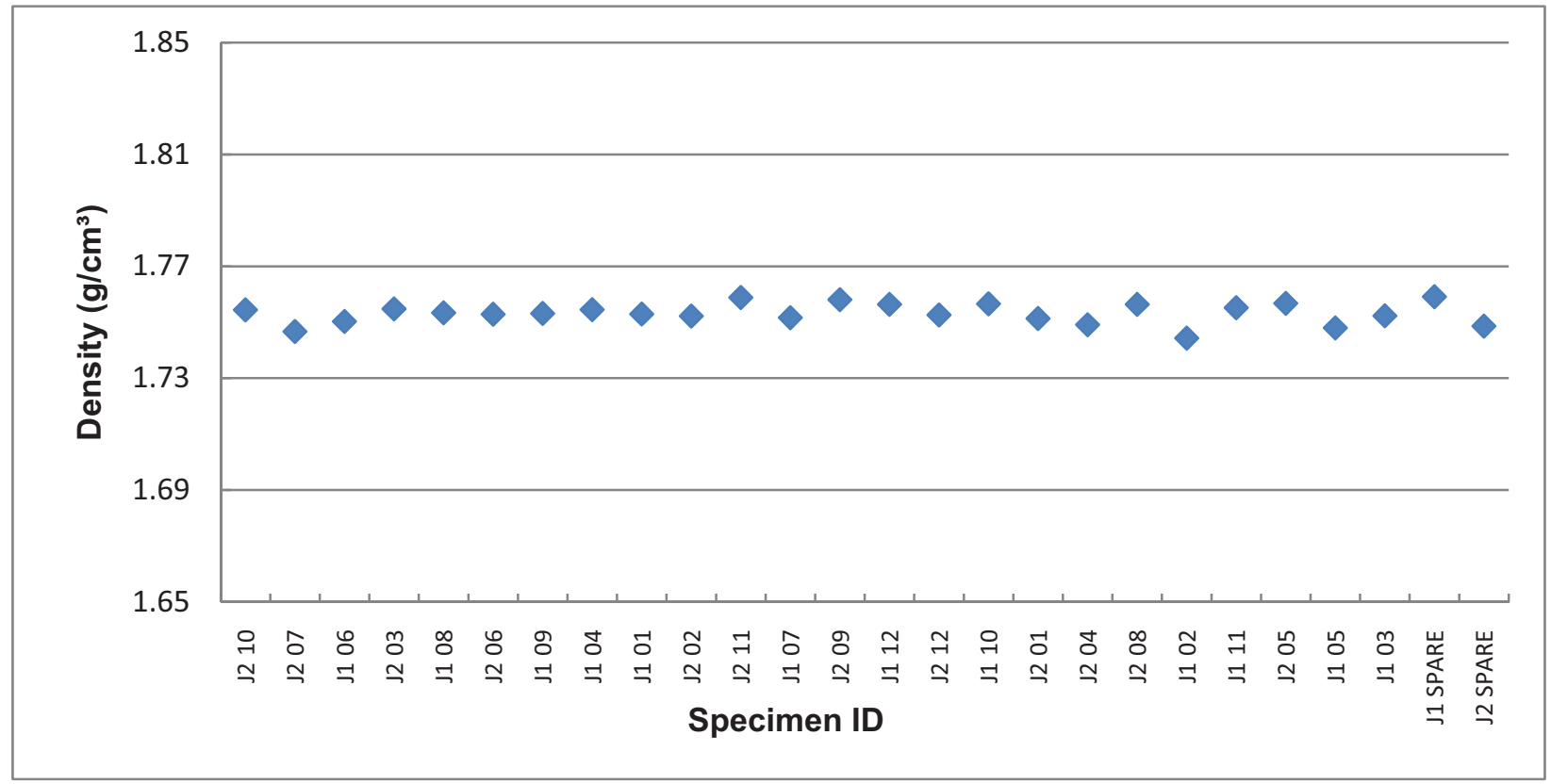

Figure A-45. Density for HLM.

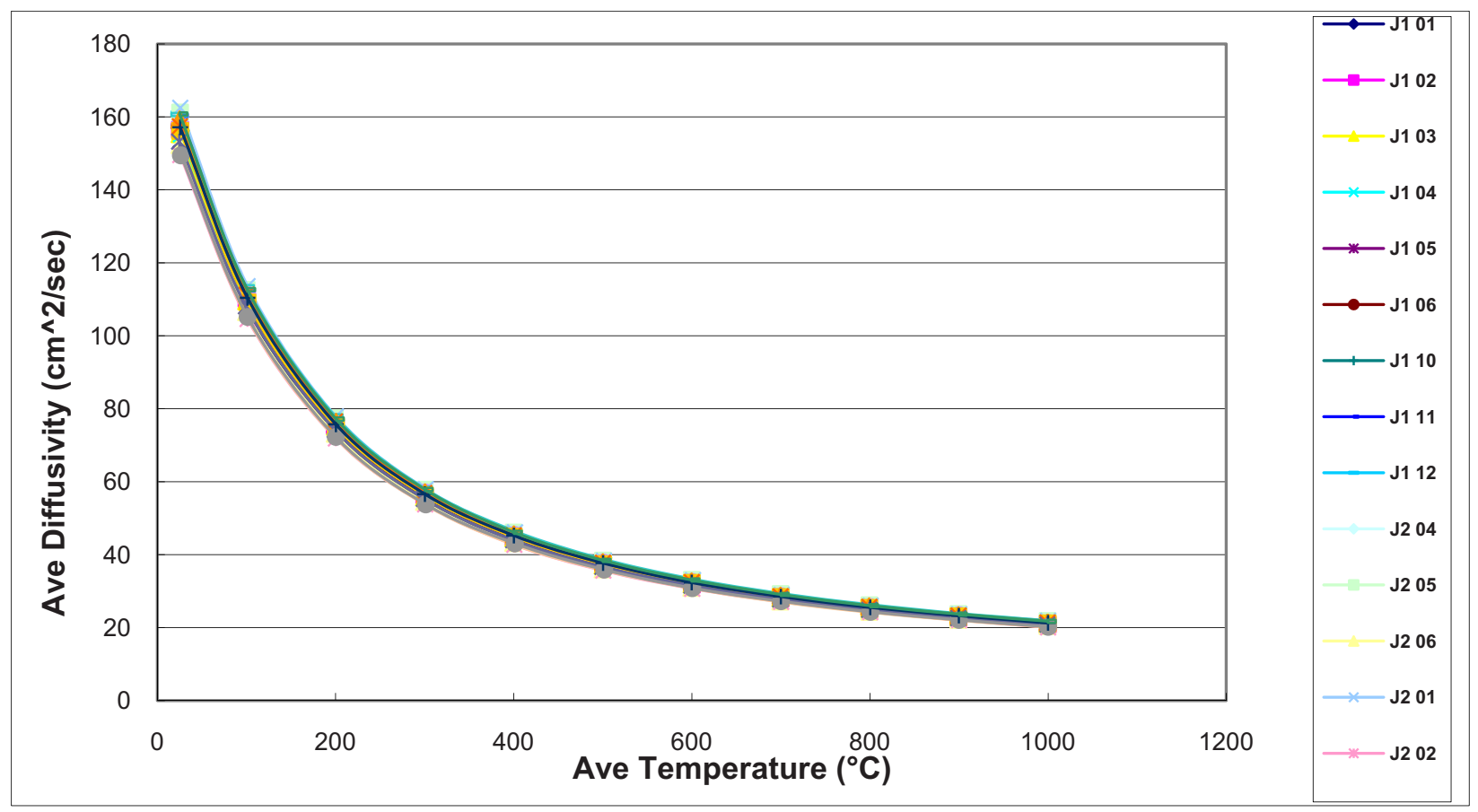

Figure A-46. Thermal diffusivity for HLM. 


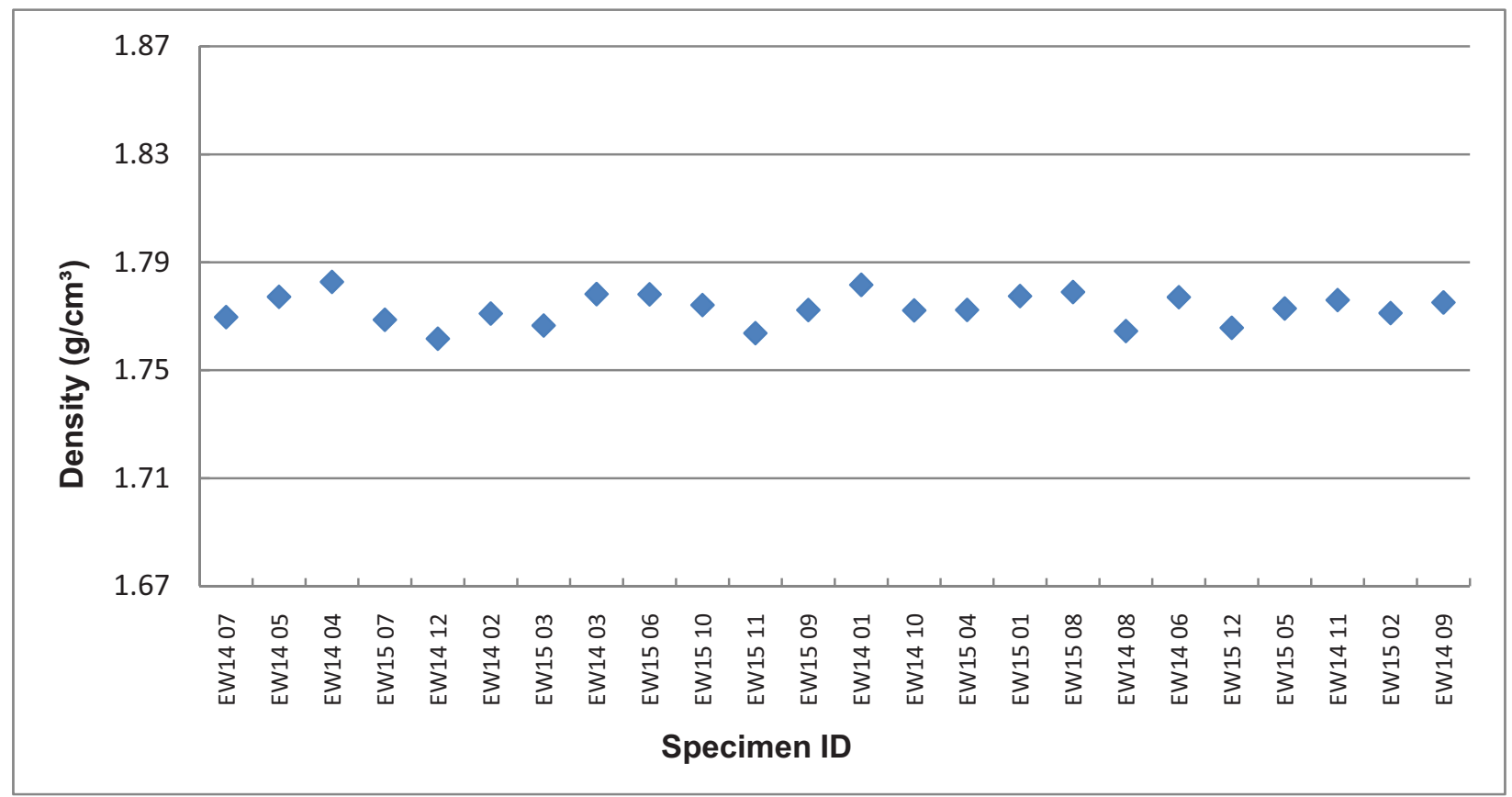

Figure A-47. Density for IG-110.

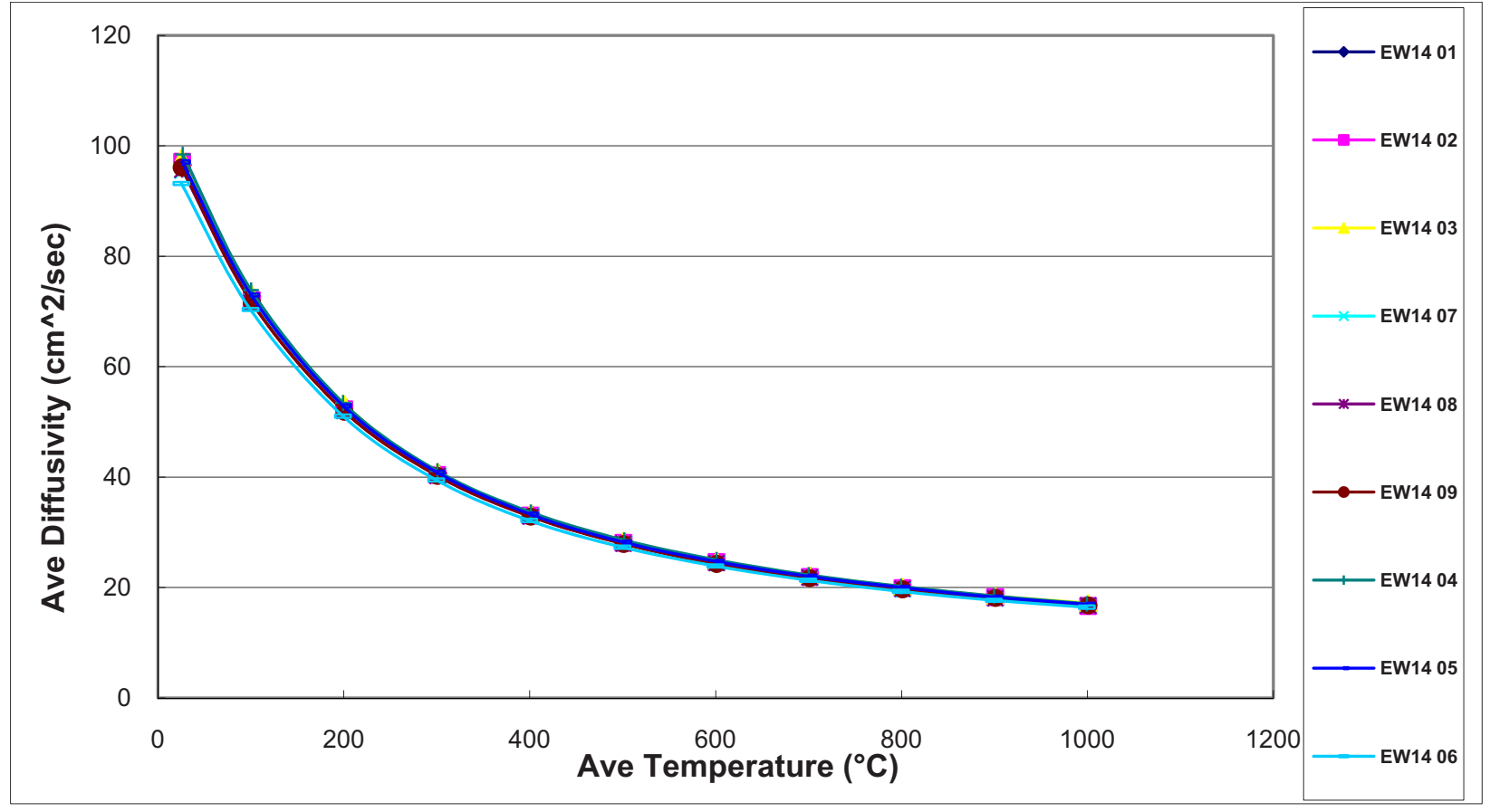

Figure A-48. Thermal diffusivity for IG-110. 


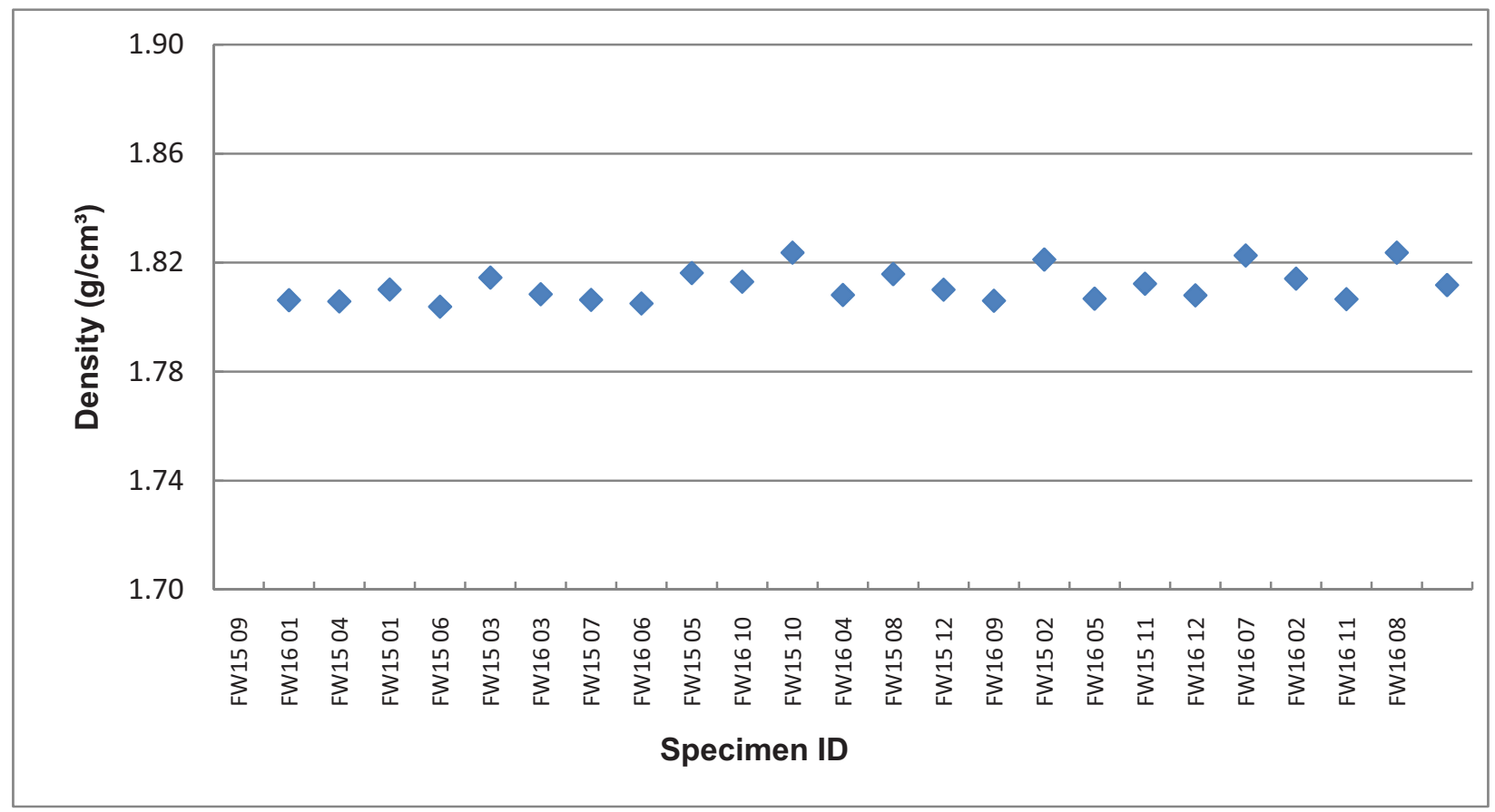

Figure A-49. Density for IG-430.

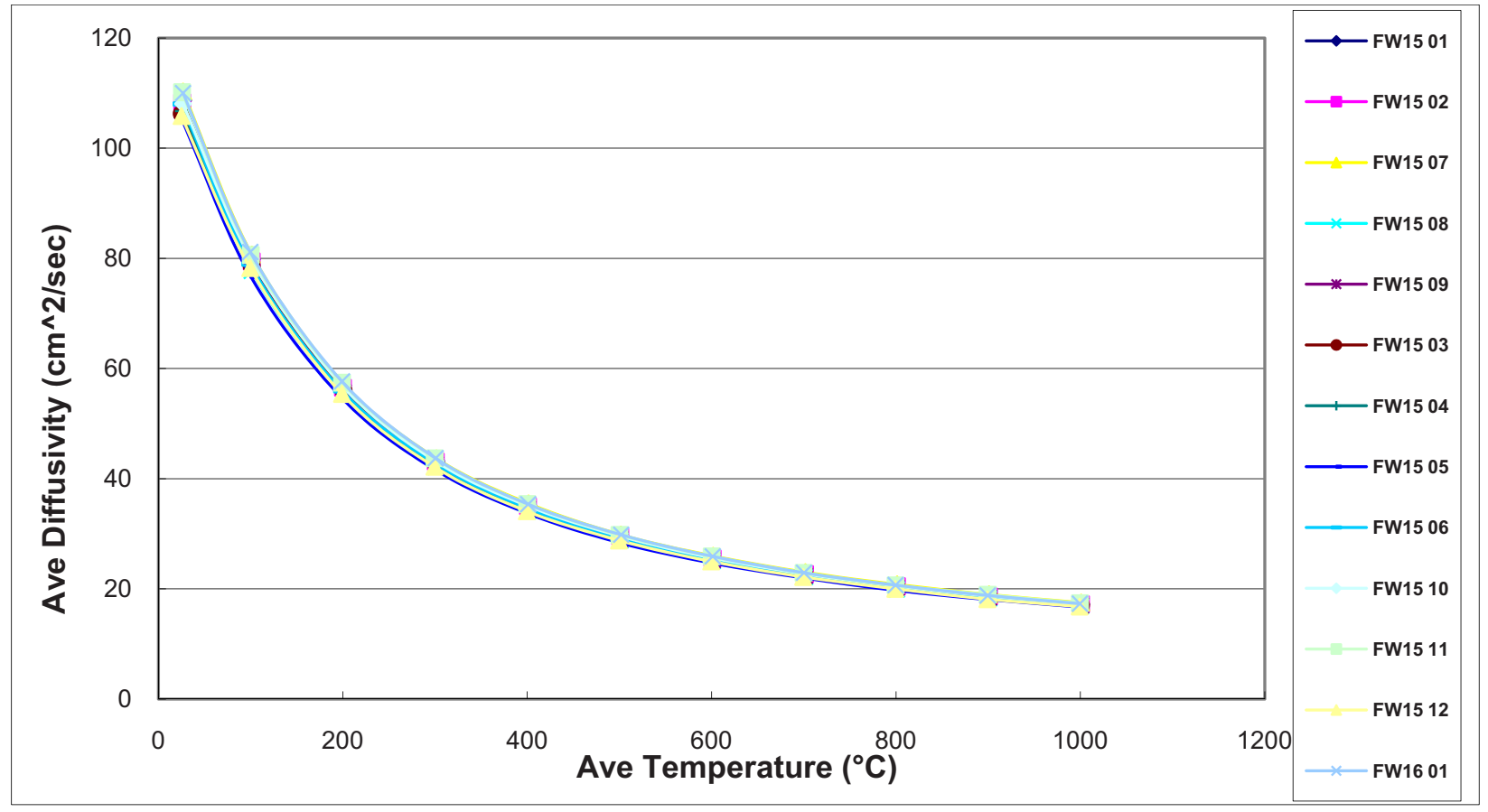

Figure A-50. Thermal diffusivity for IG-430. 


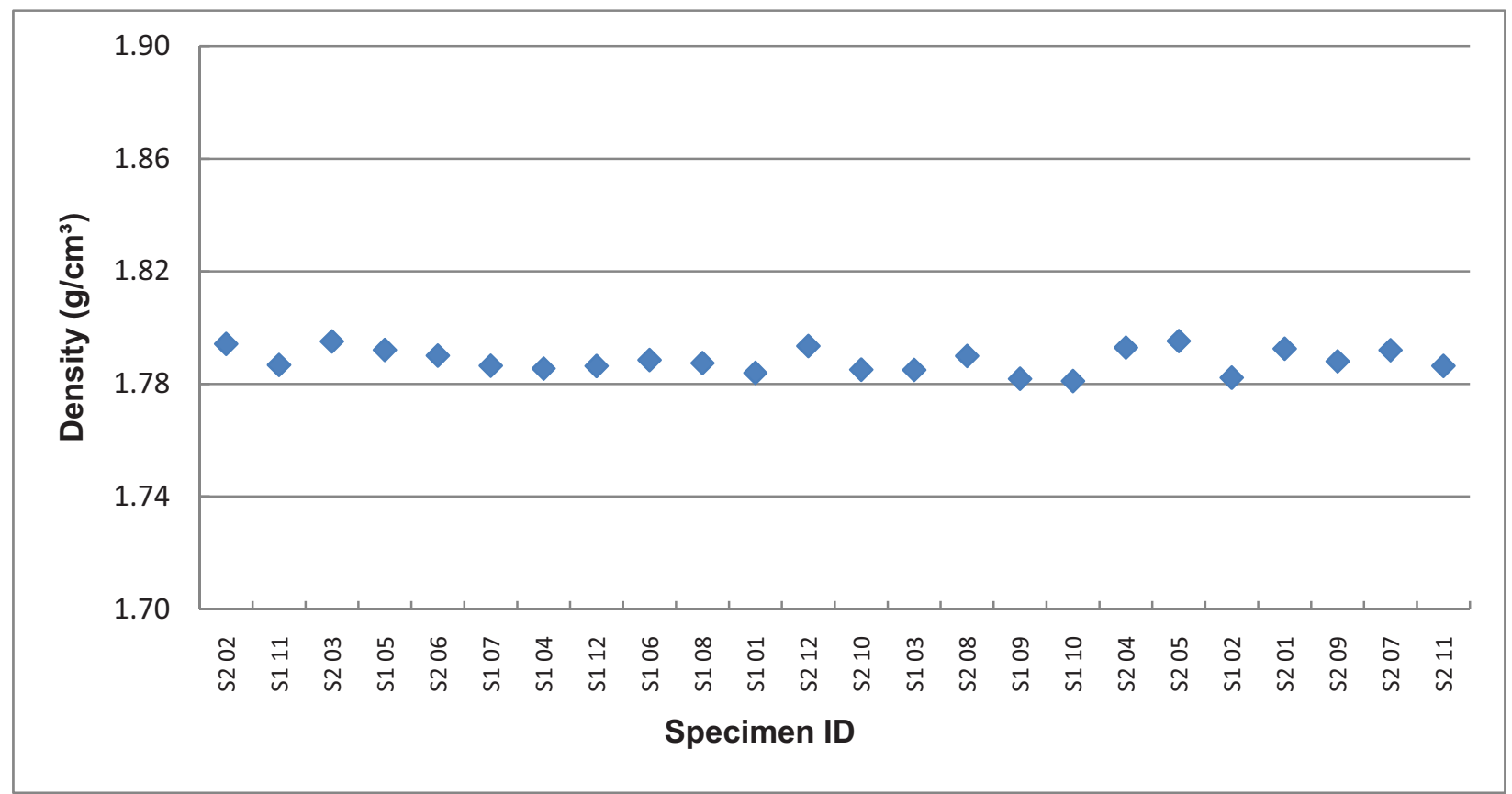

Figure A-51. Density for NBG-10.

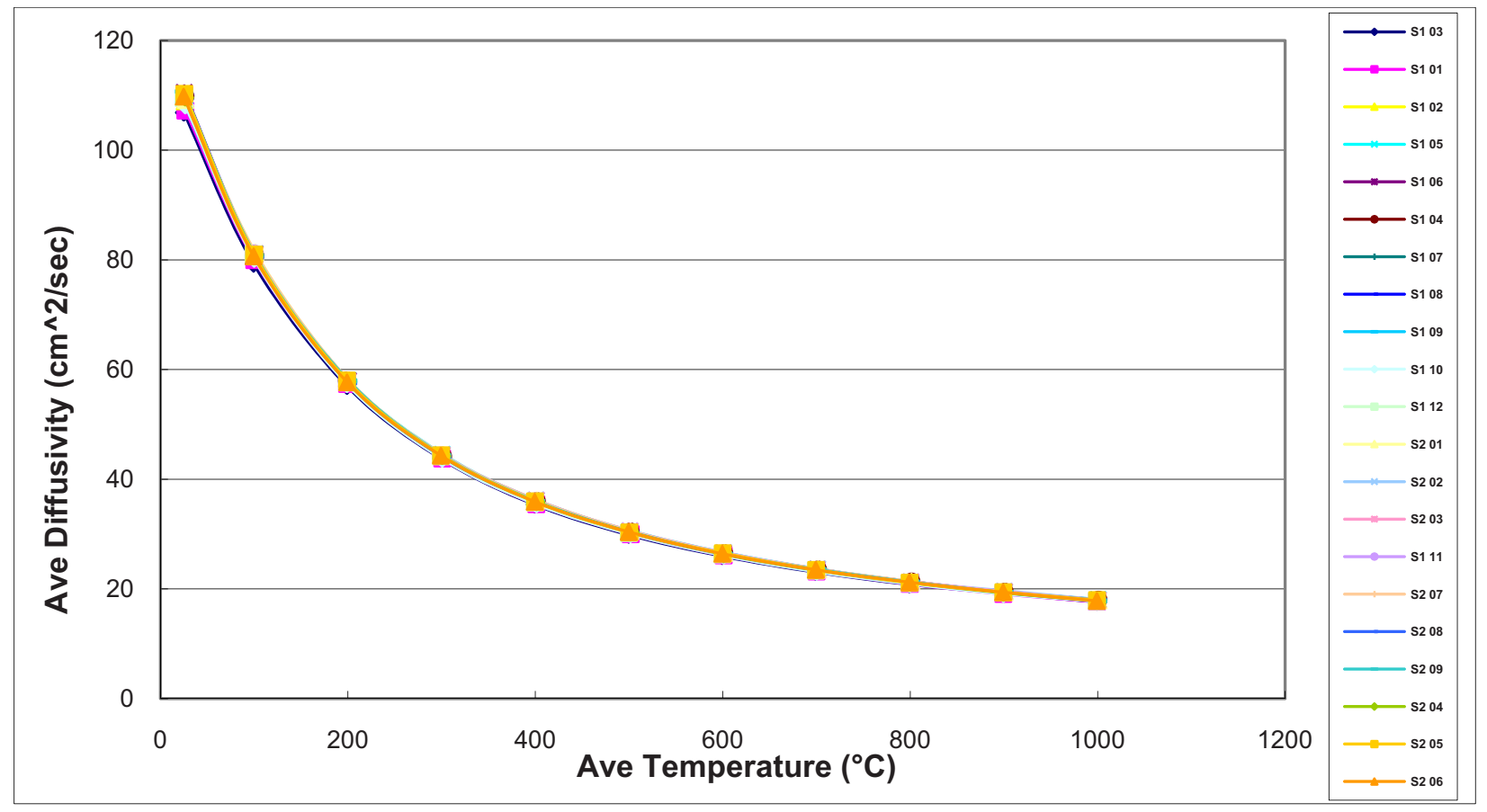

Figure A-52. Thermal diffusivity for NBG-10. 


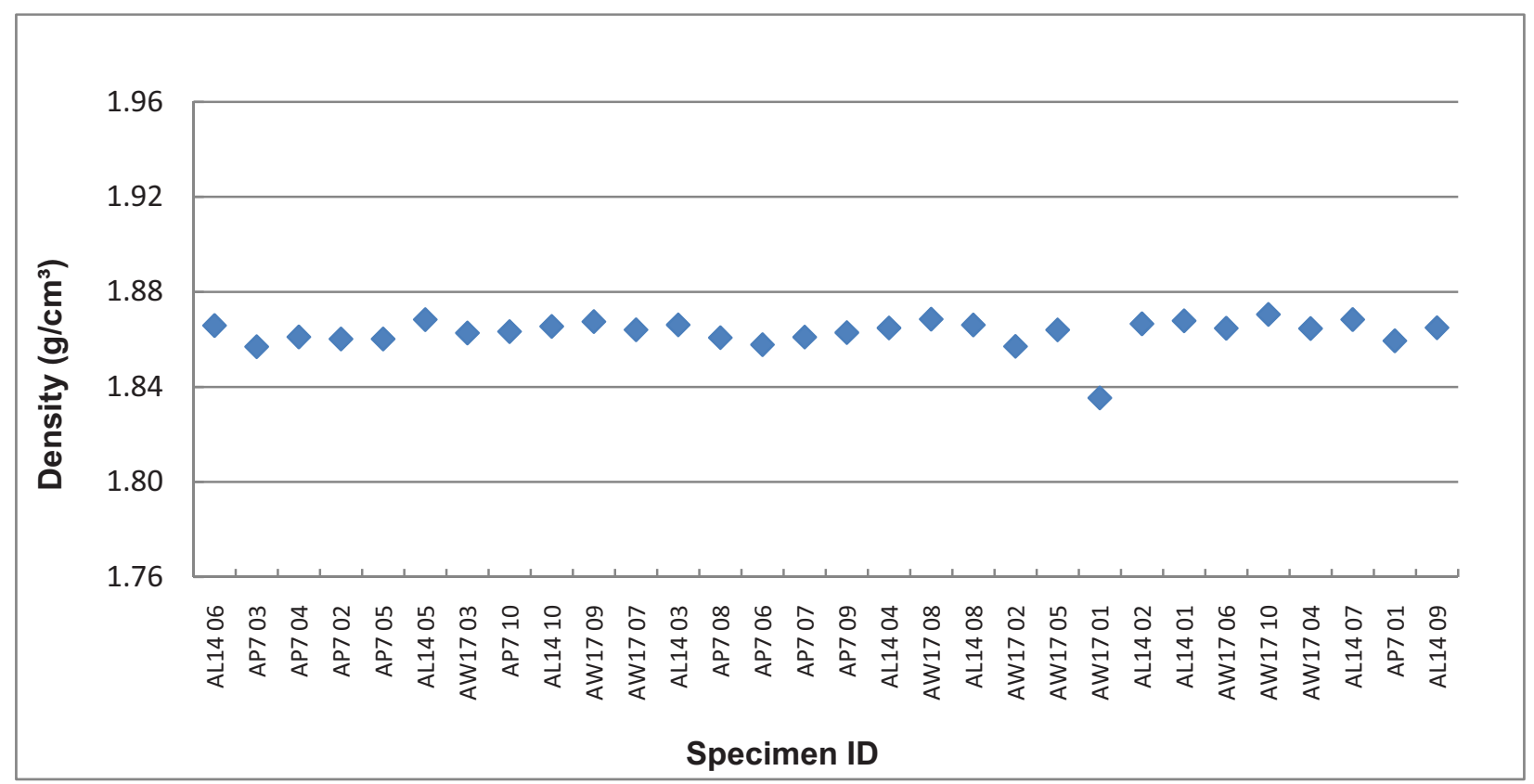

Figure A-53. Density for NBG-17.

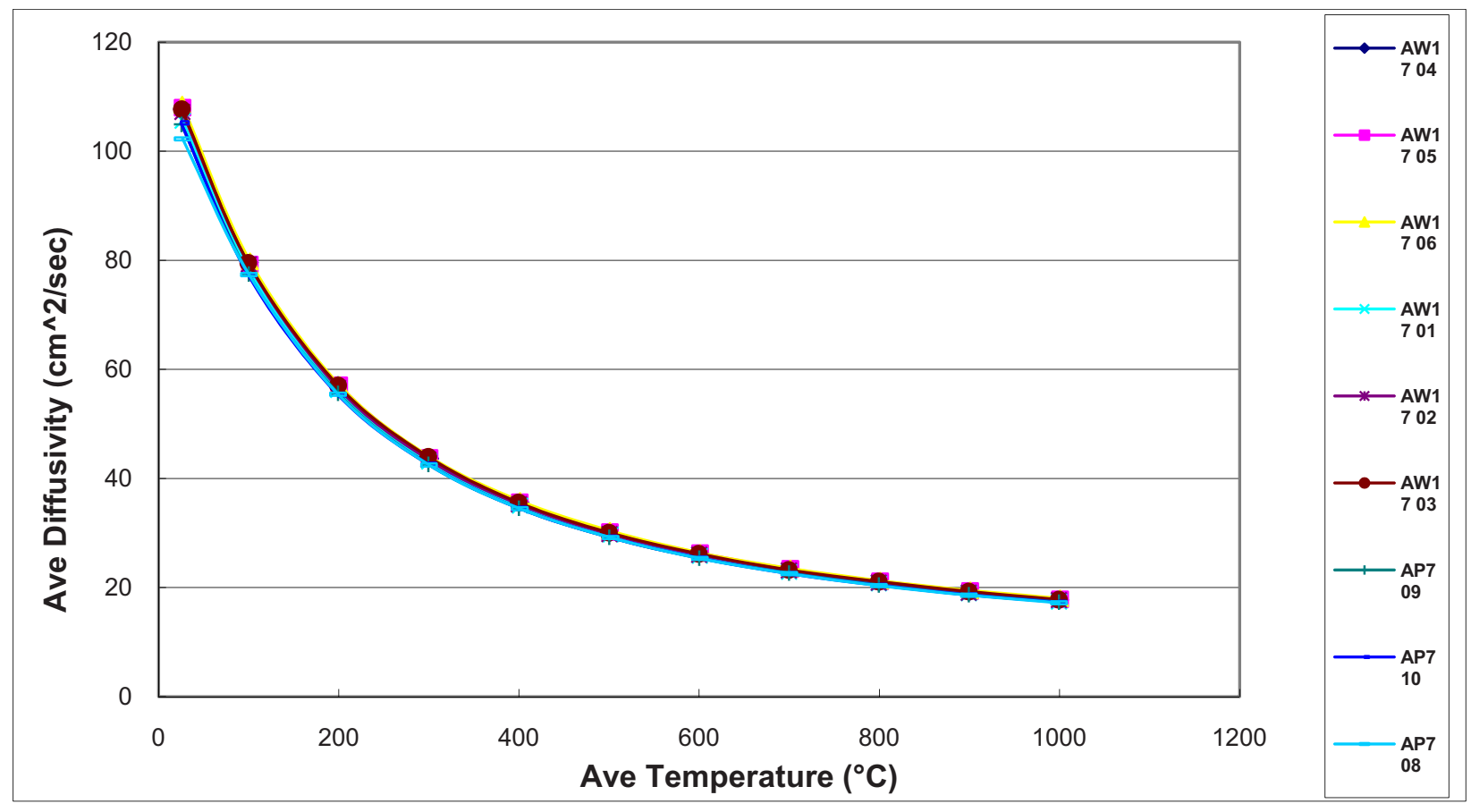

Figure A-54. Thermal diffusivity for NBG-17. 


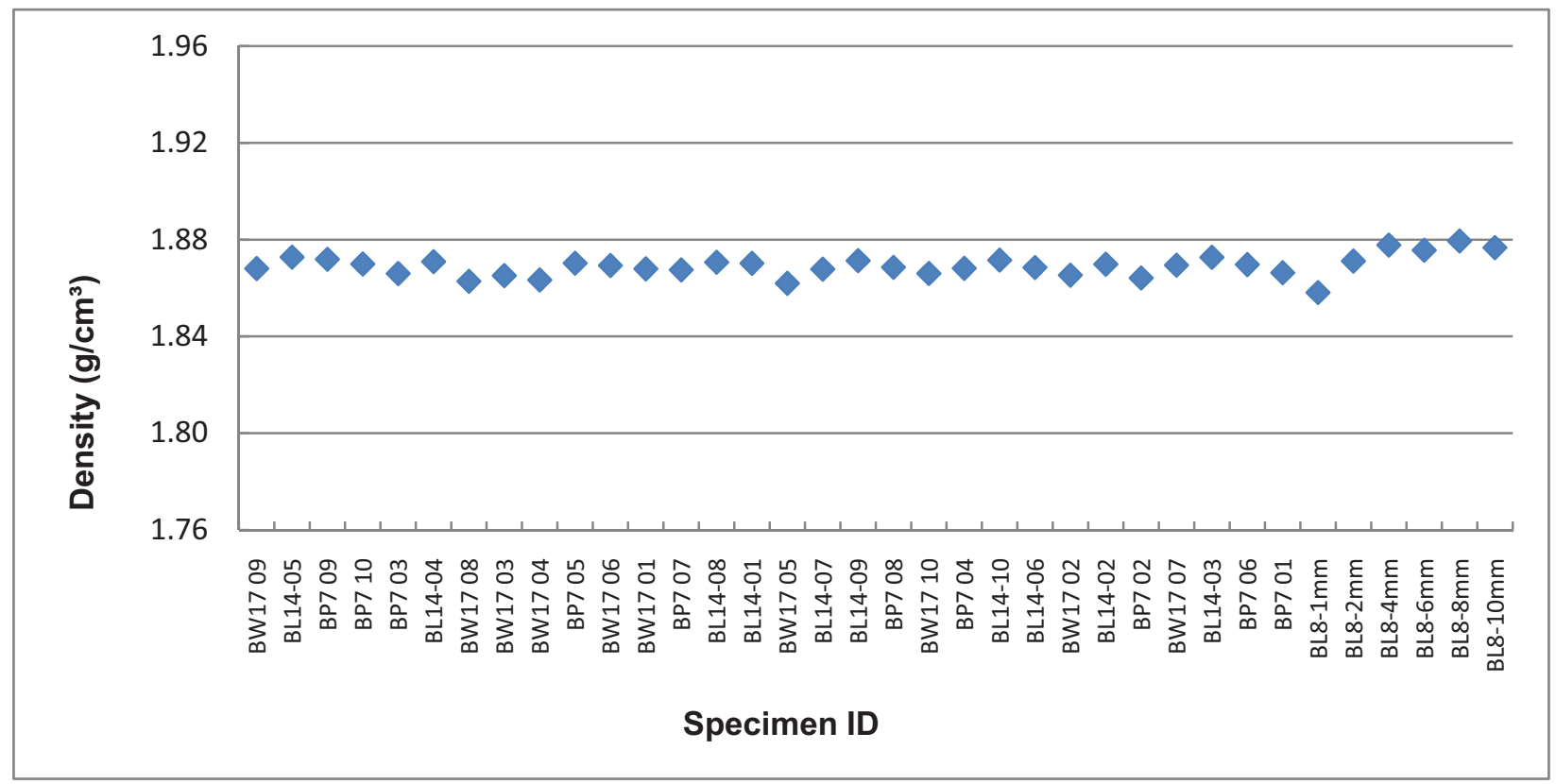

Figure A-55. Density for NBG-18.

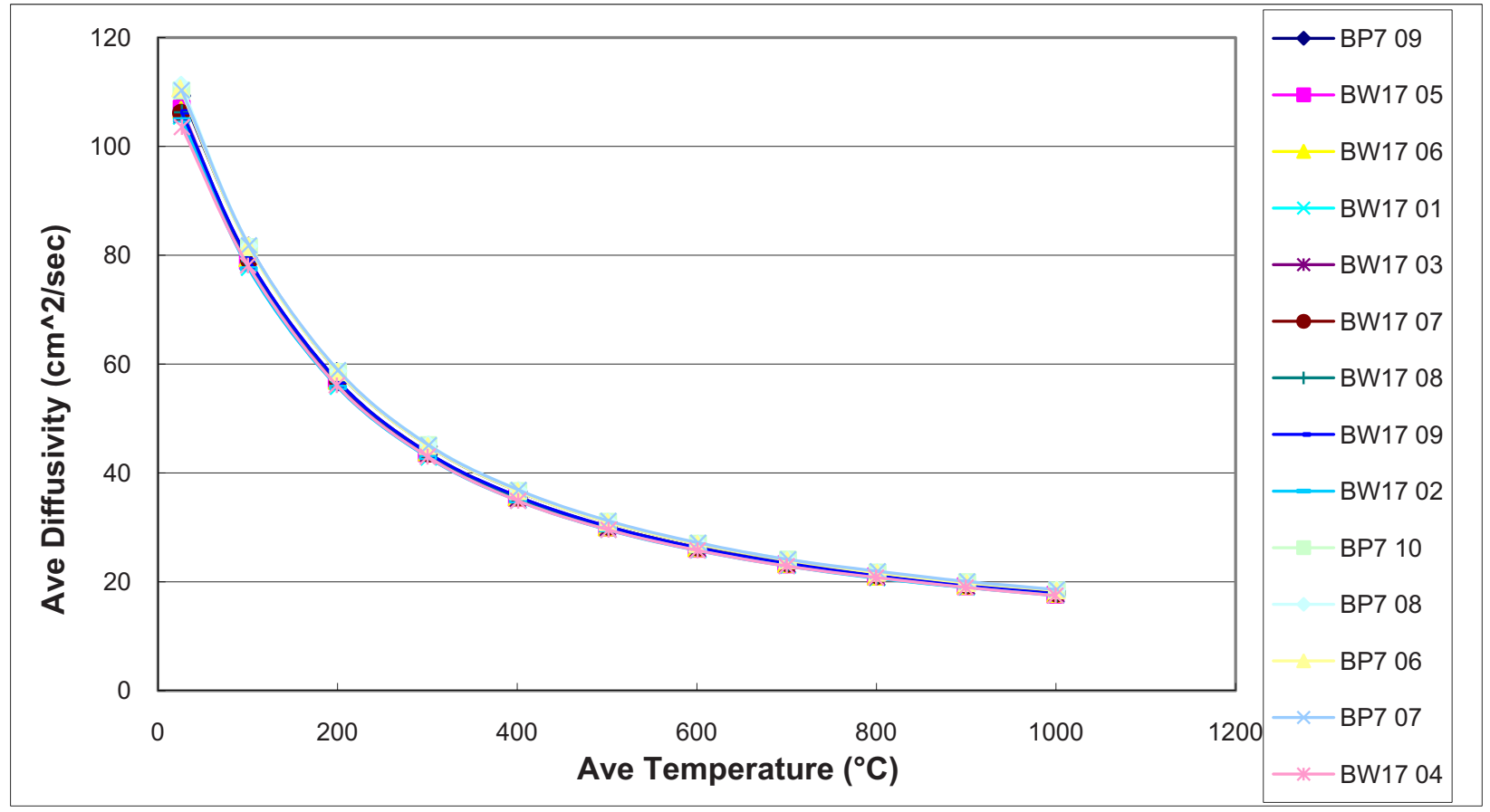

Figure A-56. Thermal diffusivity for NBG-18. 


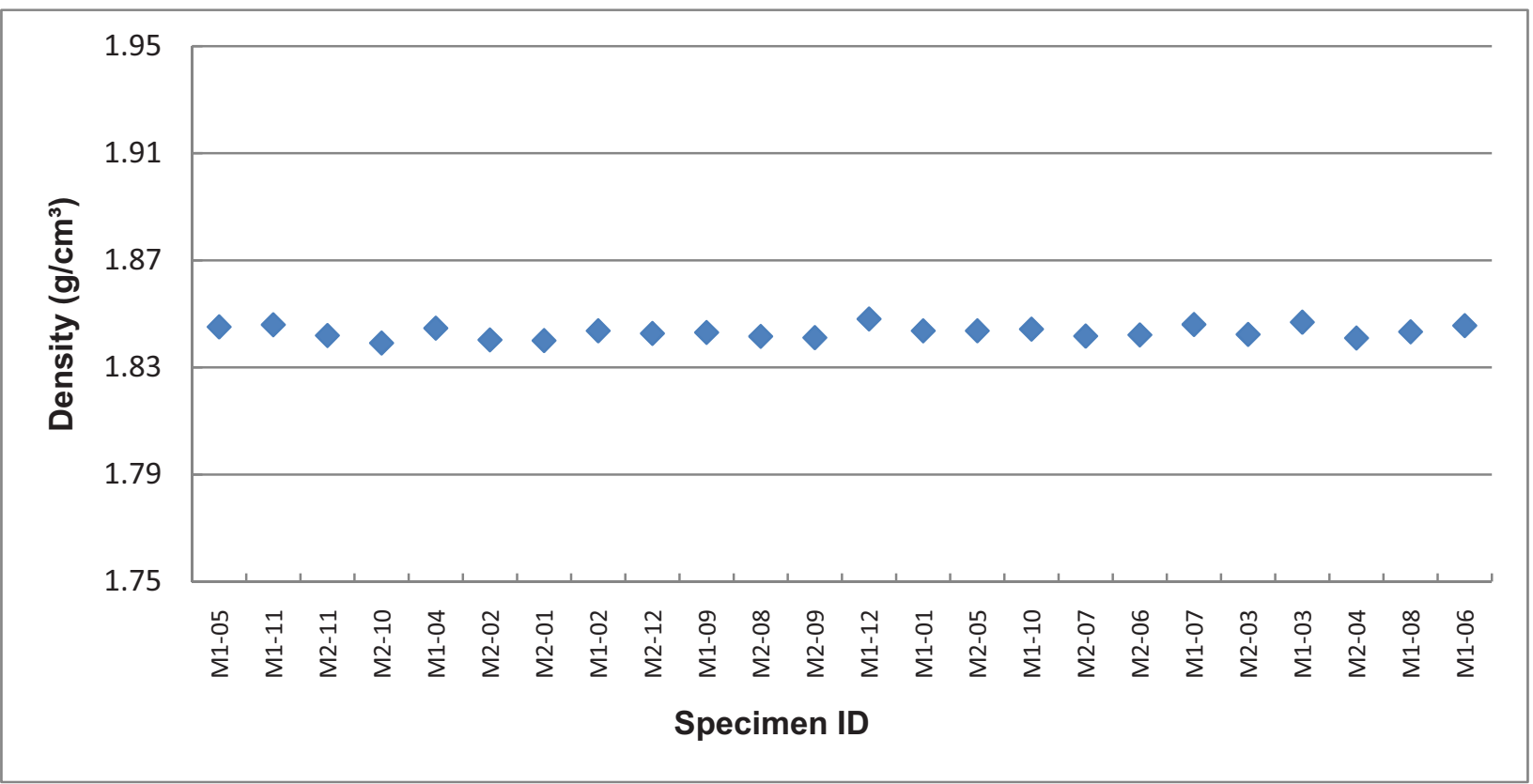

Figure A-57. Density for NBG-25.

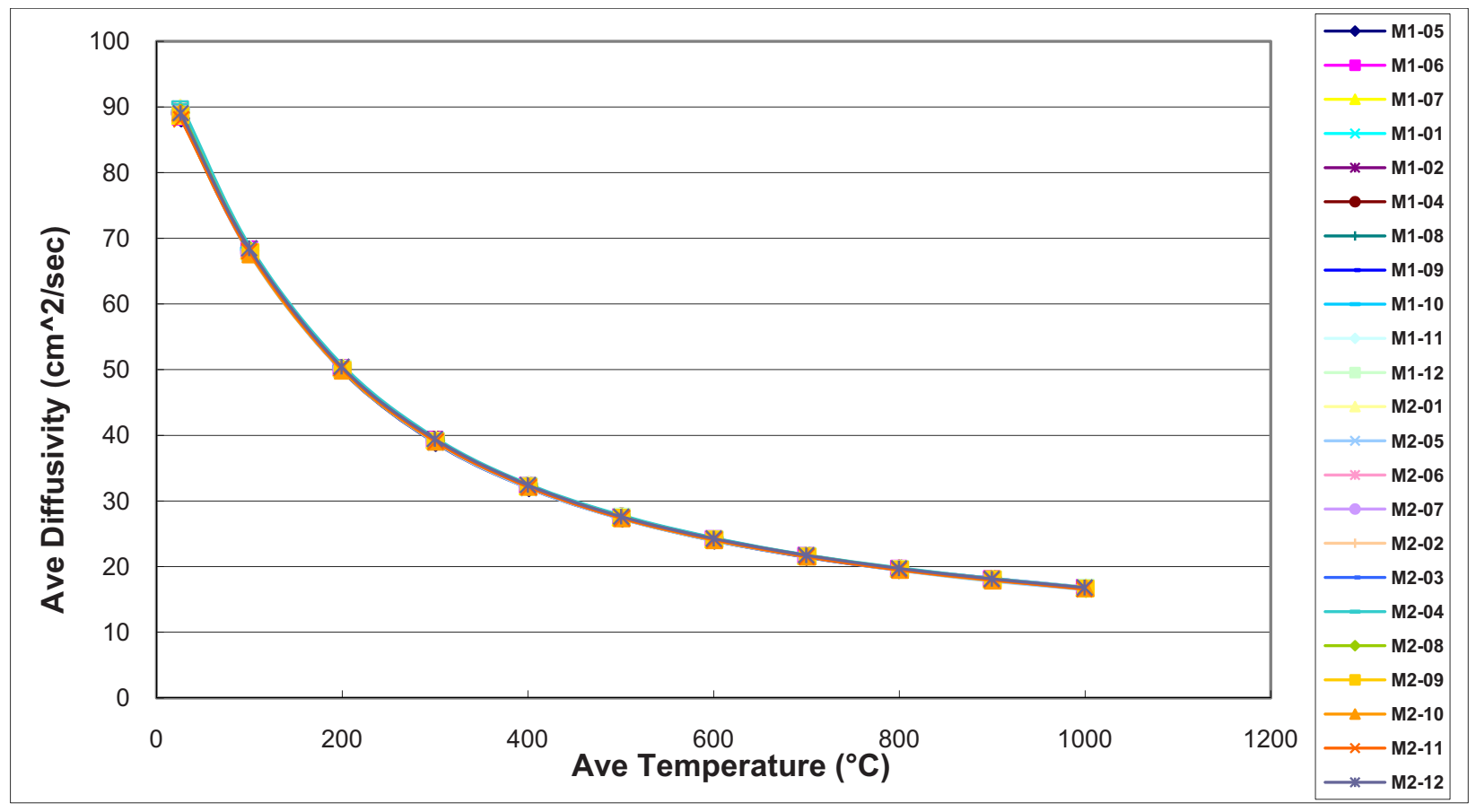

Figure A-58. Thermal diffusivity for NBG-25. 


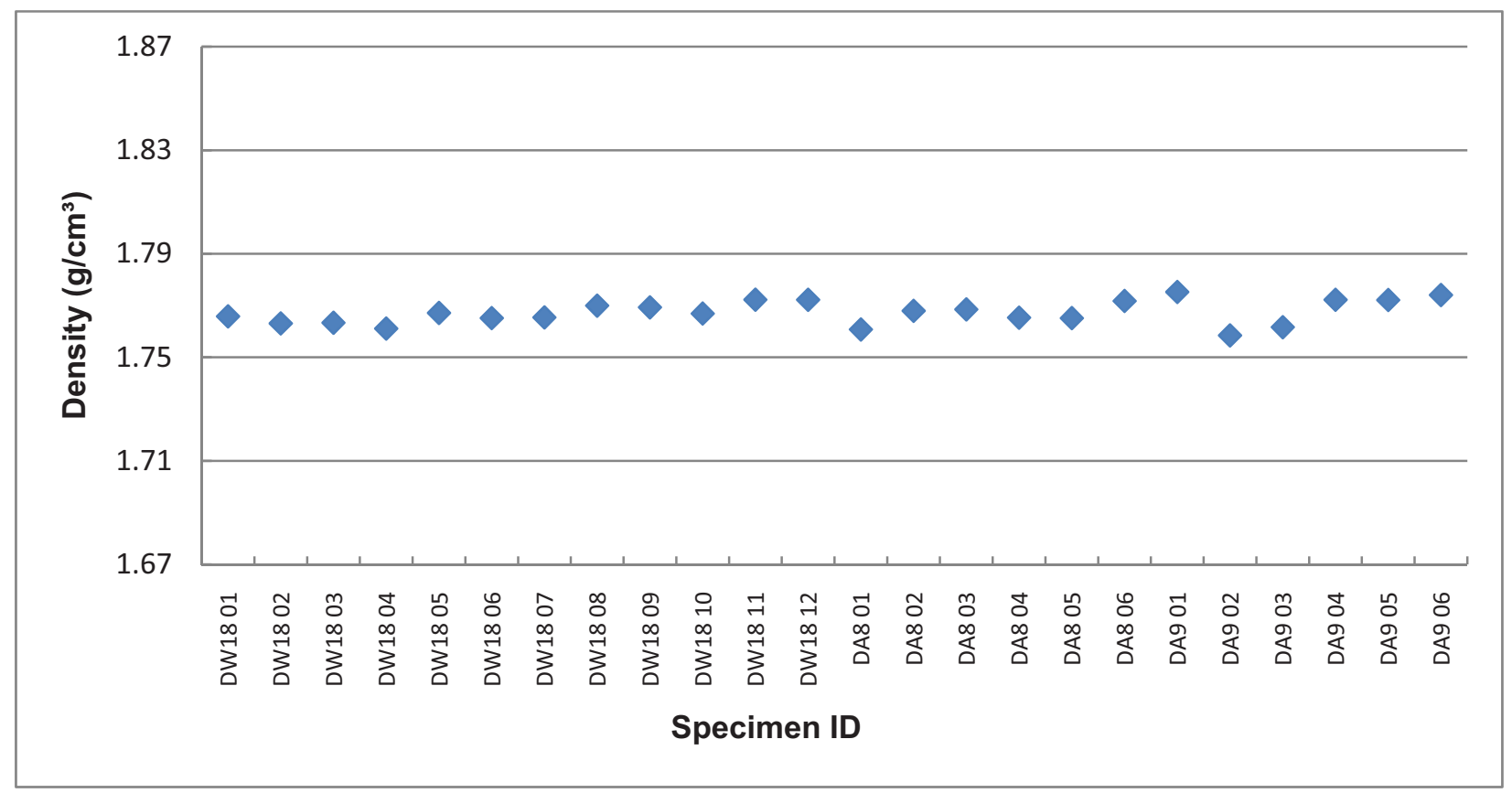

Figure A-59. Density for PCEA.

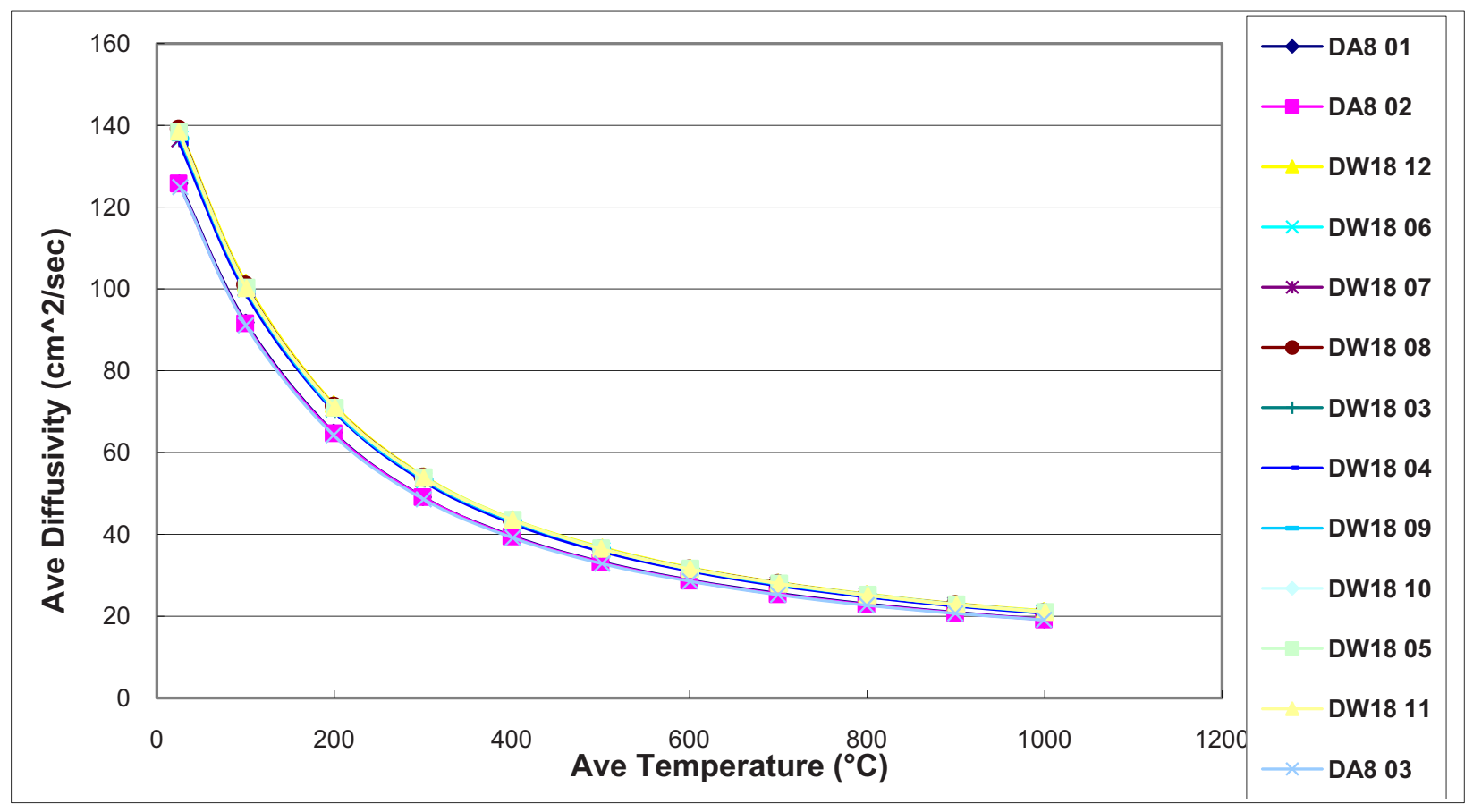

Figure A-60. Thermal diffusivity for PCEA. 


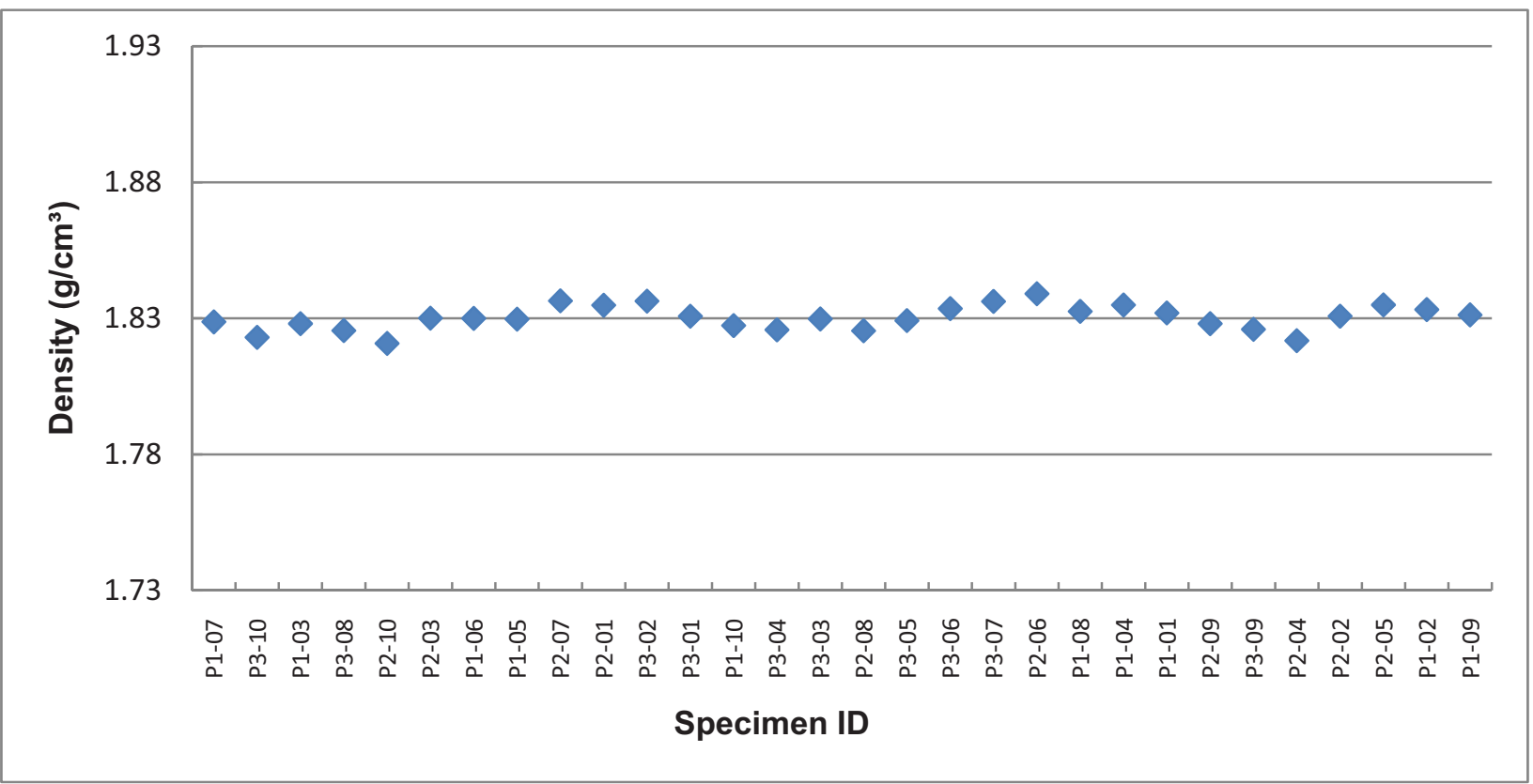

Figure A-61. Density for PCIB.

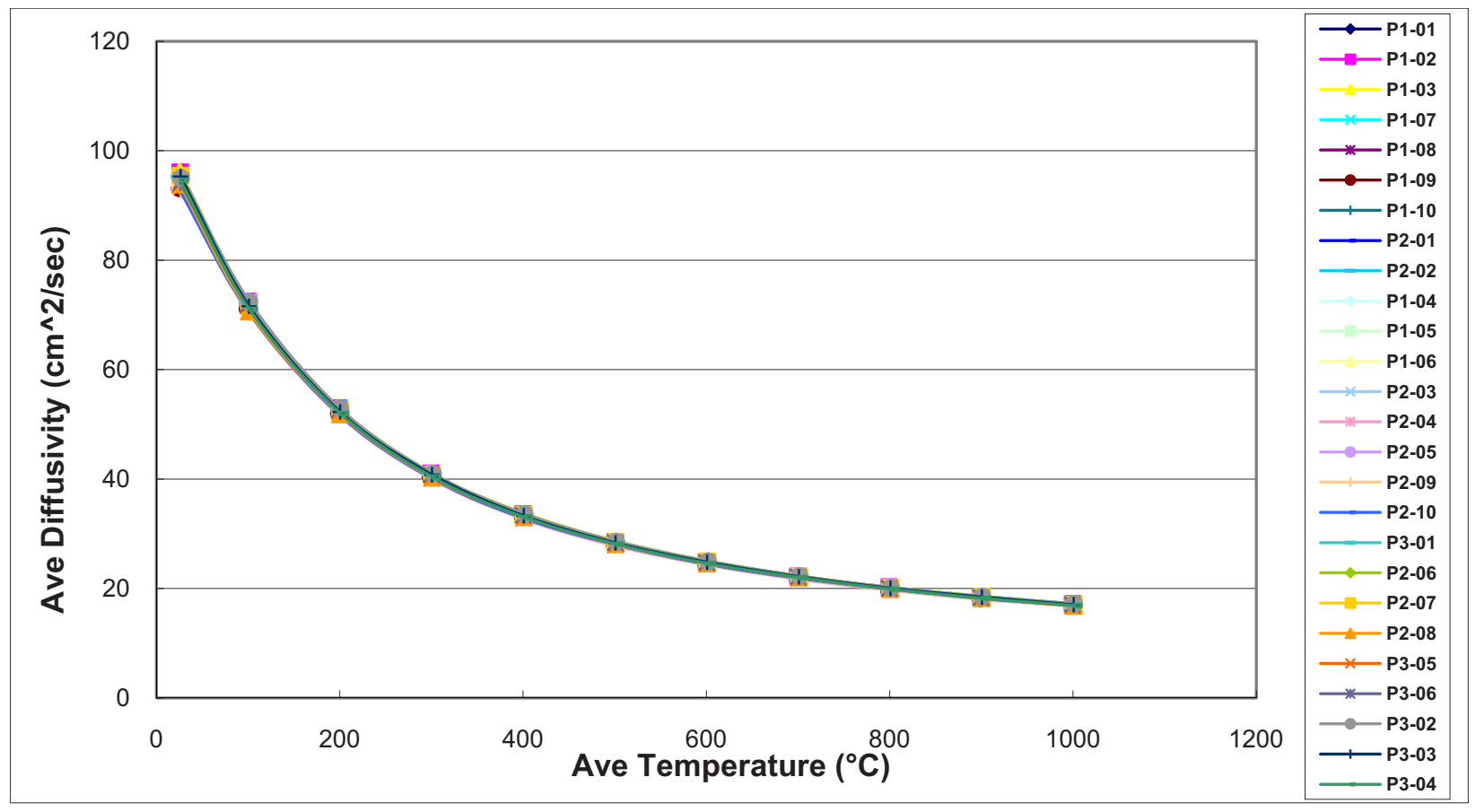

Figure A-62. Thermal diffusivity for PCIB. 


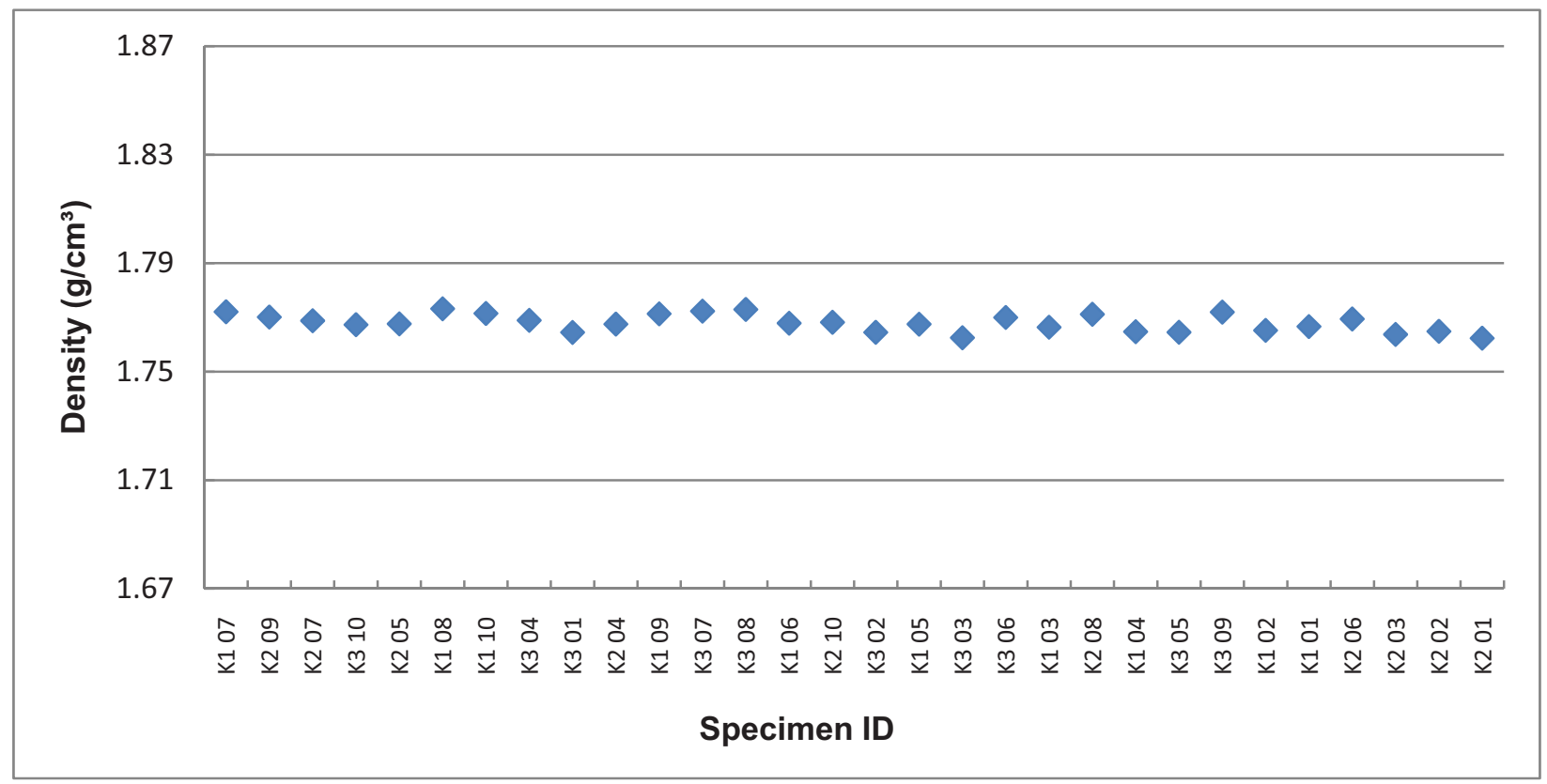

Figure A-63. Density for PGX.

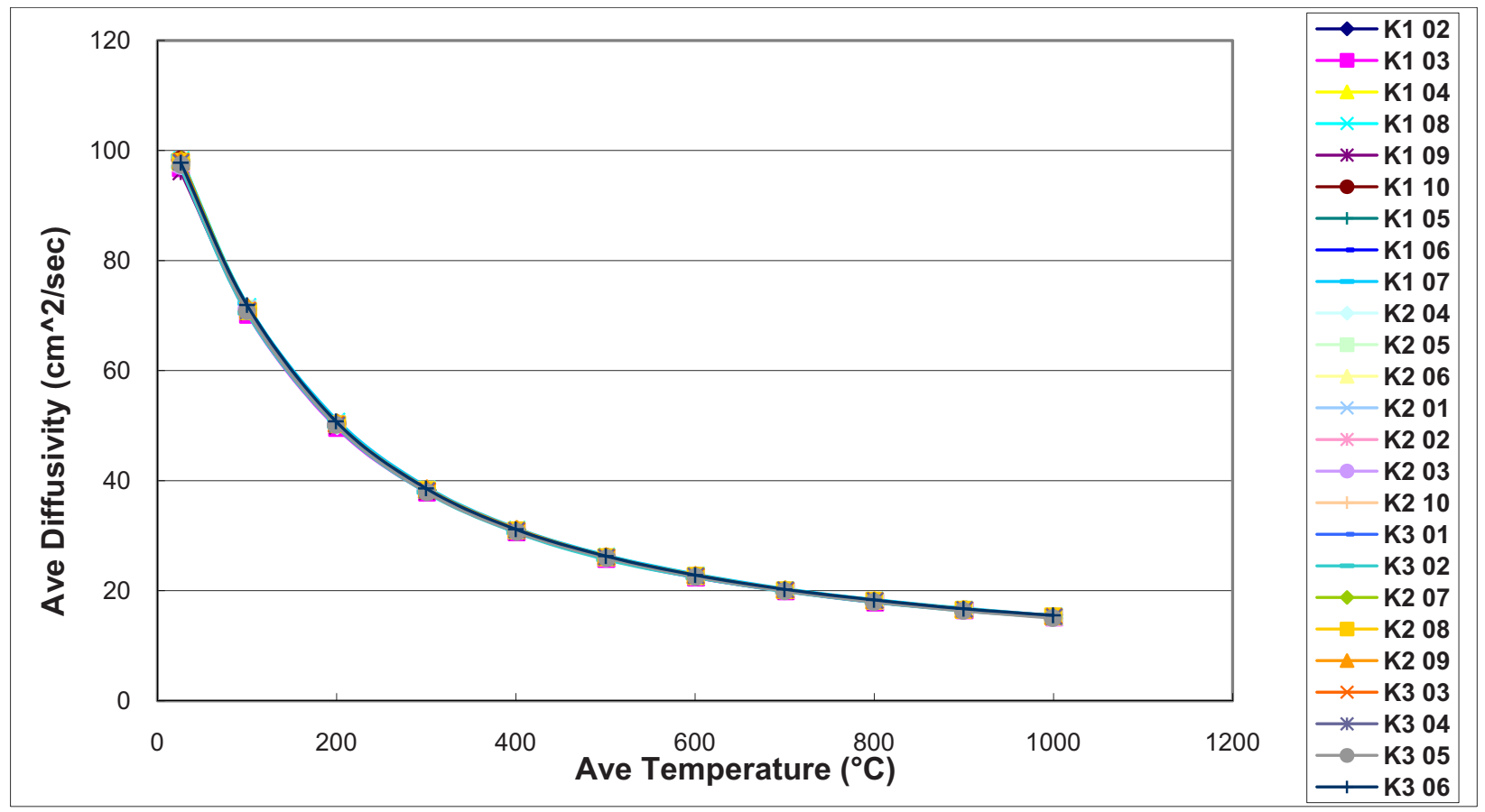

Figure A-64. Thermal diffusivity for PGX. 


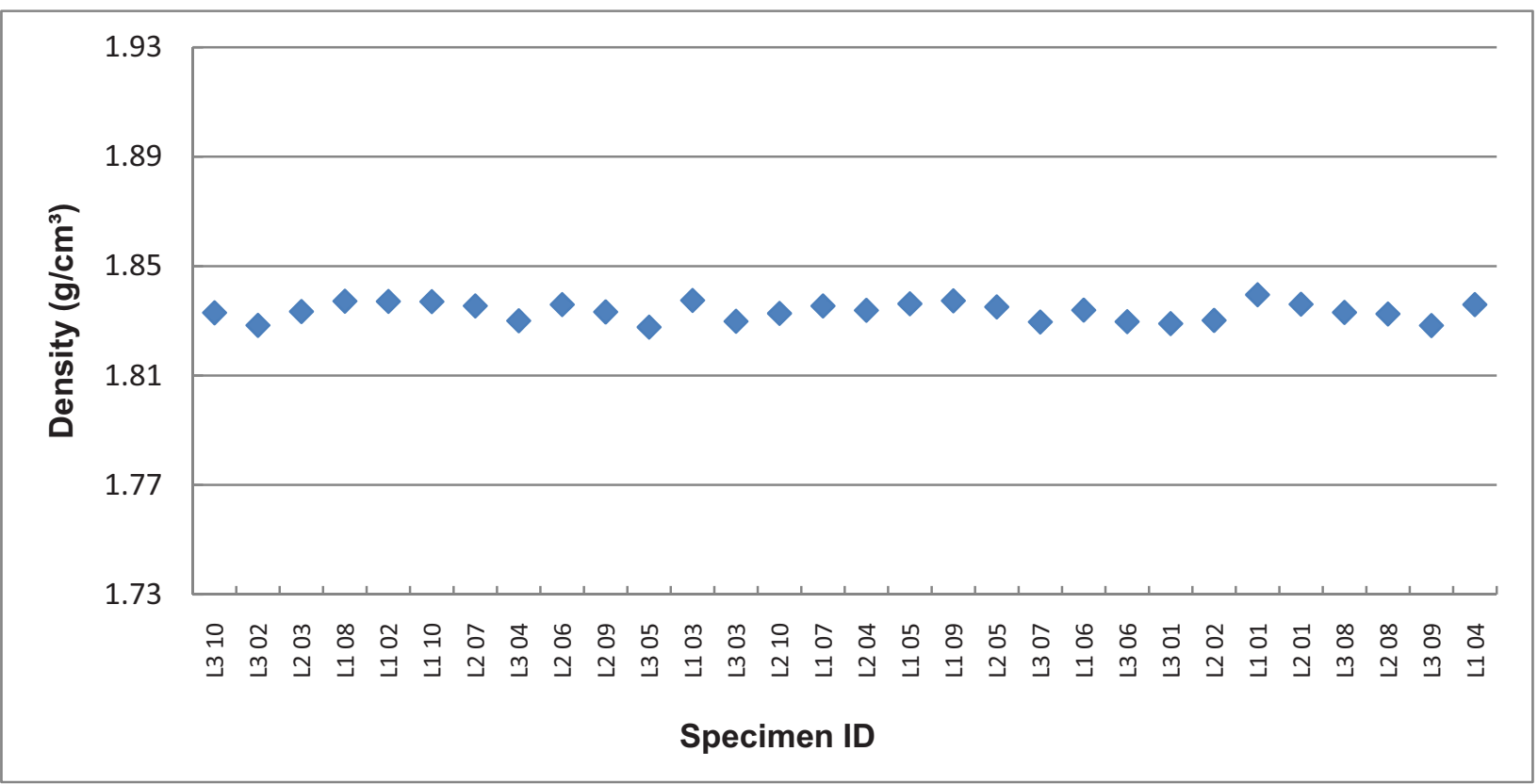

Figure A-65. Density for PPEA.

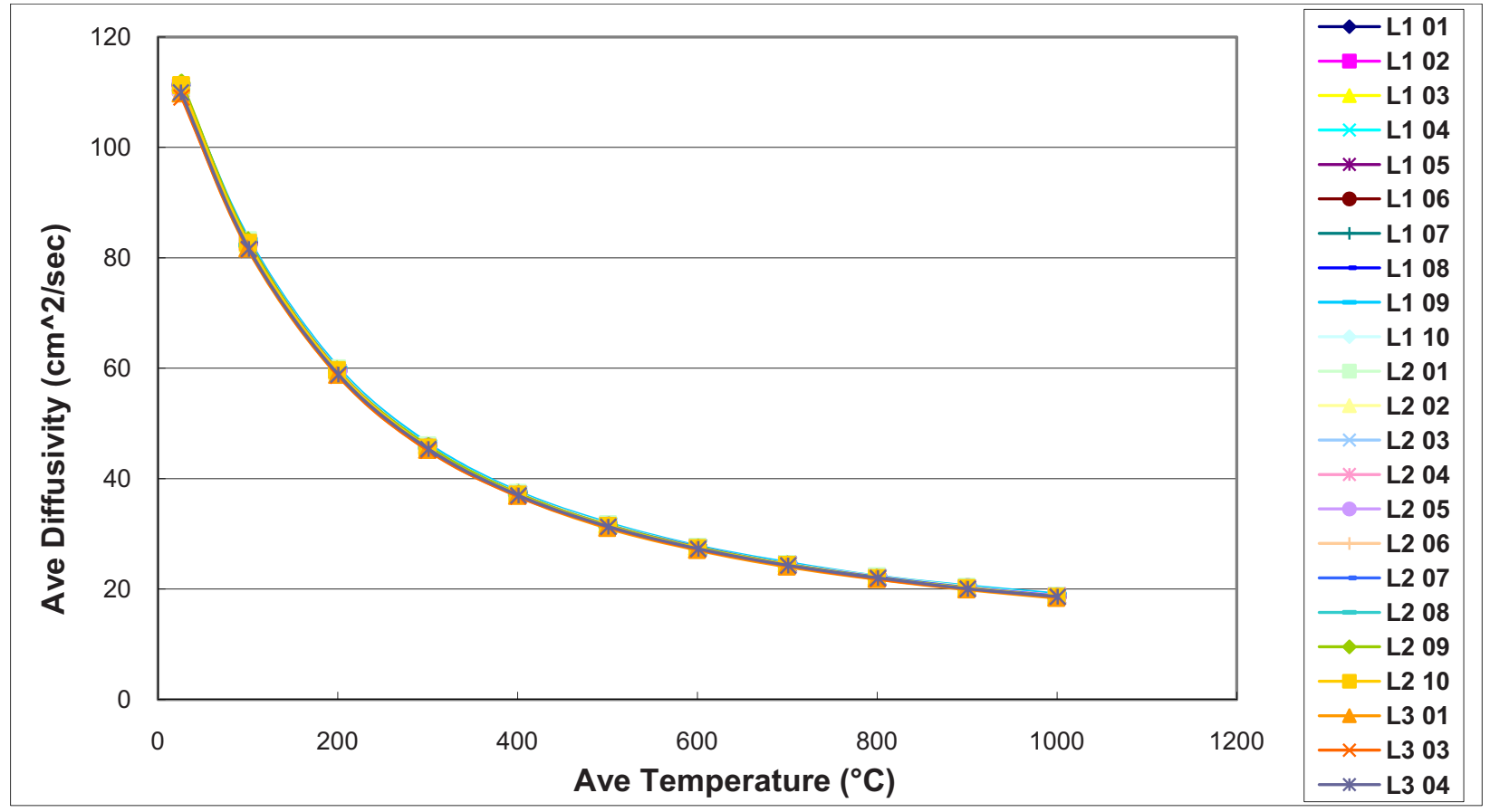

Figure A-66. Thermal diffusivity for PPEA. 
This page is intentionally left blank 


\section{Appendix B}

Source/Receiving Inspection Instruction for AGC-2 Specimens 


\section{Appendix B \\ Source/Receiving Inspection Instruction for AGC-2 Specimens}




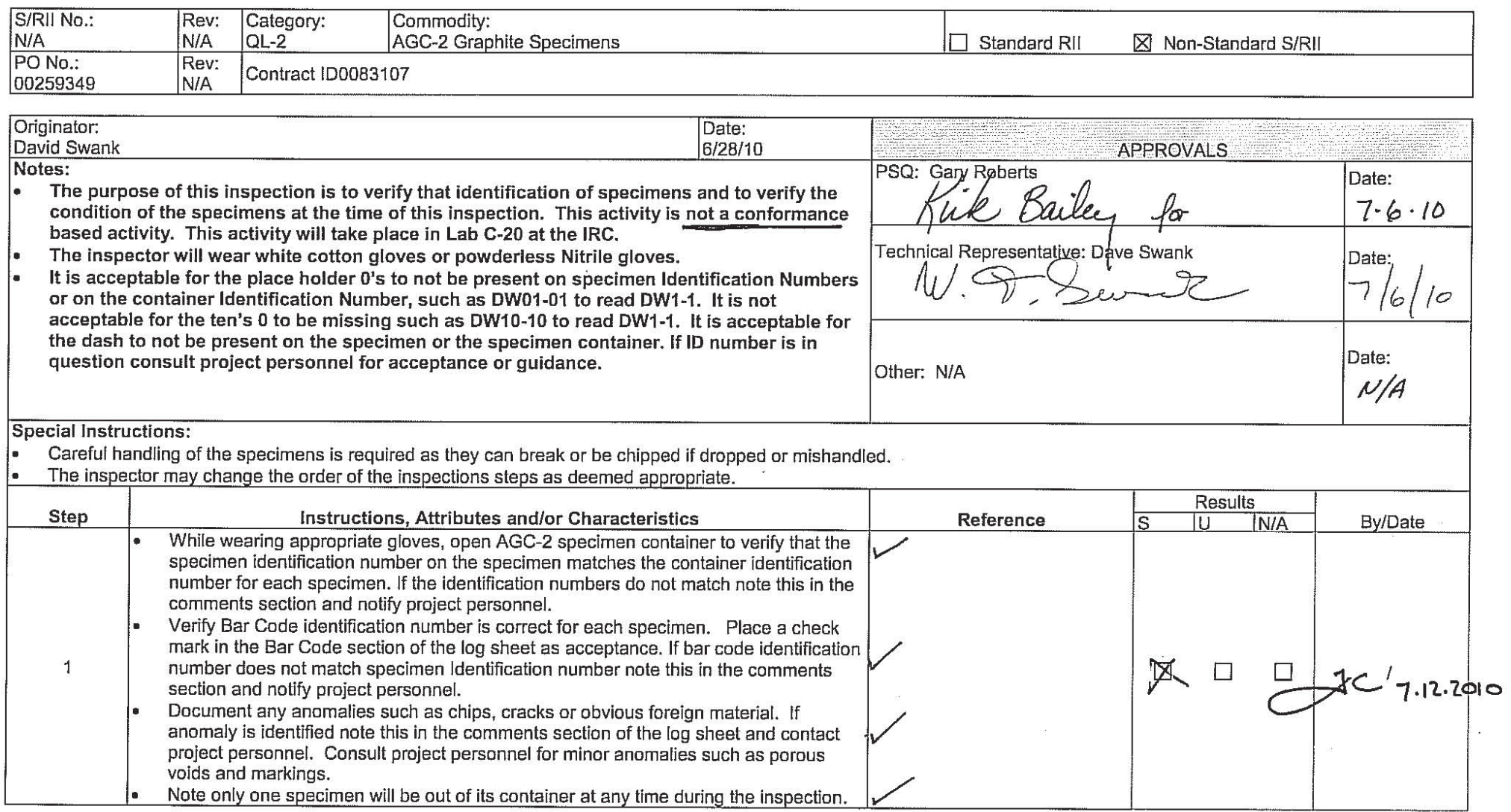

SEE LOG REPORT FOR ALL NOTES:

THIS IS NOT AN INSPECTION FOR CONFORMANCE. REVIEW TO DOCUMENT SPECIMEN CONDITION AND VERIFY CORRECT SPECIMEN AND CONTAINER NUMBER. 


\begin{tabular}{|l|l|l|l|l|}
\hline S/RII No.: & $\begin{array}{l}\text { Rev: } \\
\text { N/A }\end{array}$ & $\begin{array}{l}\text { Category: } \\
\text { QL-2 }\end{array}$ & $\begin{array}{l}\text { Commodity: } \\
\text { AGC-2 Graphite Specimens }\end{array}$ & $\square$ Standard RII $\quad$ Q Non-Standard S/RII \\
\hline PO No.: & Rev: & Contract ID0083107 & \\
\hline O0259349 & N/A & Q & \\
\hline
\end{tabular}

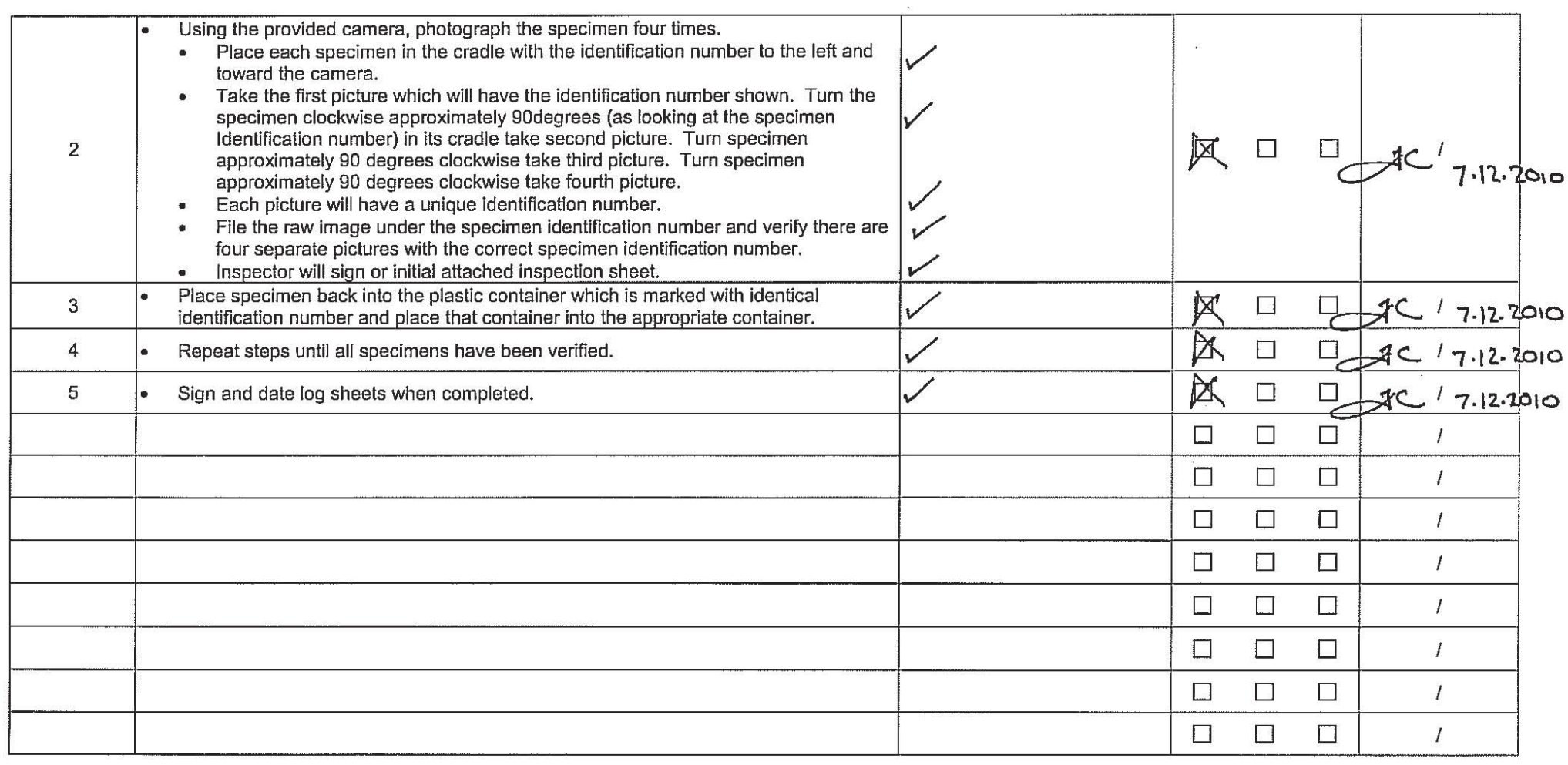

NOTE: See MCP-13327, Development and Control of Inspection Instructions, Appendix B, for information on S/RII Numbering, Category, Commodity, and Extension, 